UNIVERSIDAD NACIONAL DE LA PLATA

FACULTAD DE HUMANIDADES Y CIENCIAS DE LA EDUCACIÓN SECRETARÍA DE POSGRADO

\title{
CUERPO Y DANZA: UNA ARTICULACIÓN DESDE LA EDUCACIÓN CORPORAL
}

\author{
Lic. María Carolina Escudero \\ Tesis para optar por el grado de Magíster en Educación Corporal \\ Director, Dr. Ricardo Luis Crisorio, UNLP \\ Co-Directora, Arq. Susana Tambutti, UBA
}


Para Marcelo, Elena y Lucía Por darle sentido a mis decisiones 


\section{AGRADECIMIENTOS}

Esta tesis no hubiera sido escrita si no hubiera contado con el apoyo, la escucha atenta y la generosidad de mi director Ricardo Crisorio, quien orientó la dirección tanto de mis preguntas, como de mis respuestas, con el interés puesto en la producción de saber. En primer lugar entonces, mis agradecimientos se dirigen a él.

A Susana Tambutti, co-directora de este trabajo, cuya lectura dedicada al detalle y sus consejos, contribuyeron a la solidez de los argumentos aquí presentados y a la coherencia en la estructura del trabajo.

A Edgardo Castro, ya que sin su apoyo, su estímulo y sus consejos, esta tesis no hubiera sido presentada.

A Diana Rogovsky, mi maestra, quien me enseñó a bailar y pensar la danza, a Carolina Herman, que me enseñó a mirar la danza y a Analía Thiele, por hacerme sentir que la danza es un juego.

Gracias a Agustín Lescano y a Liliana Rocha, quienes supieron escuchar mis preguntas, mis ideas y mis apuestas, y estuvieron dispuestos a recibirme desinteresadamente, haciéndole un lugar a la danza, en la apuesta que tienen de forjar una Educación Corporal.

A Juan Manuel Dominguez Rozas, porque fue un interlocutor constante en todo este proceso y porque de manera más o menos explítica me ayudó a organizar las ideas.

A todos los que de un modo u otro, más directa o indirectamente, contribuyeron a la producción de este trabajo, que es mío claro, pero también del grupo de investigación del que formo parte. Sin esos otros con quienes he dialogado, unas veces en silencio y otras a viva voz, esta tesis no hubiera sido posible.

A mi mamá, a mi papá y a mis hermanos.

Gracias especialmente a Marcelo, Elena y Lucía, quienes me acompañaron incondicionalmente en esta tarea.

Carolina Escudero

City Bell, Agosto de 2013 


\section{INDICE}

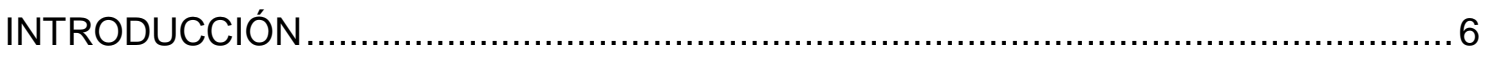

1. INTRODUCCIÓN A ALGUNOS ELEMENTOS DE LA DANZA............................... 11

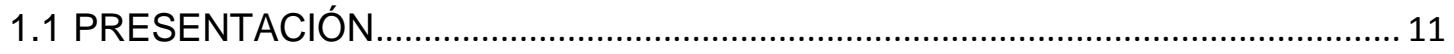

1.2 EMERGENCIA DE LA DANZA COMO ARTE, DANZA ESCÉNICA....................... 13

La técnica clásica: mecanicismo racionalista y cuerpo bello.................................... 16

Las técnicas de danza moderna: la expresión, la emoción y el cuerpo orgánico .. 20

La autonomía de la danza: la centralidad de la forma y la especificidad del cuerpo

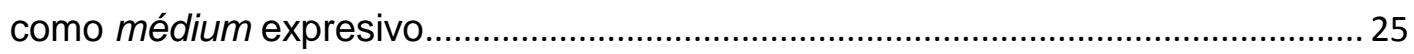

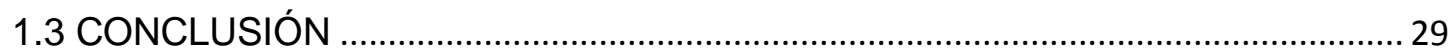

2. TEORÍAS SOBRE LA DANZA: ¿CÓMO CONSTRUYEN SU OBJETO?..................31

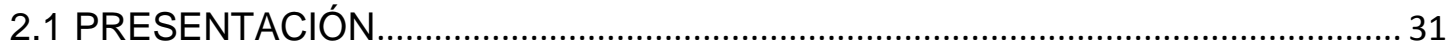

2.2 ¿QUÉ ES LA DANZA PARA LA FILOSOFÍA? ...................................................... 32

La danza como metáfora del espacio y el tiempo ........................................................ 32

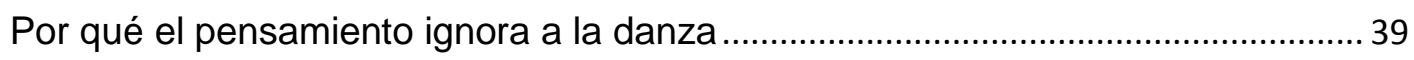

Qué es la danza para la teoría del arte............................................................... 42

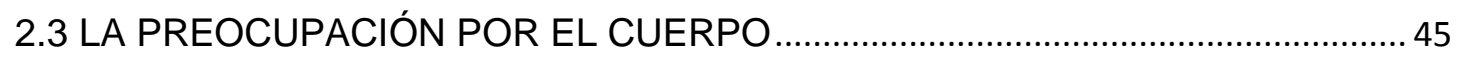

2.4 EL CONOCIMIENTO DE LA DANZA COMO ARTE COREOGRÁFICO ............... 56

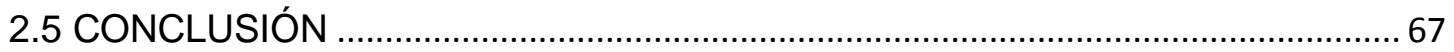

3. LA PREGUNTA POR EL CUERPO EN LA DANZA. ............................................ 69

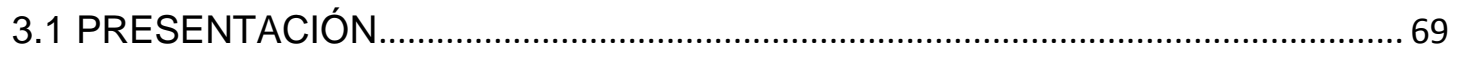

3.2 LA CONCEPCIÓN ARTÍSTICA DE LA DANZA. EL CUERPO INSTRUMENTO Y

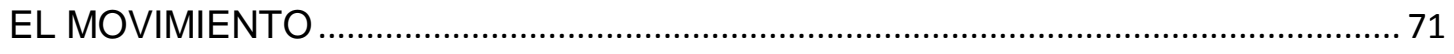

La danza como movimiento y el cuerpo como medio durante los siglos XVII a XX

3.3 CONCLUSIÓN. CONTINUIDADES CONCEPTUALES EN LA COMPRENSIÓN Y CONSTITUCIÓN DE LA DANZA COMO ARTE ........................................................... 92

4. LA PROBLEMATIZACIÓN DEL CUERPO DE LA DANZA ….................................97 


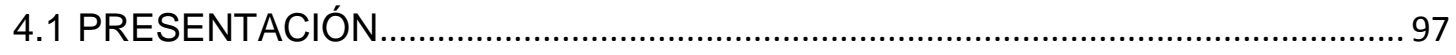

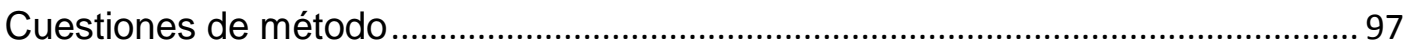

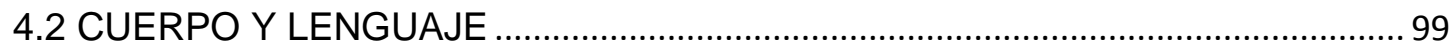

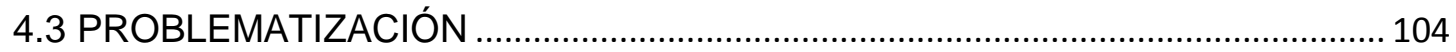

4.4 LA DANZA COMO PRÁCTICA CORPORAL Y LA EMERGENCIA DEL CUERPO

4.5 ELEMENTOS PARA UN ANÁLSIS DEL CUERPO DE LA DANZA. LA CUESTIÓN DE LA TÉCNICA ................................................................................. 111

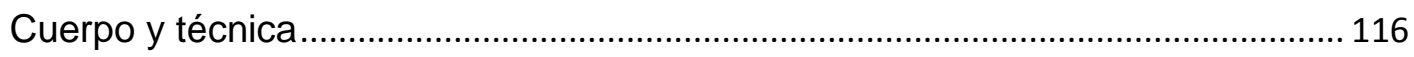

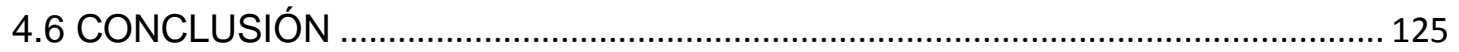

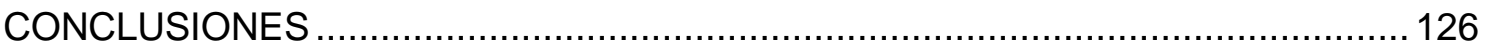

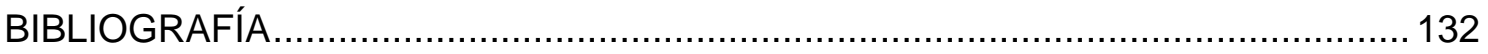




\section{INTRODUCCIÓN}

El trabajo de investigación que volcamos en esta tesis es el resultado de una pregunta de investigación y de una apuesta por el saber. La primera tiene que ver con cuestionar qué lugar ocupa el cuerpo y el pensamiento sobre el cuerpo en la práctica y las teorías de la danza. La segunda se vincula con la necesidad de proponer la danza como un contenido de la Educación Corporal. De hecho, la siguiente es una tesis que se escribe en el marco de la Maestría en Educación Corporal.

La construcción de un saber que sea operativo a la educación del cuerpo nos obliga a indagar el contenido desde una perspectiva situada en la lógica de producción del mismo y, en la medida en que encontramos allí elementos que consideramos equívocos e incluso ajenos al cuerpo de las prácticas, nos fuerza a ofrecer una perspectiva alternativa, a habilitar una forma de producción de saber que encuentre en el cuerpo su objeto de conocimiento. Sabiendo que el objeto de conocimiento no es dado, sino que siempre es construido, resulta que la presente tesis ofrece a la vez un método de trabajo y una teoría de análisis orientada a problematizar el cuerpo de la danza. Esto tiene como consecuencia un desplazamiento respecto de un conjunto de objetos típicos en las teorías de danza: el movimiento, la condición de instrumento del cuerpo, la pieza de arte o la autonomía de la danza, entre otros.

La danza ha sido objeto de análisis a la luz de diversas perspectivas, pero no abundan aquellas que ponen el acento en el cuerpo y menos aún en su caráter de práctica corporal. El énfasis fue puesto, de manera recurrente, en el estatuto artístico de la danza. Como dijimos arriba, la puesta en juego de un saber y de una mirada analítica construye el objeto. Hasta ahora la danza no fue mirada en los términos de un contenido de la Educación Corporal, y consideramos que es por eso que el cuerpo no ha sido tomado por objeto de las teorías de la danza de manera sistemática. Con esto no queremos decir que la danza no haya, de hecho, educado al cuerpo. Por el contrario, los efectos de todo su dominio de prácticas llegan al cuerpo y lo construyen, pero hasta el momento no hubo una apuesta positiva de construir al cuerpo como objeto de esas prácticas, como objeto del saber que esas prácticas implican, Y aquí, 
[l]a práctica se concibe como un conjunto de conexiones y pasajes de un punto teórico a otro y la teoría como un empalme de una práctica con otra. Entre la teoría y la práctica no hay relaciones de aplicación o consecuencia, de inspiración o creación, de representación ni de totalización en un sentido o en otro: sólo hay acción, de la teoría y de la práctica, en relaciones de relevos y redes. Por un lado, la teoría no expresa, no traduce ni aplica una práctica, es una práctica (Crisorio 2011, mimeo).

La Educación Corporal entiende que "el cuerpo se construye en las prácticas simbólicas, a partir de su inclusión en el orden simbólico a través del lenguaje" (Crisorio y Escudero 2012: 1), lo que supone, en primer lugar, que el cuerpo no es natural ni esencial, sino histórico; sobre esa historia hay que indagar si se quiere hacer un análisis del cuerpo de la danza. Por otro lado, proponer la danza como contenido de la Educación Corporal nos obliga a repensar no sólo la categoría de cuerpo, sino también la de técnica, que fuera interpretada siempre a la luz de su dimensión instrumental, esencializando esa perspectiva y obturando la posibilidad de pensar la técnica como un modo de la acción orientado a la creación de formas nuevas. Esta tesis debería ser leída entonces como una revisión crítica de la práctica de la danza y como una propuesta analítica para pensar la danza de una manera nueva, ya no como arte, ya no como movimiento, sino como práctica. Para ello, el recorrido que proponemos se organiza de la siguiente forma.

El capítulo 1 tiene por objetivo presentar los diversos componentes que formaron y construyeron la práctica de la danza escénica occidental desde su constitución como práctica artística y objeto de arte. Tomaremos como eje de presentación del texto, las diversas técnicas que organizaron las producciones de danza desde la creación de la Academia de Danza en 1661 hasta la consolidación de la "modernidad estética" en la danza y las concepciones de cuerpo que las mismas representaban. Para ello haremos una descripción de los principios técnicos que desarrollaron las distintas formas de danza según la etapa histórica que consideremos, haciendo hincapié en el cuerpo que cada una de esas técnicas supone y por lo tanto construye. Se tomará como recurso la historia de la danza y su constitución como objeto artístico con la función operativa de mostrar la constitución y el devenir de unas configuraciones de movimiento históricamente particulares.

En el capítulo 2 trabajaremos con la presentación y el análisis del saber producido sobre danza utilizando algunos textos paradigmáticos. 
Explicitaremos los temas y las formas que la teoría de la danza tiene de analizar y de construir la práctica de la danza: para ello trabajaremos con material específico sobre crítica y teoría de danza, presentaremos los principales debates acerca del conocimiento de la danza y las posibilidades y el sentido del mismo. Presentaremos un conjunto de posiciones teóricas sobre la danza escénica occidental, entendida como aquella que se construye con una pretensión u objetivo artístico. El recorrido tiene por finalidad ubicar en ese conjunto de escritos teóricos -que pasan por la filosofía, la estética, la teoría del arte, la sociología y las teorías para el análisis coreográfico- la pregunta por el cuerpo que danza. Mostrar si su conceptualización es explícita o si emerge como un supuesto necesario a la práctica de la danza, identificando en cada caso las características, cualidades y formas de hacer que lo construyen. Mostraremos la primacía del paradigma artístico en la comprensión del fenómeno, señalando las consecuencias que esa forma de pensar tiene en relación al cuerpo, sea por situarlo en el lugar de condición dada, de medio o material poético. Pondremos en evidencia que muchas de las teorías de danza no discriminan en relación al género al momento de proponer criterios para el análisis, cuestionando la versión de la historia de la danza en términos de ruptura entre un género y otro.

El Capítulo 3 ofrece una revisión de los contenidos trabajados en los tres capítulos anteriores. Para ello presentamos algunos de los criterios metodológicos y conceptuales de los que nos servimos, poniendo especial atención en los desplazamientos que es necesario hacer y en la tarea de interpretación. A la luz de esta posición mostraremos cómo la reducción del cuerpo a instrumento o a material poético impide su constitución como objeto de la danza y haremos hincapié en lo histórico de la identidad entre arte y danza. Esta revisión nos muestra cómo el cuerpo de la danza se ha identificado con lo orgánico, en términos de una identidad entre naturaleza y verdad de lo bailado; con lo físico, en términos de su constitución como entidad móvil en un espacio determinado; o con lo simbólico, pero en términos de signo, de encarnación de un contendido poético específico (el cuerpo de los negros, el cuerpo de los gays, el cuerpo común, etc.) y no en términos de una doctrina del orden simbólico. Por último, mostramos que los supuestos epistemológicos con los que fue pensada la danza comparten una serie de elementos que impiden 
la emergencia del cuerpo como problema y como objeto de la misma, y que incluso impiden pensarlo como construido por las prácticas a partir de su inclusión en el orden simbólico a través del lenguaje. En este capítulo mostramos, entonces, de qué perspectivas debemos alejarnos para pensar la danza en términos de una práctica corporal.

En el capítulo 4 ponemos en escena nuestra perspectiva analítica, explicitamos nuestro método a la luz del concepto de problematización y desplegamos la categoría de práctica corporal mostrando, a la luz de algunos registros que nos ofrecen las fuentes, la potencia de esta perspectiva para pensar el cuerpo de la danza. Trabajamos sobre la relación cuerpo/lenguaje y proponemos revisitar la categoría de techné, ya que creemos que allí hay un elemento que nos permite problematizar el cuerpo de la danza sin reducirlo a condición, ni a medio, ni a material poético, sino que nos permite trabajar un acceso al cuerpo en términos de resultado de la acción. Esto nos pone en relación directa con la cuestión del arte y de la estética, pero a partir de un desplazamiento que nos obliga a revisar la identidad histórica entre arte y danza para pensar la historicidad del cuerpo como forma de vida a la luz de una estética de la existencia, que se aleja en mucho de las discusiones que propone la institución moderna del arte y nos pone de cara al problema de la relación sujeto/cuerpo. Sobre este asunto, el capítulo apenas abre una serie de elementos que volverán en la conclusión para delinear un conjunto de preguntas orientadas a un trabajo de más largo aliento.

Por último, las Conclusiones Finales delinean una serie de preguntas que buscan situar la relación de la práctica de la danza, en tanto contenido, con la Educación Corporal, a partir de mostrar que construir el cuerpo como objeto nos obliga a pensar la cuestión del sujeto, ineludible en cualquier programa educativo.

Nuestro interés y nuestro esfuerzo en esta tesis se orientan a pensar la danza de otra manera y con otra epistemología. Nos interesa construir un objeto distinto, no con el objetivo de desacreditar las preocupaciones artísticas que constituyen el panorama de la danza actual, sino porque creemos que allí hay una clave para pensar la educación del cuerpo, algo que en el contexto de una maestría en Educación Corporal nos resulta fundamental. Proponemos esta tesis como un primer escalón, para que aparezca el cuerpo como un asunto de 
la danza, como un tema del que ésta se tiene que ocupar. Creemos que tiene sentido hacerlo en la medida en que su comprensión como práctica nos habilita a pensar la danza en el marco de los problemas que plantea la educación y la transmisión del saber de aquellas acciones que construyen al cuerpo y los elementos del orden simbólico que, en el registro de la enseñanza, lo toman por objeto. 


\section{INTRODUCCIÓN A ALGUNOS ELEMENTOS DE LA DANZA}

\subsection{PRESENTACIÓN}

En este capítulo se hará una presentación de aquello que generalmente se describe como "la historia" de la danza académica y escénica en occidente. Tomaremos como eje de la presentación, las diversas técnicas que organizaron las producciones de danza, desde la creación de la Academia de Danza en 1661 hasta la consolidación de la "modernidad estética" en la danza, y las concepciones de cuerpo que las mismas representaban. Tomamos como referencia "Itinerarios teóricos de la danza", un artículo de Susana Tambutti publicado en 2008, en el cual organiza la presentación de la historia de la disciplina en base al modelo historiográfico del Bildungsroman que adopta Arthur Danto para pensar la historia del arte y que Tambutti retoma para proponer una lectura de la historia de la danza. La estructura de este modelo historiográfico se presenta como "un modelo progresivo, fundado en el avance de la "autonomía" entendida como autoconciencia" (Tambutti 2008: 13). Aquí, la idea de sentido histórico juega un papel central, de hecho la autonomía de la danza como arte sería el elemento que define la dirección de aquél sentido.

Tomamos entonces los tres momentos que reconoce Tambutti 2008) para pensar la historia de la danza, desplazando nuestra preocupación de las cuestiones específicamente artísticas hacia las coordenadas que nos ofrecen la técnicas con las cuales la danza se desarrolló y las concepciones de cuerpo que se articulaban en ellas. El interés de esta presentación es introducir al lector en el modo con el que trabajaremos en la tesis: presentar algunas categorías específicas con las que se describe y nombra a la danza, junto con una serie de problemas y nombres que caracterizan la práctica y la teoría (que es, cómo veremos, una forma de la práctica). Esto reviste cierta complejidad, ya que nos vemos obligados a presentar, de manera sintética y en un número acotado de páginas, un conjunto de acontecimientos que se sucedieron durante cuatro siglos y medio.

Sin embargo, cabe aclarar que el objetivo de esta tesis no es hacer una historia de la danza, ni tomar como objeto a la constitución de la danza como arte. Este trabajo no se inscribe en una perspectiva histórica ni de análisis histórico, por lo 
que, no daremos las discusiones historiográficas que se están desarrollando en el campo de la historia de la danza. Tomar como recurso la historia de la danza y su constitución como objeto artístico tiene como función operativa e instrumental mostrar la constitución de unas particulares configuraciones de movimiento (y su devenir), las cuales, si se las considera como una práctica corporal, en su sistematicidad, generalidad y homogeneidad, pueden reinterpretarse como elementos de uso para una Educación Corporal.

Tomamos un modelo de historia de una disciplina artística con el interés de recoger de ahí los elementos que nos permitan pensar la educación y la formación de un cuerpo entrenado en algunas capacidades corporales básicas. En esta tesis, el acento no está puesto en las discusiones y teorías que se orientan a pensar y problematizar la danza como arte, sino que nos interesa pensar qué elementos de esa danza devenida arte, pueden servir de contenido a una educación del cuerpo. En este sentido, la reflexión sobre los fundamentos de las técnicas y las concepciones de cuerpo que ellas ofrecen, nos llevan a considerar la constitución del cuerpo como médium expresivo del arte de la danza y el movimiento como su objeto, características sobre las cuales propondremos un desplazamiento que nos lleve a pensar el cuerpo como objeto de la práctica de la danza, corrimiento a partir del cual nos resulta posible pensar su inclusión en una educación del cuerpo.

El hecho de tomar como eje organizador los fundamentos técnicos que se sucedieron desde el siglo XVII hasta el XX y las concepciones de cuerpo que se articulan a ellas tendrá dos consecuencias importantes, por un lado simplificar los derroteros de la historia efectiva de la disciplina, dejando de lado matices importantes; por otro, nos ayudará a identificar de manera más precisa qué elementos de la danza pueden articularse a una preocupación más educativa que artística, circunscribiendo el objeto a la educación del cuerpo de manera específica.

La secuencia histórica responde a los tres momentos que Tambutti identifica, describe y explica (2008) con los siguientes términos:

"[u]n primer momento, derivado de las posiciones racionalistas y neoclasicistas, en donde la preocupación principal estaba relacionada con la teoría de la imitación y la representación de la belleza ideal. El segundo, nacido del modelo establecido por la idea romántica del arte instalaba a la teoría de la expresión como verdadera, lo cual ponía en conflicto la 
tradición anterior. El tercero, procedente del formalismo kantiano, daba cumplimiento a los requisitos de la modernidad estética, develando el carácter no literal del vocabulario de la danza y alejándose de la teoría que la definía como arte que expresaba las emociones del artista" (14).

Cabe destacar que este modelo progresivo no supone la superación definitiva de un momento por otro, si bien es posible reconocer en la sucesión histórica momentos de supremacía relativa de uno sobre otro, cabe destacar que las características y cualidades que definen cada una de estas etapas conviven de manera superpuesta, incluso, con cierto diálogo y momentos de colaboración entre las diversas concepciones.

Presentamos aquí algunas advertencias importantes: en esta presentación del desarrollo de la danza durante el siglo XX quedarán fuera la danza butoh y el contact improvisation. Las razones para ello difieren en cada caso. La exclusión del butoh se debe especialmente a que es una danza de origen japonés, de la segunda posguerra, que si bien reenvía a la recepción en Japón de algunos elementos de la cultura occidental unidos a una serie de críticas a elementos propios del teatro y la danza japonesas, no por ello pierde su característica propiamente oriental, cargada de códigos y diálogos internos que suponen la referencia a cuestiones que exceden los límites de esta tesis. Si bien podríamos haber decidido trabajar con la recepción en occidente del butoh, elegimos dejarlo afuera porque introducir este tipo de danza sin mencionar cuestiones propias de la cultura japonesa implica simplificar el fenómeno y extrapolar sin contextualizar varios elementos importantes. La decisión de no incluir el contact improvisation se debe especialmente a que no se propone como una danza escénica, sino que surge como una danza de estados y posteriormente es utilizada cómo técnica de entrenamiento y de improvisación para componer danzas de escenario. En sí misma, la danza de improvisación por contacto no busca ser una danza escénica.

\subsection{EMERGENCIA DE LA DANZA COMO ARTE, DANZA ESCÉNICA}

La palabra ballet proviene del vocablo italiano balleto (bailar), que a su vez proviene del latín ballare (bailar) emparentado con los griegos ballizein (bailar) y ballein (tirar, arrojar con fuerza). El ballet es una puesta en forma del baile, un ordenamiento específico de la danza. La danza, entendida como "una sucesión 
rítmica de movimientos corporales cuya comprensión como secuencia de danza depende del contexto social dado" (Henckmann y Lotter 1998: 68), es un componente del ballet, pero no lo agota.

Lo que se denomina ballet es una forma específica de danza, ligada al divertimento y la contemplación, y si bien podemos encontrar en los ballets históricos o modernos funciones de legitimación simbólica respecto del estado de cosas en el campo del arte o en el espacio social, aquellas no son funciones explícitas, sino que se desarrollan en base a la lógica de la práctica, de los modos de hacer y ver en medio de los cuales el ballet se desarrolla como práctica corporal y artística. En este sentido es oportuno decir que el ballet se diferencia de: a) las danzas rituales, que se ejecutan a sabiendas de que cumplen una función con sentido para la comunidad y en las cuales se convoca a la danza para tener éxito en el decurso de los acontecimientos esperados; b) las danzas festivas de tipo religioso, que se ejecutan en servicio de la creencia en una divinidad y esperando también una función, de perdón o de salvación; c) las danzas paganas o de carnaval que tienen por función o sentido social poner al hombre común en contacto con el universo y, a través de éste, con otra temporalidad; y d) las danzas de salón, sean corales o de parejas. Sobre este último punto vale la pena reforzar la idea que nos permite sostener que si bien el ballet reconoce en las danzas de salón su antecedente directo, en la medida en que se institucionaliza como arte se irá diferenciando sustantivamente de ellas.

Algunos de los materiales bibliográficos consultados sostienen que el ballet de los siglos XVII-XVIII tuvo la intención de asemejarse a la triunica choreia antigua (Tambutti, 2009, mimeo; Salazar 1948; Regner 1949), forma de representación que unía la palabra, a través del canto, con la música y la danza: era un arte expresivo (no constructivo) en el cual la danza cumplía una función esencial. De hecho, la palabra choros no significaba, en el contexto de la triunica choreia, el canto colectivo, sino la danza colectiva. Incluso, en la palabra coreografía podemos ver el vocablo choreia. Sin embargo, a diferencia de lo que sucederá con el ballet en el siglo XVIII, cuando se convierte en arte para ser visto, la triunica choreia era un arte de expresión vinculado a la acción y no a la contemplación, de manera semejante a las primeras formas de ballet desarrolladas durante los siglos XVI y XVII. El ballet en sus primeras formas 
también era un arte o una techné construida y orientada en su función a la ejecución por parte de los personajes de la corte y de los sectores sociales dominantes del período: la nobleza aristocrática y la burguesía comercial. Hay al menos un siglo entre la creación de los primeros ballets de corte (óperaballet y comedia-ballet) y el uso generalizado de bailarines profesionales en escena. Recordemos, en este sentido, la función de legitimación y de educación ejemplar que la danza tenía en el contexto de la corte, especialmente en las prácticas de las aristocracias nobiliarias del siglo XV. Los elementos y actividades que se mencionan de manera recurrente en la bibliografía son: a) la organización de los bailes de salón, en los cuales aristócratas y burgueses comerciantes traducían su nobleza de espíritu en la buena educación del cuerpo ${ }^{1}$ y en la construcción de formas geométricas puras. Estas danzas se oponían en su forma y en su sentido a los bailes populares y paganos -articulados al ritmo del trabajo-y a los bailes festivoreligiosos de la época; b) la aparición de la figura -en el marco de la corte- del maestro de baile, personaje destinado de manera exclusiva a la educación de los modales del cuerpo, del ritmo, la armonía y la gracia: figura central en la transformación, organización, sistematización y conocimiento de las danzas, ya que cumplió la función de seleccionar y depurar los bailes existentes y estilizarlos de acuerdo a las necesidades de la aristocracia y de la burguesía comerciante de la época; y c) la escritura de los primeros tratados que intentaban definir, explicar y analizar las danzas de salón del momento.

Es recién hacia fines del siglo XVII, y especialmente a lo largo del siglo XVIII, que pueden identificarse una serie de elementos que son constitutivos del dispositivo ${ }^{2}$ danza: a) el discurso público-político de formación de la institución

\footnotetext{
${ }^{1}$ Los bailes organizados por las cortes cumplían diversas funciones sociales, una de las cuales era volver a los salones un espacio público y común, en el cual los personajes de la corte mostraban la jerarquía de su posición social de manera homóloga a cómo ejecutaban el baile, es decir, en función del lugar que ocupaban en el espacio y del momento temporal asignado en la secuencia del mismo. El objetivo era mostrar la correspondencia entre moralidad y corporalidad, entre el valor moral de la persona y su buena disposición corporal, ya que, en las danzas de salón, quienes bailaban y ejecutaban las danzas eran los aristócratas y burgueses, algo que va a cambiar luego, con la conversión de las danzas de salón en un objeto artístico. La idea de que la forma del cuerpo se corresponde con el ser del alma es una idea que se sostiene en diversos momentos y formas de la danza. La libertad del cuerpo que promueve Isadora Duncan, por ejemplo, apunta a ser reflejo de cierta libertad en la forma de vida. El cuerpo muestra así una ética constitutiva del ser.

${ }^{2}$ La noción de dispositivo como categoría técnica se define como la red de relaciones que se puede establecer entre elementos heterogéneos y establece la naturaleza del nexo que se da
} 
y de construcción de una simbología funcional a la monarquía; b) el discurso político moral, de educación del cuerpo en los buenos modales, en la medida en que refleja una buena forma; c) el discurso propiamente disciplinar de organización y fundamentación de las prácticas; d) la emergencia y formación de sujetos apropiados a la danza (maestros, bailarines profesionales y nobles bien educados); y e) la emergencia de espacios escénicos. En este contexto se define el ballet en términos de espectáculo mimado que debe dividirse en actos y escenas las entradas se concebían y definían simplemente como pretextos para dar lugar a la danza.

\section{La técnica clásica: mecanicismo racionalista y cuerpo bello}

La creación de una técnica de danza separada del uso político y de clase que habitualmente se hacía del cuerpo y del baile en los salones de las cortes europeas hacia el siglo XVII, se entiende a partir de los criterios del racionalismo estético y del modo neoclasicista que adoptó el ballet, ya que estas concepciones obligaron a pensar una técnica de movimiento corporal que sirviera a la construcción de un arte centrado en la representación de la belleza ideal. Así,

[e]n la técnica d'ecole se conjugaba el placer estético con la racionalidad de la mente, en la convicción de que ambos obedecían a las mismas leyes. Esta convicción vinculó la técnica con un orden geométrico que respondía tanto al afán de someter el cuerpo al imperio de la razón como también al deseo de embellecerlo, potenciando su atractivo al acercarlo a las categorías estéticas griegas [...] (Tambutti 2011: 3).

En este contexto, el papel desempeñado por la Real Academia de Música y Danza, creada en 1661, resulta central ya que brinda una organización institucional a un conjunto de principios abstractos y concepciones teóricas constitutivas del modo clásico de la danza. En este sentido, es posible sostener que la creación de la primera academia oficial y estatal de danza constituye un doble movimiento de especialización y profesionalización de la práctica junto con el reconocimiento oficial y la sanción positiva al ejercicio de la misma ${ }^{3}$.

entre esos elementos. Cabe destacar que el dispositivo como tal se sostiene en la medida en que tiene lugar un proceso de sobredeterminación funcional (Castro 2011: 114).

${ }^{3}$ Por un lado, el proceso de diferenciación funcional de esferas y de racionalización interna que nos muestra Weber como una característica de occidente, explica el armado de una institución por causas que trascienden el gusto personal del rey de turno. Si bien el reinado de Luis XIV se 
Uno de los principales movimientos que hay que destacar es que la institucionalización de la danza y la formación del dispositivo disciplinar provocó una independencia relativa de la práctica respecto del mecenazgo nobiliario. Esta independencia, que puede interpretarse en los contenidos de las obras pero también en el hecho de que ya no son los nobles los que ejecutan la danza, sino un profesional. La danza, en tanto dispositivo, va ganando autonomía relativa en relación a su lugar de emergencia, lo que permite, en términos de "discurso del origen", su constitución como práctica artística que busca autonomía, lo que supone que la danza presenta una capacidad propia a la disciplina para construir sentido y para representar un drama o un contenido. Aquí, la técnica todavía no se había instrumentalizado, ya que era, en sí misma, la que brindaba las condiciones de posibilidad de la forma artística, en este sentido. Tambutti (2011) sostiene,

[a]hora bien, el problema es que en la danza la técnica no fue solo un medio. Originalmente, la técnica y el lenguaje de movimientos utilizado en diversas danzas se fusionaron y la técnica se transformó en el lenguaje corporal, por lo tanto, técnica y vocabulario de movimientos se intercambiaban en el entrenamiento $y$ en la escena, es decir: las secuencias técnicas desarrolladas en el siglo XVIII [...] (2)

Y más adelante leemos,

[t]écnica y lenguaje de movimientos conformaban una unidad y ambos partían del mismo fundamento expresado en proposiciones que reducían la danza a diseños geométricos, iluminados por "la sola luz de la razón", es decir, a la manera de las demostraciones de la aritmética y la geometría. De ese modo, las posiciones del cuerpo fueron numeradas según su complejidad y los diseños espaciales fueron estudiados siguiendo una complicada combinación de direcciones precisas y calculadas (4).

Veamos cuáles son las características constitutivas de la técnica clásica que se desarrolla entre los criterios del racionalismo estético y los principios del neoclasicismo (Tambutti 2008, 2011 mimeo) ${ }^{4}$ sintetizables en los criterios de

corresponde claramente con el absolutismo monárquico, no es menos cierto que los procesos de transformación y de acomodación de instituciones existentes a las transformaciones sociales suponen un tiempo histórico que va más allá de una fecha precisa. En este sentido nos interesa reforzar la idea según la cual una forma histórica determinada, en este caso el estado absolutista feudal, incorpora y resignifica elementos (diferenciación funcional y emergencia de instituciones) con el objetivo de sostenerse como tal forma histórica.

${ }^{4}$ El neoclasicismo es una corriente artística y de estética filosófica propia de los siglos XVII y $\mathrm{XVIII}$, que se fundamenta en la reinterpretación en clave racionalista de los principios de la antigüedad clásica. Algunos autores utilizan la palabra clasicismo para caracterizar el período, pero optamos por la de neoclasicismo ya que refleja de manera más clara el hecho de que es una reinterpretación de los códigos clásicos. Cfr. Tambutti 2009, mimeo. 
orden, proporción, simetría y mesura en combinación con una geometrización del espacio. Dentro de esta cosmovisión y de estos fundamentos orientados a la constitución del arte, se ubicó el desarrollo de los elementos técnicos, ya que el código de movimiento tenía sentido en relación a las necesidades de la representación. Así, los fundamentos del código de movimientos basado en la técnica clásica también se ordenan según criterios racionalistas y neoclasicistas, en los que hay un canon de belleza ideal que sirve como criterio y orienta la construcción del cuerpo del bailarín. La belleza era la forma sensible de la verdad y la verdad del racionalismo cartesiano no se encontraba en la naturaleza, sino en la idea misma de Dios y en la razón que nos ofrece para ordenar y construir el mundo. Hay una metafísica constitutiva de la técnica clásica que explica el esfuerzo por la desmaterialización del cuerpo que orientó la construcción del código de movimientos que se utilizó en el ballet. La idea de que el cuerpo es una res extensa posible de constituirse como tal por la actividad de la res cogitans posibilitó la construcción de un sistema de movimientos apriorísticos ligados al ideal de belleza corporal, cuyos rasgos característicos Tambutti (2004) describe como este enganche no me cierra

[i]nstalados por el neoclasicismo francés del siglo XVII estaban constituidos por un cuerpo perfectamente acabado, severamente delimitado, joven, visto desde el exterior, individual, una imagen sin falla, un cuerpo del que se eliminaban todas las expresiones de vida interna.

Junto con la idea de que la danza no es sólo la representación del cuerpo sino del alma, apareció en el clasicismo romántico de la primera mitad del siglo XIX algo novedoso: la belleza corporal se puso en un plano trascendente, estableciendo que la belleza de los cuerpos era directamente proporcional a su desmaterialización (a mayor liviandad, mayor belleza). Su condición etérea los hacía similares sustancialmente a lo etéreo de las almas (8).

Tenemos, entonces, una técnica y un ideal de cuerpo construidos por los criterios del racionalismo y del neoclasicismo, lo que da por resultado una matematización y geometrización del movimiento y de las posibilidades de representación que el cuerpo como médium de la danza tenía; pueden leerse también en relación con la emergencia de la sociedad disciplinar y las técnicas de construcción de cuerpos dóciles y útiles, tal como describe Foucault en Vigilar y Castigar (1989): una microfísica de los cuerpos fundamenta las técnicas de ordenamiento espacial y temporal de las acciones, en la cual la 
geometrización se entiende en términos de clausura del espacio y localización individual de las posiciones, junto con la distribución en serie del ordenamiento del conjunto, lo que pone en relación el espacio con el tiempo, a partir de la inclusión de la secuenciación de la tareas según el orden lógico de ejecución y el orden espacial de distribución puestos en relación con una totalidad funcional. ${ }^{5}$ En este sentido, podemos referir un conjunto de citas en las que vemos la relación entre el racionalismo como criterio y la necesidad de entrenamiento como forma específica que adopta en el cuerpo la posibilidad de conseguir y plasmar ese criterio:

[p]or supuesto, una técnica convertida en lenguaje cuya finalidad era el desocultamiento de la belleza guardada en los cuerpos, solo podía ser posible en base a un entrenamiento riguroso, cuya condición de posibilidad era la posesión de un cuerpo joven semejante a los de la estatuaria clásica que pareciera tan inmortal como las figuras de los dioses griegos.

La impronta geométrica de la técnica de entrenamiento fue continuación de la geometría ya presente en las danzas renacentistas, fruto del neoplatonismo de la época, y en ella se manifestó un simbolismo hermético que fue "leído" a partir de los diseños coreográficos (Franko, 1993:16). Esta geometría estaba basada en las antiguas danzas cósmicas reservadas a la expresión de los misterios religiosos y a la especulación filosófica. Fruto de esta concepción, la espontaneidad fue desestimada en aras de una técnica capacitada para entrar en relación simbólica con el mundo de las Ideas, cuya condición de posibilidad era la pérdida de toda resonancia humana, la exclusión de todo tipo de vivencias, sentimientos, pasiones, emociones, es decir, todo lo que hay en nuestra alma que nos alejara de la contemplación de un cuerpo transformado en guía hacia la belleza o al menos al de una imagen que a ella pudiera conducirnos (Tambutti 2011: 5).

Por otro lado tenemos la referencia al texto de Noverre (1945) quien sostiene

[a]sí ven ustedes, que para bailar con elegancia, caminar con gracia y presentarse con nobleza, es absolutamente necesario invertir el orden de las cosas y constreñir las partes del cuerpo por una aplicación tan larga como penosa a tomar una posición distinta de la que tenía originalmente (129).

Por último, la referencia al manual de danza de la Opera de París La gramática de la danza clásica (Guillot y Prudhommeau 1974), en función del cual podemos sostener no sólo la continuidad de la técnica clásica originada en el siglo XVII, sino su constante perfeccionamiento. Allí leemos,

[s]er bailarín, decíamos, es obligarse cada día y durante toda la vida activa a un entrenamiento difícil y cuidadosamente regulado [...] Las reglas a las que se somete el debutante, como la estrella, no tienen nada de arbitrario.

\footnotetext{
${ }^{5}$ Foucault (1989) denomina a esto una subjetividad celular, orgánica, genética y combinatoria
} 
Son la aplicación al cuerpo humano de las leyes de la física relativas al equilibrio y el movimiento (7).

Por último, la concepción del cuerpo como una máquina, característica de este período, explica en cierto sentido el hecho de que la danza clásica sea una danza de posiciones estáticas, donde el acento esta puesto en la forma de la que se parte y a la que se llega y no tanto en las transiciones por las que pasa. Con una importante estabilidad, aunque en constante perfeccionamiento, la técnica de la danza clásica que se constituye entre los siglos XVII y XIX convive actualmente y dialoga con un conjunto de técnicas desarrolladas en el siglo XX; ejemplo de esto es la emergencia en el siglo XX del ballet moderno, cuyo ejemplo paradigmático es el de los Ballets Russos, cuyos diálogos con las tendencias de danza moderna, pueden verse en la reconocida carta de Fokine al New York Times ${ }^{6}$.

\section{Las técnicas de danza moderna: la expresión, la emoción y el cuerpo orgánico}

La expresión "danza moderna" fue creada por John Martin respecto de la danza de Martha Graham, con el interés de hacer ver el sentido histórico que la misma tenía. De manera general, los diversos autores sostienen que la danza moderna surge como reacción al academicismo y al severo entrenamiento del ballet; sin embargo, la expresión es al menos compleja en su uso y acepción, ya que existen al menos dos reparos: uno que refiere a la relación entre lo histórico/cronológico y lo estético, y otro que refiere a la multiplicidad de expresiones y formas que existieron y se desplegaron dentro de lo que se denomina vulgarmente danza moderna, categoría que tiende a englobar expresiones artísticas bastante diversas. Al respecto, Tambutti (2008) sostiene que el término danza moderna, "pese a su incapacidad para abordar la rica profusión de creaciones que los distintos artistas produjeron, tuvo el gran mérito de unificar las obras en una tipología minimizando, peligrosamente, sus diferencias" (19).

Aun así, la historia de la danza reconoce a principios del siglo $X X$ un movimiento orientado a poner en cuestión la forma clásica de construir una

\footnotetext{
${ }^{6}$ Para ampliar, cfr., por ejemplo, La danza contemporánea de Leonetta Bentivoglio (1985)
} 
obra de arte, centrada en la representación de un canon ideal, con el recurso a un código de movimientos apriorístico y, como consecuencia, en la forma académica de entrenamiento y construcción del cuerpo del bailarín. ${ }^{7}$ El eje de la puesta en cuestión estuvo dado por la necesidad de introducir la expresión como criterio de construcción de la composición artística y, ligada directamente a esto, la necesidad de introducir la subjetividad del bailarín/coreógrafo en el hecho artístico. La medida de la belleza ya no estaba situada en el exterior de la forma como ideal a conseguir (aunque veremos que la preocupación por la forma no se abandona completamente), sino que estaba dada en la interioridad a expresar, la verdad no estaba asociada a un canon de belleza ideal, sino a la sinceridad de una emoción y la posibilidad de expresarla. La introducción de las emociones y la ubicación del centro de gravedad en la interioridad del artista dieron por resultado la construcción de un abanico de códigos de movimiento, resultado cada uno de ellos, de las necesidades expresivas del artista, "la nueva representación puso al cuerpo al servicio de la 'expresión', a la vez que se desplegó un interés por la introspección. El cuerpo seguía siendo un instrumento, un medio; esta vez, el medio que permitía conocer la vida interior del artista" (Tambutti 2004: 8).

Tambutti (2007) sostiene: "aunque guiados por diferentes objetivos, el alejamiento de la mimesis y el rescate de las emociones como fuente originaria del movimiento frutificó, de diversas maneras" (10). Sin pretender soslayar esos matices, para los fines de esta tesis es posible caracterizar a la danza moderna estadounidense y a la danza de expresión alemana como un

"[c]onjunto de expresiones artísticas que oscilaban entre una danza entendida como producto de las distintas fuerzas que actuaban en el interior del hombre, desbordando la esfera de lo racional, como las tendencias que buscaban un desarrollo formal violando los límites de las formas academicistas, imposibilitadas de abordar las nuevas inquietudes artísticas" (Tambutti 2008: 20)

\footnotetext{
${ }^{7}$ Sally Banes (1987) nos muestra la dificultad que genera la denominación "danza moderna", especialmente si se considera la relación que el calificativo moderno tiene con lo que los autores consideran el modernismo como actitud. La expresión danza moderna puede tener cierta utilidad para ordenar en términos estrictamente cronológicos la emergencia de una forma de danza que viene después de la danza clásica; sin embargo, las dificultades se multiplican cuando se hace evidente que, aun en el período moderno de la danza, la forma clásica continúa existiendo y desarrollándose, y cuando se advierte, además, que no encontramos la actitud modernista -en tanto modo de poner en juego el conocimiento de los materiales, del medio, las cualidades esenciales, la forma, los elementos, la eliminación de referencias externas- en su máxima expresión en la danza sino hacia la década de 1950 y 1960.
} 
Como características generales podemos destacar en primer lugar el peso del componente expresivo: la danza debe expresar una emoción, una experiencia o un interior. Debe expresar y no representar; para ello cada bailarín y cada coreógrafo encontrarán un lenguaje corporal adecuado al mensaje que quieren enviar (Bentivoglio 1985); es decir, cada coreógrafo construirá una técnica, un sistema de movimientos codificados, que le permitirá construir una forma expresiva. La posibilidad de desarrollar un movimiento expresivo se vincula, a nivel del desarrollo técnico, con ciertos principios de oposición a partir del reconocimiento de la inestabilidad/descontrol del cuerpo como momento necesario en la ejecución de un movimiento "verdadero", y con la creciente importancia que, en este sentido, adquiere el movimiento continuo, entendido en términos de "frases de movimiento", en tanto unidad mínima de sentido y en detrimento del movimiento como transición entre poses estáticas, tal como se supone que se compone en base a la técnica clásica. En términos dinámicos hay un principio estructural de oposición, en torno al cual se articula la continuidad del movimiento; los elementos de oposición variarán en cada caso, redundando en diversas especificaciones técnicas.

El despliegue en términos técnicos que opera en la danza moderna se vincula con la necesidad de volver más expresiva la danza, y también el cuerpo en tanto es su médium específico. En todos los desarrollos técnicos ningún movimiento puede calificarse como pura forma o puro diseño. Lo que importa es la capacidad de comunicación que el movimiento contiene, su substrato emocional" (Bentivoglio 1985: 30). En este sentido, otra característica importante de la danza moderna y la danza de expresión será el supuesto subjetivismo de los sistemas de movimiento creados, ya que los mismos responderían a la necesidad del coreógrafo de expresar un contenido dramático específico: "si la génesis es subjetiva, en tanto originada por la exigencia expresiva individual del coreógrafo; sin embargo los resultados se sistematizan de forma objetiva, inmediata y, por consiguiente, a formar cada vez sistemas verdaderamente didácticos" (Bentivoglio 1985: 29). Para ello se recurre a una mayor combinación posible de movimientos -ya que se reconoce una multiplicidad de centros motores-, se presta atención a las articulaciones del cuerpo como lugares de flujo de movimiento, se prioriza la flexibilidad por sobre la rigidez de tono y se incluye además a la respiración como componente 
funcional del movimiento. No se supone un cuerpo mecánico como el del ballet, sino un cuerpo orgánico cuyas partes se relacionan en términos de su contribución al equilibrio y la armonía. Podemos pensar que se buscó construir un cuerpo expresivo, "no dominado instrumentalmente" por la técnica y una rutina arbitraria; a nivel de la ejecución de las piezas comienza a desarrollarse una analítica del movimiento en relación al espacio y al tiempo en la que se incorpora como elemento fundamental la gravedad y, por lo tanto, la relación del bailarín y de la danza con la tierra. Esto promueve dos cosas entrelazadas: una ideología naturalista, en función de la cual lo humano y el arte del hombre son mejores y más verdaderos si se reconoce la unidad del hombre con el mundo, a partir de poner al primero en relación con la naturaleza por medio del suelo, y el desarrollo de códigos técnicos -en varios puntos tan artificiales como los del ballet- que amplían las posibilidades expresivas de la danza, que se comprenden en función de la cosmovisión naturalista y en cierto punto romántica, de la cual son producto. La emoción, como elemento característico de la subjetividad, se vincula con esta concepción naturalista del hombre y se entiende, también, si consideramos que a principios del siglo XX había un clima de época que promovía la crítica a los malestares que produjo el desarrollo industrial en la cultura occidental.

Para Laban, por ejemplo, la rutina del trabajo inhibe las posibilidades expresivas naturales del movimiento; por eso es necesario desarrollar una nueva danza que contribuya al desarrollo de los potenciales del mismo. De hecho, pensando la relación entre el trabajo industrial y la danza moderna, Laban sostiene que

[s]abemos hoy que los hábitos laborales modernos crean con frecuencia estados mentales perjudiciales que nuestra civilización está inevitablemente destinada a sufrir de no encontrar alguna forma de compensación. Las compensaciones más evidentes son, por supuesto, aquellos movimientos capaces de equilibrar la desastrosa influencia de los hábitos de movimiento desequilibrados que se originan en los métodos contemporáneos de trabajo (Laban, 1978: 18).

Ahora bien, estos desarrollos técnicos basados en la inclusión de la emoción y su expresión como criterio de verdad, contribuyeron al desarrollo de un conjunto de códigos de movimiento que, lejos de significar una ruptura sustantiva con los principios del neoclasicismo, apenas los soslayaron. De hecho, siguieron operando: la cultura estética del modelo expresivo convive 
con una fuerte preocupación formal. Por eso Tambutti (2008) interpreta esta etapa en términos de un segundo momento dentro de la historia progresiva de la danza entendida en términos de la autonomía de su médium expresivo. Las rupturas son aparentes y -si bien contribuyen a la proliferación de nuevos códigos de movimiento, que consideran ampliar las posibilidades expresivas y de movimiento de la danza a partir de poner atención en el componente dinámico, en la respiración y en el desequilibrio (pensemos en la contracción/relajación y en la caída/recuperación, por ejemplo), en los esfuerzos y calidades del movimiento- no interrumpen la progresión de la historia en el punto en que

[p]or un lado, el clasicismo siguió presente tanto en la profundización del patrón matemático del movimiento como en la concepción instrumental del cuerpo. Por otro lado, el romanticismo reapareció en el misticismo religioso, en la nueva mirada que inducía a investigar los sentimientos y en la atención puesta en un nuevo centro de gravedad: el interior del artista. (Tambutti 2007: 11)

Las preocupaciones formales, dijimos, no fueron abandonadas en las concepciones de las técnicas modernas y en la construcción del cuerpo que proponían, sino que la forma, en lugar de articularse con una exterioridad, se ponía en relación con la necesidad expresiva interior, o bien, se "exploraba la expresividad propia a la materialidad del movimiento" (Tambutti 2007: 11). Incluso este formalismo incipiente, que es posible vincular con los desarrollos de Laban, por ejemplo, no se aleja de una concepción organicista del cuerpo, que tiene por efecto su fisicalización y que si bien nos aleja de la concepción mecanicista característica que va desde el siglo XVII a fines del XIX, y de las concepciones más orgánico/biologistas ligadas al romanticismo del siglo XX, sigue anclando los fundamentos de la construcción del cuerpo en un orden natural.

Por último, cabe destacar que

[a] pesar de las orientaciones conceptuales divergentes, de la bifurcación de los programas artísticos y de las heterogéneas percepciones del mundo moderno asumidas por estas tendencias, la amenaza de interrupción de la historia progresiva no se cumplió, por el contrario, ésta continuó y se expresó en nuevas sistematizaciones construidas sobre las bases acuñadas en los siglos anteriores por las teorías artísticas del racionalismo estético, del neoclasicismo y del romanticismo. En este segundo momento se profundizaron dichas teorías extendiendo el vocabulario de movimiento y desarrollando las viejas estructuras coreográficas, ampliando sus 
posibilidades y contribuyendo al desarrollo de la danza posterior. Producto de estas indagaciones se produjo la organización de nuevas escuelas y la sistematización de nuevas propuestas (Tambutti 2008: 20)

Vemos aquí que la ruptura que opera la danza moderna y sus desarrollos técnicos respecto del ballet y la técnica clásica es antes un mito que una verdad que se pueda verificar, y que si bien hay diferencias entre una y otra forma de danza en relación a los fundamentos de sus principios técnicos, (unos más estáticos y mecánicos y otros más dinámicos y orgánicos) son diferencias que podrían pensarse como diferencias de grado y no de cualidad. En relación al lugar del cuerpo como médium de la danza, podemos arriesgar que los diversos códigos técnicos, sufrieron en su desarrollo un proceso de instrumentalización que los aleja de la técnica entendida como techné, equivalente al que ocurriera con la técnica clásica. Cabe destacar, sin embargo, que los movimientos modernos y expresivos tuvieron la función de amplificar las posibilidades expresivas y formales de la danza como arte, consolidando en ese sentido el desarrollo de la historia progresiva.

\section{La autonomía de la danza: la centralidad de la forma y la especificidad del cuerpo como médium expresivo}

Siguiendo el modelo que retoma Tambutti (2008), a partir de Danto, para proponer una interpretación de la historia de la danza, podemos decir que hacia mediados del siglo XX se da en la danza escénica occidental, un movimiento con características modernistas, cumpliendo con el desarrollo de los principios del modernismo estético. Veremos qué significa esto, qué relación tiene con los códigos de movimiento que describimos anteriormente, y qué espectro de acciones que también forman parte de la danza quedan fuera de este tercer momento y dan inicio al período posthistórico o, de la danza contemporánea.

Presentemos en primer término la idea de que la danza desarrolla una actitud modernista y logra alcanzar la modernidad estética. En el apartado anterior dijimos la complejidad que reviste el término danza moderna y explicitamos dos consideraciones: por un lado, el hecho de ser un término que engloba un conjunto de manifestaciones sumamente disímiles y heterogéneas entre sí y, por otro lado, que si bien reviste cierta utilidad cronológica, los códigos y trabajos que se desarrollaron a principios del siglo XX no representaban al 
modernismo en términos estéticos. Pues este se define por el hecho de poner en primer plano la pregunta por las condiciones y posibilidades que ofrece a la danza su medio expresivo (el movimiento del cuerpo) eliminando referencias externas a la danza, lo que da como resultado colocar el medio y la forma por sobre el significado.

[c]on el reconocimiento de la forma como único contenido de la obra coreográfica surgieron nuevas preguntas, especialmente aquéllas referidas al lenguaje. Si el movimiento era un lenguaje, qué tipo de lenguaje era? Este tercer momento fue testigo de la profundización de este interrogante y, por consiguiente, del reconocimiento final de las diferencias de este lenguaje simbólico respecto de otros géneros artísticos. La renuncia a los modos tradicionales se produjo por el virulento rechazo de los artistas a que la danza fuera ilustración de historias o de relatos emocionales. De este modo, apareció, por primera vez en danza, el concepto de danza pura, verdadera aparición del modernismo en danza. (Tambutti 2008: 21)

Y más adelante continúa:

[p]or primera vez se entiende que el sistema de movimientos creados a partir de los principios establecido por el racionalismo estético y el neoclasicismo, ampliados y enriquecidos por artistas y teóricos durante casi cuatro siglos, era un vocabulario autónomo que no reconocía un fin práctico, fuera éste la narración de una historia o la expresión de un sentimiento, por lo tanto, su principal característica era su perfil "autotélico", es decir, su finalidad estaba en sí mismo, era autorreferencial (Tambutti 2008: 22).

Una vez que, de manera reflexiva, la danza reconoce la distancia insalvable entre un código de movimientos o lenguaje artístico autotélico y cerrado en sí mismo, respecto de las diversas intenciones contenidistas, miméticas o expresivas, se puede decir que la danza logra "cumplir uno de los mayores postulados modernistas: aquél que reivindicaba la pureza y autonomía de los lenguajes artísticos" (Tambutti 2008: 22).

En este sentido, las principales innovaciones que se introducen apuntan a desligar a la danza del problema dramático narrativo y sentimental expresivo: no hay nada que contar, ni del lado de la belleza ni del lado de la verdad, no hay que volver verosímil una representación ni forzar la emergencia de un significado preestablecido para la danza. Al haber abstracción de contenidos dramáticos, la cuestión del mensaje o del sentido de la danza adquiere una connotación diversa, el movimiento formalmente montado evoca una multiplicidad de sentidos, emociones y experiencias que no se vinculan de manera inmediata con la existencia de una historia con un significado preciso. 
Esto supone dos movimientos: de un lado, la puesta en juego del público como componente activo y necesario en la constitución de la danza como obra de arte, y del otro, la desaparición de la intencionalidad del artista como agente soberano del mensaje o construcción metafórica que la obra de danza propone. En relación a la construcción de los trabajos de danza vemos que no hay primacía anatómica o fisiológica que fundamente el motor o sentido del movimiento ejecutado en la danza; por el contrario, las diversas partes del cuerpo adquieren primacía alternativamente en relación al movimiento y a su localización temporal/espacial, el cuerpo se articula y desarticula respecto de sí mismo y respecto del espacio cada vez y de una manera distinta. A nivel de la obra, también hay un movimiento similar: se liquidan, por ejemplo, las jerarquías entre bailarines y desaparecen los frentes, en el sentido de que no todos los bailarines bailan mirando al público y se construyen diversos espacios en una misma obra. En relación al tiempo, la danza no se subordina a la música, son acontecimientos simultáneos que comparten una organización temporal. Bentivoglio (1985) sostiene que para Cunningham "danzar significa lanzar una energía directamente corpórea que penetra en la realidad de cada gesto y de cada acción. La danza se manifiesta entonces, como inmersión en la realidad" (Bentivoglio 1985: 47). Y más adelante

[e]sta es la estética totalizadora y extensiva de Cunningham y Cage, dominada por lo aleatorio como principio que, en la coreografía, se manifiesta a través de una escritura gestual estructurada e institucionalizada a través de la técnica. Elemento esencial que excluye a priori los diletantismos, la técnica se manifiesta siempre inflexible en la sublimación del cuerpo (1985: 48).

Esto se entiende en relación a los fundamentos que aporta el formalismo kantiano, Tambutti (2008) sostiene que "los términos de raíz kantiana, propios de la modernidad estética emergieron en este último momento: contemplación, desinterés, atención a la obra por su propio valor, intencionalidad sin intención" (23). Vemos entonces que hay un recurso poético, y no ético, a los códigos de movimiento desarrollados, lo que termina por completar la autonomía de la danza y consolidar la función de médium que para este arte tiene el cuerpo en movimiento.

Respecto de las concepciones de cuerpo que este modernismo en danza implica, cabe destacar la continuidad de las formas clásico-racionalistas y 
orgánico-expresivas, aunque cabe reconocer que hacia medidados del siglo XX se abre un frente de diálogo con una serie de disciplinas corporales ligadas a la conciencia sensible. La sensopercepción e incluso diversas técnicas orientales como el yoga o el tai-chi, se recuperan desde la danza para "perfeccionar" y complementar los códigos provenientes del racionalismo y el expresivismo. Si en relación a la técnica clásica pensábamos en un cuerpo mecánico y en relación a las técnicas de danza moderna pensamos en una máquina con motor, o en un organismo, podemos sostener que los diálogos que abren la puerta a las disciplinas ligadas a la conciencia sensible del cuerpo, introducen el elemento psíquico-sensitivo en el cuerpo que suponen.

Respecto de esto, Tambutti (2004), sostiene:

[l]a danza que hoy se inscribe dentro de la tradición racionalista deja de lado aquélla concepción corporal idealista, espiritualista y moralista, atendiendo sólo a su formalismo externo, aplicando leyes geométricas en todo su infinito despliegue, tal como podemos verlo en coreógrafos como William Forsythe, quien en lugar de recobrar y reproducir las formas del ballet clásico que son parte de un catálogo fijo de movimiento, despliega y abre estas formas hasta que aquéllas leyes matemáticas potencialmente ocultas en la sintaxis del ballet se hacen visibles. Ya no quedan rasgos del antiguo clasicismo aunque tenga en él su origen; tampoco se persigue la representación de un cuerpo etéreo o inmaterial producto de la intuición interior de una forma trascendente (9).

\section{$[\ldots]$}

[e]stas nuevas propuestas que de alguna manera continúan la tradición clásico-racionalista, conviven con el despliegue de otras propuestas que restituyen lo psíquico y lo fisiológico dentro de la estructura total del sujeto y, más aún, la de dicho sujeto y su mundo (9).

En este punto nos encontramos en un límite, no sólo en relación a la concepción de cuerpo que los diversos fundamentos de las técnicas ponen en juego, sino de la idea misma de la danza y, por ende, del cuerpo en movimiento en tanto médium expresivo. Tambutti (2008) sostiene que el cumplimiento del modernismo estético en la danza se entiende como cumplimiento del sentido histórico y, por lo tanto, como punto que marca una diferencia respecto de lo que describe en términos del inicio de la contemporaneidad en la danza a la cual define como el comienzo de la posthistoria. Los temas y problemas que trae aparejados esta etapa exceden en cierto sentido los límites de esta tesis, ya que remite a consideraciones de orden estético, justamente el elemento de la danza que decidimos dejar de lado para pensarla como práctica puesta en 
relación a una Educación Corporal. Sin embargo, creemos oportuno concluir con la siguiente referencia:

[e]l final de la historia progresiva fue también un archè (principio), un nuevo comienzo, que ya no se podrá definir como la búsqueda de un umbral unificador. Las múltiples posibilidades que se abrían demostraban más la presencia de un orden libre que la búsqueda de un principio único que funcionara como eje organizador de todas las transformaciones futuras (Tambutti 2008: 26).

Quizás esta característica, que define la situación de la danza actual, es la que funciona como condición epistémica de esta tesis, quizás sea eso lo que abre la posibilidad de pensar la danza como práctica y no como arte, y al cuerpo no como medio sino como su objeto y, por lo tanto, como contenido de una Educación Corporal.

\subsection{CONCLUSIÓN}

Me gustaría destacar aquí algunos elementos que procuraré retener a lo largo de toda la tesis. En primer lugar, el hecho de que la danza como arte es una invención occidental del siglo XVII: en el comienzo no había una idea de danza ligada a la construcción de una forma coreográfica bella destinada a la contemplación y no había tampoco bailarines profesionales; el cuerpo no era, en los bailes de salón y en los bailes de corte, un instrumento de trabajo artístico ni un medio expresivo, era un objeto de uso al que se educaba en función de unos intereses de clase.

Por otro lado, si bien la construcción del código técnico se orientó por la geometrización del cuerpo y por la racionalidad de su uso en el espacio escénico, el entrenamiento y el trabajo diario construían también un cuerpo de las acciones. El cuerpo de los bailarines se volvía geométrico, racional y etéreo en función del entrenamiento técnico. Las construcciones metafóricas que esos cuerpos habilitaban una vez en danza no deberían confundirse con los cuerpos para la danza.

El cuerpo no fue algo que se haya problematizado en el ámbito de los creadores de códigos técnicos ni en el de los coreógrafos: se sabía que el cuerpo estaba allí para ser dominado. El cuerpo como tema aparece en las reflexiones románticas y naturalistas, y no llegan a problematizar el lugar del cuerpo sino que tienden a mostrar la necesidad de construir y proponer nuevos 
códigos de movimiento, que permitan ampliar las posibilidades expresivas del cuerpo y desarrollar nuevas, distintas y "más humanas" obras de danza. El cuerpo sigue siendo un instrumento de la danza, un medio que se supone dado de alguna manera.

Por último, el siglo XX de la danza se abre con un período de experimentación y se cierra con diversas institucionalizaciones parciales, lo que explica la supervivencia en simultáneo de un conjunto de formas diversas de danza, todas de entrenamiento riguroso y todas apostando al arte escénico. Las discusiones que se fueron dando entre los diversos géneros, escuelas y códigos técnicos, tenían por eje a la danza y la cruzaban con elementos propios del campo de la práctica artística y de la estética filosófica. La pregunta por el cuerpo en la realización de la danza no aparece sino hasta la década de 1960, y cuando lo hace, no es en relación al cuerpo de la danza en tanto objeto construido por la práctica. La referencia al cuerpo lo implica en tanto metáfora tangible de la experiencia del hombre: el cuerpo pasa a ser un tema de poética coreográfica, no un objeto de la danza. 


\section{TEORÍAS SOBRE LA DANZA: ¿CÓMO CONSTRUYEN SU OBJETO?}

\subsection{PRESENTACIÓN}

Existe un número reducido pero importante de textos que se proponen pensar y conceptualizar la danza. En su mayoría son textos que no recurren a una historia de la disciplina, sino que refieren a piezas de danza, a escuelas, coreógrafos o bailarines, y los ponen en relación a un horizonte teórico y conceptual. La mayoría de las veces la preocupación intelectual se asocia a la necesidad de construir un conjunto de conceptos que sean específicos a la problematización y conocimiento de la disciplina. En otros casos, se recurre al préstamo de categorías (generalmente de las teorías del arte y la filosofía estética) con el interés de incrementar las formas de comprensión de la danza, suponiendo que a mayor comprensión, mayor capacidad de apreciación de la performance. También encontramos un registro en el que se busca definir la especificidad de la danza como objeto del pensamiento artístico y estético. Por último, hay veces en que la danza se vuelve objeto de la filosofía, que indaga sobre su constitución, sobre su ontología.

El presente capítulo tiene por objetivo presentar de manera sistemática algunos de los referentes más citados para cada una de estas diferentes formas en que la teoría de la danza se desarrolló, indicando en cada caso qué idea de danza se construye. El interés es reconocer la utilidad de estas formas de conocimiento pero a la vez mostrar, si no el límite, sí la necesidad de complementar estas concepciones a la luz de una teorización que parta de concebir a la danza como una práctica corporal, prescindiendo si se quiere de su estatuto artístico y con el interés de hacer aparecer el cuerpo como objeto de la danza.

[s]ostener hoy la posibilidad de "una" teoría de la danza, en el sentido fuerte del término, es entrar en franca contradicción con las características de un conjunto de objetos artísticos agrupados bajo ese nombre, pero cuya naturaleza es cada vez menos evidente. (Tambutti, 2008: 13) 


\section{2 ¿QUÉ ES LA DANZA PARA LA FILOSOFÍA?}

\section{La danza como metáfora del espacio y el tiempo}

A continuación voy a presentar las ideas sobre la danza que desarrollan Alain Badiou (1998) y Paul Valéry (1998). Si bien es posible reconocer los antecedentes de Badiou y Valéry en Nietzsche y en Mallarmé, no es menos cierto que las interpretaciones que los primeros ofrecen sobre ellos son agudas y acertadas: retoman sus tesis y las actualizan, las inscriben en un horizonte de pensamiento contemporáneo al tiempo que nos muestran su vigencia. Para esta presentación elegimos respetar el orden cronológico de aparición de los textos.

El texto de Valéry es de 1936, se llama "Filosofía de la danza" y se propone pensar la danza en términos de una actividad humana. Sostiene que toda cultura que se haya preguntado, intrigado o comprendido al cuerpo humano ha cultivado la práctica de la danza. ${ }^{8} \mathrm{El}$ autor inscribe esta práctica en el exceso de energía, en el mayor número de potencias que tiene el cuerpo humano respecto del número de necesidades y de la subsistencia. Así, la danza es un tipo de acción que se sustrae a las necesidades prácticas cotidianas y a las necesidades de la máquina de vivir.

El autor define la danza como una forma del tiempo que ignora lo que la rodea, ignora la tierra y la gravedad, el cuerpo de la danza es un cuerpo que se separa de los equilibrios ordenados y, sin embargo, su inestabilidad es regulada, hay una cadencia que ordena el movimiento. La bailarina crea un mundo que tiene un tiempo y espacio propios, ajenos a la práctica cotidiana. En este sentido Valéry sostiene:

[p]ero ese desapego al medio, esa ausencia de finalidad, esa negación de movimientos explicables, esas rotaciones completas (que ninguna circunstancia en la vida exige de nuestro cuerpo), esa misma sonrisa que no es para nadie, todos esos rasgos son decisivamente opuestos a aquellos de nuestra acción en el mundo práctico y de nuestras relaciones con él. En éste nuestro ser se reduce a la función de un intermediario entre la sensación de una necesidad y el impulso que satisfará esa necesidad. En ese papel, procede siempre por el camino más económico, si no siempre por el más corto: busca el rendimiento. La línea recta, la mínima acción, el tiempo más breve, parecen inspirarle (1998: 183).

\footnotetext{
${ }^{8}$ La categoría de práctica con la que trabaja Valéry no es equivalente a la que nosotros proponemos en esta tesis. En Valéry remite a aquello que los hombres hacen, mientras que nosotros, siguiendo a Foucault (1999), comprendemos la práctica como aquello que hace a los hombres (ver capítulos 4 y 5).
} 
Lo importante aquí es la consecuencia que extrae el autor respecto de la finalidad (del término) de la danza. En el punto en que la danza se construye por exceso de impulsos, su límite no le viene de sí, sino de una marcación exterior: la necesidad del espectáculo o el agotamiento físico del intérprete. Ensí, la danza podría ser absoluta o eterna, su finitud le viene de afuera:

[c]esa como un sueño, que podría seguir indefinidamente: cesa, no por la consumación de una empresa, sino por el agotamiento de otra cosa que no está en ella. Y entonces -permítanme alguna expresión audaz- [...] ¿no podríamos considerarla, y ya se los he dejado presentir, como una manera de vida interior, dando ahora a ese término de psicología, un sentido nuevo en el que domina la fisiología? Vida interior, pero enteramente construida de sensaciones de duración y de energía que se responden, y forman como un recinto de resonancias. Esta resonancia, como cualquier otra, se comunica (Valéry 1998: 184).

Por último, el autor traduce la idea de la danza como vida interior del cuerpo, con la idea de una poesía de la "acción general de los seres vivos" (186), de las potencias del ser. Aquí la poesía se identifica con la idea de metamorfosis, "pirueta de ideas" en función de la cual opera una separación del ser con el mundo práctico, en tanto la idea de acción de metamorfosis remite a la representación de un "estado general del ser" y no a la acción que tiene por finalidad la satisfacción de una necesidad. Estas consideraciones y características de la danza reconocen la necesidad de un régimen periódico que organice la práctica:

[e]s un hecho fácil de observar que todos los movimientos automáticos que corresponden a un estado del ser, y no a un fin figurado y localizado, requieren un régimen periódico; el hombre que anda requiere un régimen de esa clase; el distraído que balancea un pie o que tamborillea los cristales; el hombre en profunda reflexión que se acaricia el mentón, etc. (186).

Cierra esta idea de régimen asociándolo al ritmo que asume el trabajo del artista e inscribe el análisis en la pregunta por el tiempo en función del cual la danza podría definirse como una metamorfosis del tiempo práctico.

Podemos concluir entonces que, para Valéry, la danza se define como una forma de tiempo. Esa forma muestra estados del ser que no se corresponden directamente con el orden de la necesidad. Estas dos características revisten cierta importancia al momento de pensar la danza, ya que impactan de manera directa en lo que el autor sostiene respecto de su finitud-que no es interna, sino que termina por algo que le viene de fuera-, lo que podría significar, 
arriesgo, que la práctica de la danza adquiere sentido inteligible al ser puesta en relación con su ejecución, con su perfomance; si no, sería una pura mostración de los estados del ser. Justamente porque tiene un límite es que tiene un sentido como pieza de danza. La idea que opera aquí implica una sacralización del objeto de arte: incluso si consideramos lo que trabaja Valéry en relación al cuerpo, también queda claro que hace abstracción del conjunto de acciones que posibilitan la construcción de un cuerpo para la danza. De hecho, para que el cuerpo que baila pueda olvidar lo que tiene al lado, tiene que haber aprendido a relacionarse con eso de manera tal que el olvido sea una posibilidad. Por último, queda claro que el autor está pensando en la danza académica, como nos muestra la relación de huida con la gravedad o la mención a las piruetas (piruets).

Veamos ahora el texto de Alain Badiou; es un artículo de 1993 que tiene por título "La danza como metáfora del pensamiento", y la tesis central que desarrolla se vincula más con el pensamiento que con la danza. Sin embargo, esto no le impide sacar conclusiones específicas sobre esta última. El autor entiende el arte en general como una forma de pensamiento irreductible a la filosofía y sus reflexiones en este texto apuntan a la categoría de pensamiento en general, por eso aparece en el título la cuestión de la metáfora. Si la danza como arte supone, como dijimos, un pensamiento irreductible a la filosofía, la danza como forma de ser es metáfora respecto del pensamiento en general "porque se opone al espíritu de pesadez" (Badiou 1998: 105). Su idea central sostiene, entonces, que "la danza sería la metáfora de que todo pensamiento verdadero está suspendido de un acontecimiento. Porque un acontecimiento es precisamente aquello que queda no decidido entre el tener-lugar y el no-lugar, un surgir que es inseparable de su desaparecer" (109). Ahora bien, ¿qué quiere decir esto y qué nos informa acerca de la danza?

Badiou retoma a Nietzsche y desarrolla varios elementos. Primero, la relación constitutiva de la danza entre proyección hacia lo alto y atracción terrenal (lo que supone una referencia implícita a la danza clásica y al ballet contemporáneo, que claramente proyectan hacia lo alto). El cuerpo danzante se ubica mediando esa relación y siendo vehículo de la inversión de ambos polos, y la idea de que el aire está en lo alto como ligereza se trueca, vía el cuerpo danzante, en el aire de la respiración a partir del cual se está sobre la 
tierra. Subsidiaria a esta idea está la cuestión de la operatividad, de la efectividad de la danza y del pensamiento. La danza trastoca el lugar pero ocurre en un lugar; para expresar este elemento recurre a la idea de intensificación y supone que el cuerpo danzante es el cuerpo orientado a su cenit, es el pensamiento volcado a su propia altura. Respecto de esto hagamos algunas consideraciones: por un lado hay cierta identidad entre danza y movimiento, movimiento del cuerpo en el espacio, sí, pero también movimiento y más precisamente inversión de los cuerpos y los elementos. En este sentido hay un vínculo estrecho entre movimiento e impulso, pero el impulso entendido de una manera específica. Retomemos el texto de Badiou en dos extractos:

[p]ero entonces, la imagen de la danza es natural. Transmite visiblemente la idea del pensamiento como intensificación inmanente. Mejor digamos, una cierta visión de la danza. En efecto la metáfora sólo tiene valor si descartamos toda representación de la danza como obligación exterior a un cuerpo flexible, como gimnasia del cuerpo danzante regulada desde fuera [...] O sea, un régimen del cuerpo ejercitado en someterse a la coreografía (Badiou 1998: 107).

Más adelante, concluye: "La danza no es en absoluto el impulso corporal liberado, la energía salvaje del cuerpo. Por el contrario es la mostración corporal de la desobediencia a un impulso. La danza muestra cómo un impulso puede ser vuelto inefectivo, de manera que no se trate de una obediencia sino de una retención" (108).

A continuación el autor sostiene que la danza como metáfora del pensamiento remite más al movimiento virtual que al movimiento real. El juego de tensiones y de inversiones del cuerpo danzante, cuando lo vemos no desde su técnica y su gimnasia, sino desde la retención del impulso como desobediencia y desde la inversión de lo aéreo y lo terrenal, abre un espacio de virtualidad. Esta idea de virtualidad se completa con la de acontecimiento y explicita la metáfora: la danza es pura espacialización ya que es lo que tiene lugar en el no-lugar, es lo que pasa antes de que se lo nombre con suplemento indicativo, antes de que se le asigne un lugar en el orden de las cosas, de la historia y del tiempo. La danza como metáfora del pensamiento es lo que pasa antes del tiempo, es la suspensión del tiempo en el espacio y, por lo tanto, la interpretación en danza hace visible en el espacio (o virtual) el elemento pretemporal. En este sentido Badiou sostiene que, 
[e]l nombre es lo que decide el haber-tenido-lugar. La danza indicaría así al pensamiento como acontecimiento, pero antes de que aquél tenga su nombre, al borde extremo de su verdadera desaparición, en el desvanecimiento de sí mismo, sin el abrigo del nombre. La danza imitaría al pensamiento todavía indecidido. Sería el pensamiento nativo, o no fijado (1998: 110)

En relación a este núcleo conceptual, a esta epistemología del movimiento de la danza (la danza es virtualidad y forma del acontecimiento porque es espacio antes de tiempo -ya que el tiempo aparece con el nombre y la danza acontece antes de ser fijada, como desobediencia a un impulso-), el autor concluye con algunas consideraciones de relevancia para el saber sobre la danza.

a) En primer lugar reconoce una obligación de espacio: ya que la danza simboliza la espacialización del pensamiento y, a diferencia del teatro, en el que la exigencia es de tiempo (por el texto), interpreta la suspensión del tiempo en el espacio, está por lo tanto constreñida a este último.

¿[q]ué debe entenderse por eso? Es necesario regresar una vez más sobre el origen acontecimental de todo pensamiento. Un acontecimiento está siempre localizado en una situación, no la afecta nunca "completa": hay lo que he llamado un sitio de acontecimiento. Antes de que la denominación funde el tiempo donde el acontecimiento "trabaja" la situación como su verdad, está el sitio. Y como la danza es mostración del antes del nombre, es necesario que se despliegue como recorrido de un sitio (1998: 112).

b) La segunda consideración remite al anonimato del cuerpo. En la medida en que la danza no representa más que el espacio antes del tiempo, y que certificamos una vez más la ausencia de "vocablo", es posible entender la idea de que el cuerpo danzante no es imitación de personajes sino generador de virtualidad. Badiou retoma de Mallarmé la idea de cuerpo emblema y la explica en términos nietzscheanos:

[e]mblema se opone ante todo a una imitación. El cuerpo danzante no imita a un personaje $\mathrm{o}$ a una singularidad. No figura nada [...] el cuerpo danzante no enrolado en ningún rol, es el emblema del surgimiento puro. Pero "emblema" se opone también a toda forma de expresión. El cuerpo danzante no expresa ninguna interioridad, es él, todo en su superficie, intensidad visiblemente retenida (113).

El cuerpo danzante es anónimo respecto de lo que aparece ante nosotros como un cuerpo.

c) El tercer principio remite a la omnipresencia borrada de los sexos, y Badiou sostiene que la danza muestra siempre la conjunción y disyunción de las posiciones sexuadas a partir de organizar en una forma la triplicidad del 
encuentro, la unión y la separación. Si bien se recurre al sexo del hombre y la mujer (bailarín y bailarina), eso desaparece ante el juego esencial que propone la remisión de la danza a la sexualidad como un juego un poco más general de la relación entre ser y desaparecer.

d) El cuarto principio remite a la sustracción de sí. Esto se entiende también a la luz del concepto de acontecimiento como aquello que tiene lugar en el nolugar. Si entendemos que el lugar como situación (no como sitio) supone ya el nombre, y entendemos que a partir del nombre se instituye una cosa como teniendo lugar y se construye en una forma de saber sobre eso que ha ocurrido, la sustracción de sí del cuerpo danzante se entiende como la manera en que quien baila no sabe aquello que baila.

[s]u saber (que es técnica, inmensa, dolorosamente conquistado) está atravesado, como ningún otro, por el surgimiento puro de su gesto. "La bailarina no baila" quiere decir que lo que nosotros vemos no es en ningún momento la realización de un saber, aunque ese saber sea la materia o el apoyo. La bailarina es el olvido milagroso de todo su saber de bailarina, ella no ejecuta ninguna danza, es esa intensidad retenida que manifiesta la indecibilidad del gesto. En realidad, la bailarina destruye toda danza sabida porque dispone su cuerpo como si fuera inventado (115).

e) La quinta consideración es la desnudez del cuerpo danzante, desnudez no empírica sino esencial. La danza se muestra antes del tiempo y del nombre, antes de toda relación con otra cosa que con ella misma. La desnudez remite, en este sentido, al desnudo del surgimiento, donde no hay necesidad de decorado ni ornamentación.

f) Finalmente, la sexta consecuencia de esta epistemología de la danza remite a la mirada absoluta a la que está sometida. Esto se vincula con varios de los elementos desarrollados, especialmente el estatuto acontecimiental de la danza, su condición efímera, su juego de ser-desaparecer, su falsa totalidad, la sustracción de sí por ausencia de nombre propio. En este sentido, Badiou sostiene que

[l]a danza, precisamente debido a que es un arte efímero, ya que ella desaparece apenas ha tenido lugar, posee la carga de eternidad más fuerte. La eternidad no consiste en quedarse igual o en la duración. La eternidad es precisamente aquello que conserva la desaparición [...] la danza, en cambio, atrapada por el espectador verdadero, no puede desgastarse, precisamente porque ella no es otra cosa que el efímero absoluto de su encuentro (117). 
El texto concluye con una reflexión que sitúa a la danza en los límites del arte, límites que sin embargo la vuelven posible. Justamente porque la danza es acontecimiento y metáfora del pensamiento, ella misma es potencia de arte pero no arte mismo. La danza nos muestra que el cuerpo es capaz de arte, lo que no equivale a decir que la danza es hacer un arte del cuerpo. Vemos aquí un pequeño desplazamiento en el que la centralidad ahora es lo que puede el cuerpo, desplazamiento que va de lo metafórico de la danza respecto del pensamiento a la realidad del cuerpo como potencia de pensamiento y de arte, de arte como aparición de un pensamiento verdadero (y no como forma objetual: por eso la danza no es arte).

[d]ecir que el cuerpo, en tanto que cuerpo, es capaz de arte, es mostrarlo como cuerpo-pensamiento. No como pensamiento atrapado en un cuerpo, sino como cuerpo que es pensamiento. Ése es el oficio de la danza: el cuerpo pensamiento mostrándose bajo el signo desvaneciente de una capacidad de arte. La sensibilidad ante la danza de cada quién proviene del hecho de que la danza responde a su manera a la pregunta de Spinoza. ¿De qué es capaz un cuerpo en tanto tal? Es capaz de arte, es decir, es mostrable como pensamiento nativo (119).

Sintetizando, podemos sostener que a diferencia de Valéry (1998), para quien la danza es una forma de tiempo, para Badiou la danza es espacialización del pensamiento, es antes del tiempo, en el punto en que el tiempo es ya historia significada -o historia con nombres y vocablos. Ambos textos están pensando el ballet y las bailarinas de ballet, y no ejemplifican con obras específicas ya que pareciera que la danza es una excusa para pensar la relación entre cuerpo/pensamiento y movimiento/forma, relación entre partes que es específica y particular de la danza pero que también es constitutiva del pensamiento y del lazo social. El texto de Badiou, sin embargo, va un poco más lejos con las consecuencias que tiene para la danza, ya que en primer lugar, como dijimos más arriba, la aleja del arte, y en segundo lugar pone en juego la relación con el saber por el que tiene que pasar un cuerpo para bailar, algo que Valéry pasa por alto sin mayor problematización. ${ }^{9}$

\footnotetext{
${ }^{9}$ Me interesa retener también la idea de arte como mostración de un pensamiento, ya que es una concepción acerca del arte que reenvía al vínculo entre arte y técnica (techné) y se acerca a cierta forma de comprensión del arte como poiesis que desarrolla Giorgio Agamben en El Hombre sin contenido (2005) y con la que voy a trabajar más adelante.
} 


\section{Por qué el pensamiento ignora a la danza}

Existen otros dos textos de referencia, ampliamente citados en el área del pensamiento sobre la danza, que apuntan a vincularla con la filosofía: el de Francis Sparshott (1981) y el de Michel Levin (1977). Ambos textos se encuentran en la compilación de Roger Copeland y Marshall Cohen ¿What is dance? Readings in theory and criticism (1983). Este es un libro de referencia indiscutida en los estudios sobre danza, tanto por el valor de los textos que incluye como por la amplitud de entradas que permite. Tiene cinco secciones y la primera de ellas -“¿Qué es la danza?”- se orienta a definir la danza en su especificidad a partir de distinguirla de otros tipos de movimientos rítmicos; en esta sección se incluyen los textos citados arriba. El de Michel Levin (Copeland y Cohen 1983: 13) se llama "Los filósofos y la danza" y la tesis central que desarrolla articula dos elementos: el componente patriarcal de la cultura occidental, ${ }^{10}$ con la aversión de la tradición filosófica de occidente hacia el cuerpo, y la sensualidad del cuerpo (sostenida en el dualismo abierto por el cristianismo). Es en relación a esto que sostiene que la danza, en la medida en que es "la perfección (o la presencia perfecta) del cuerpo humano en movimiento" (15), no ha sido objeto ni preocupación de la filosofía. La pregunta que subyace a esa sentencia es: si la filosofía no desarrolla una adecuada reflexión sobre el cuerpo humano, ¿por qué habrá de hacerlo con la danza? Hasta la estética filosófica, al preocuparse por el juicio antes que por el objeto perceptivo, ha podido olvidarse de la danza sin mayor problema, olvido que se inscribe también en la aversión de la filosofía hacia el cuerpo.

Llegado a este punto, que puede interpretarse de diagnóstico, Levin reconoce en la fenomenología una apuesta, ya que representa una corriente de la filosofía que aporta elementos para el abordaje de la danza. Así, el autor plantea,

[e]n primer término, que la fenomenología pone la comprensión del cuerpo en el centro de su problemática; y en segundo término que el acercamiento fenomenológico es el único que ha apreciado verdaderamente la sensualidad del cuerpo humano tal como es experimentada realmente [...] Lo fenomenológico de la danza debe ser visto como absolutamente fundamental para nuestro entendimiento filosófico del cuerpo. Lo que no

${ }^{10}$ Considera que la danza tiene en sus fundamentos principios femeninos, desde el ritual de fertilidad hasta el hecho de que la danza es mayormente ejecutada por mujeres o por hombres con orientaciones femeninas -mientras que la crítica y la coreografía, que son componentes intelectuales, están a cargo de hombres. 
parece haber sido visto de esta forma es en cambio, lamentablemente obvio. Todo lo que puedo decir aquí como forma de explicación es que la fenomenología es una disciplina joven cuyos recursos latentes de radicalización insumen una gran reflexión -y no menos dosis de corajepara usarla providencialmente (16).

El texto cierra proponiendo tres niveles de análisis para el abordaje de la danza como arte, cuya posibilidad de emergencia el autor asocia al desprendimiento de sus orígenes rituales. El primer nivel es el fenomenológico, que implica la descripción objetiva de lo visiblemente perceptible. Luego sigue el nivel histórico crítico, que exige una dialéctica inmanente del lugar de la obra específica en la historia de la disciplina, y una dialéctica trascendental en la cual se ubica la obra en el contexto de la producción e historia cultural. Por último, el nivel metafísico se orienta hacia lo ontológico, hacia el desocultamiento del ser mismo de la obra (invisible a la percepción fenomenológica).

El texto de Sparshott es de 1981 y su título es "Por qué la filosofía ignora la danza" (en Copeland y Cohen 1983: 7). El autor sostiene que durante los años '60 del siglo XX pasado la danza comienza a despertar interés como objeto de investigación y de análisis, lo que ocurre en el área de la antropología y de los estudios sociales pero no en el campo de la estética filosófica. Ante la pregunta de por qué pasa esto, arriesga varias hipótesis de trabajo. La primera se vincula en algo con la tesis del trabajo de Levin, según la cual la danza no ha sido objeto de la filosofía porque es un arte femenino en el contexto de una cultura patriarcal. Sin embargo, Sparshott descarta esta idea por dos cuestiones: por un lado, porque reconoce que los hombres bailan, y por otro porque la asociación entre danza y femineidad es, si no arbitraria, al menos histórica:

[quien ve] la danza como una expresión de aspectos psicológicos verdaderamente femeninos que nos libera de los discursos racionalmente estructurados. Y si la danza está aquí y ahora, en algunos aspectos, institucionalmente asociada con la feminidad, esto es un fenómeno contingente que requiere de una explicación histórica de las distintas corrientes de pensamiento antes que transformarse en una explicación en sí misma (8).

La segunda respuesta sostiene que la filosofía ignora la danza porque es corporal y los filósofos temen y odian el cuerpo. Sparshott sostiene que esto explicaría en todo caso por qué los filósofos no bailan, pero no por qué la 
danza no es objeto de la filosofía estética, ya que "la danza como arte no es, desde el punto de vista del observador o crítico, significativamente más corporal o menos espiritual que otras artes objetivables" (8).

Por último, el autor trabaja con cuestiones vinculadas a la accesibilidad de la danza como arte en relación a la existencia de los registros de notación y de video. De hecho, su inexistencia volvería a la danza un arte efímero y por tanto de difícil acceso para ser trabajado como un ejemplo de la estética. Si bien no acuerda totalmente con este argumento, se agarra de él para desarrollar su tesis explicativa, la cual sostiene que

[s]orprenderse por lo poco que se ha escrito sobre la filosofía de la danza es ser ingenuo acerca de las condiciones en las que los filósofos de las artes específicas escriben. Que un arte exista y que trabajos admirables puedan crearse en él, nunca fue motivo suficiente para que se genere una filosofía sobre ese arte. Es necesario que ese arte haya ocupado una posición cultural central en un tiempo que haya sido relevante, o que la ideología artística pueda ser integrada con la ideología cultural predominante (8).

Ninguna de estas dos condiciones se dieron en relación a la danza. Por un lado, los sistemas ideológicos creados por el pensamiento filosófico no ofrecieron un lugar para la danza; para justificar esta afirmación remite como ejemplo al sistema de las bellas artes construido por Aristóteles -donde el arte se entiende como una forma de conocimiento-, al sistema de las artes hegeliano -donde el arte es adecuación de la forma a la idea- y a los paradigmas que han dominado a la estética filosófica hasta el siglo XIX. Por otro lado, la danza ha sido una actividad cultural central en un tiempo inconveniente, ya sea por su lugar en los rituales de las sociedades primitivas, que es algo que la filosofía no tiene la capacidad "ni de imaginar" (8), o por su lugar en las cortes europeas, al que, por ser una práctica aristocrática, el pensamiento de la estética burguesa le restó importancia.

Para lograr que la filosofía se ocupe de la danza habría al menos dos pasos a seguir. Primero, asignar a la danza un significado lo más preciso posible. No puede haber una filosofía de la danza mientras su significado sea equívoco, mientras se mencione como danza desde los espectáculos mixtos en los que el componente danzado es más pantomima que baile, hasta la danza abstracta norteamericana donde la danza es movimiento organizado del cuerpo humano más allá de cualquier significación previa. Es decir, habría que construir una 
idea de danza como tal y luego habría que definir el lugar de la danza en la ideología cultural de una época, pero como lugar específico, como locus que sólo ella pudiera llenar, darle lugar en un sistema.

El texto cierra con diversos ejemplos demostrativos de la falta de correspondencia entre la actividad de la danza y las ideologías que entienden el arte. Retoma el caso de la escultura en las bellas artes como forma artística suprema vinculada al cuerpo humano, lo cual nos muestra la inferioridad de la danza en este sistema específico. Vemos que en este texto el cuerpo no ocupa ningún lugar sustantivo en la problematización de la danza, algo que responde, una vez más, a la primacía de la mirada artística sobre la práctica.

\section{Qué es la danza para la teoría del arte}

En este apartado voy a presentar las ideas de Susane Langer sobre la danza, porque es una autora paradigmática en el sentido en el que, dentro del campo de estudios de la teoría del arte, es quien más sistemáticamente refiere a la danza de manera explícita. En cierto sentido hay una línea de continuidad con el apartado anterior, especialmente en relación a la definición o especificación de aquello que es la danza. En primer lugar voy a trabajar con la sección dedicada a la danza del texto publicado en 1953, que lleva por título

Sentimiento y Forma. Agregaré también "La imagen dinámica: algunas reflexiones filosóficas sobre la danza", una conferencia incluida en el libro Los problemas del arte. Diez conferencias filosóficas, editado por primera vez en 1957.

En Sentimiento y Forma, la autora desarrolla los fundamentos para una teoría del arte en la cual la idea de forma simbólica -como construcción artificial en la cual elaboramos abstracciones y objetivaciones- se articula con la idea de sentimiento, entendido como todo aquello que surge de sensaciones físicas o espirituales. De manera general, afirma que el arte es una ilusión primaria y creada (cit. en Copeland y Cohen 1983), y en ese sentido todo arte es virtualidad, más allá de que posea una materialidad específica, el lienzo y los tintes, el sonido, el movimiento del cuerpo o la palabra. Lo específico del arte son las fuerzas e ilusiones que son creadas y que son distintas a la realidad de su soporte material; la autora arriesga incluso que la materialidad, en el sentido 
del medio del que se sirve el arte, puede operar en términos de explicación causal respecto de las posibilidades de emergencia de una obra específica, pero no explica la obra en sus efectos, en los poderes que son creados como ilusión propia del arte. En este contexto se inscriben sus consideraciones sobre la danza, a la que define en función del gesto. El gesto es entendido en este contexto como abstracción a partir de la cual la danza se organiza, ya que remite a la emergencia de una expresión no lingüística de sentido:

[e]l término gesto es definido en el diccionario como "movimiento expresivo". Pero expresivo tiene por lo menos dos significados alternativos (sin mencionar especificidades menores) significa tanto "auto-expresión", por ejemplo síntoma de condiciones subjetivas existentes o "expresión lógica", por ejemplo simbolismo de un concepto, que puede o no referirse a condiciones dadas de hecho. Un signo funciona a menudo en ambas direcciones como síntoma y como símbolo. (en Copeland y Cohen 1983: 22).

Sin embargo, aclara, el gesto es una expresión artificial, construida e imaginada y en ese sentido, es un poder ilusorio capaz de comunicar y evocar sentimientos. El gesto de la danza es un gesto virtual, construcción simbólica de la voluntad artística que busca evocar para producir sentimientos y sensaciones, no para expresar la realidad de un sentimiento vivido. En este sentido la autora sostiene que,

[e]n la danza, los aspectos reales y virtuales del gesto se mezclan de manera compleja. Los movimientos por supuesto son reales, surgen a partir de una intención y en ese sentido son gestos reales. Pero no son los gestos que parecen ser, porque parecen surgir del sentimiento y en realidad no es así. Los gestos reales del bailarín son utilizados para crear un parecido con la autoexpresión y por lo tanto, se transforman en movimiento espontáneo virtual, o gesto virtual (22).

Subyace en estas definiciones una discusión con las diversas teorías naturalistas que sostienen que la danza es expresión inmediata de la psicología del artista. Aquí hay una apuesta importante de la autora, ya que arriesga a sostener que las teorías sobre danza y las fuentes primarias sobre las que se construyen esas teorías lo hacen sobre un equívoco que identifica autoexpresión y expresión de la danza, síntoma y símbolo, hecho físico y significado artístico. Veamos cómo lo plantea la autora:

[l]a confusión casi universal entre auto-expresión y expresión en la danza, entre emociones personales y emociones del ballet, es fácil de entender si uno considera las relaciones involucradas que la danza realmente tiene con los sentimientos y sus síntomas corporales. Esta confusión no sólo es 
inducida por la concepción popular del arte como catarsis emocional, sino que además se agrava por otra doctrina igualmente seria y respetable [...] que sostiene que un artista nos da la posibilidad de una mirada interior del mundo de lo real, que penetra en la naturaleza de las cosas individuales y nos muestra el carácter único de tales objetos o personas completamente individuales. En la así llamada "Danza Moderna" el motivo más habitual es una persona expresando sus sentimientos. Entonces, la esencia absolutamente individual que tiene que ser revelada debe ser el alma humana [...] y si la persona cuyas alegrías y miedos que tienen que ser representados por la danza no es otro que el bailarín, la confusión entre sentimiento mostrado y sentimiento representado, entre síntoma y símbolo, entre motivo e imagen es imposible de resolver.(23).

Una vez que considera y desarrolla estos elementos, la autora nos muestra que, más allá de que la danza se haya convertido en arte a partir del surgimiento de un público pasivo en la contemplación, y que haya perdido sus funciones míticas y rituales, en lo esencial, tanto una como otra forma de danza tienen la misma finalidad: crear un mundo virtual; los problemas de la danza tribal o de culto eran prácticamente los mismos que los del ballet moderno, "quebrar el sentido de realidad del espectador y levantar la imagen virtual de un mundo diferente" (28).

El otro texto de Langer, "La imagen dinámica: algunas reflexiones filosóficas sobre la danza" (1966), retoma en algunos puntos lo que desarrolla en Sentimiento y forma, al tiempo que incorpora algunas precisiones. La clave, en este sentido, sigue siendo la necesidad de creación de virtualidad en el arte. En esta conferencia busca dar un significado -como construcción lógica, cuerpo coherente de ideas conexas- de lo que es la creación de danza (Langer 1966: 11-13). Sentencia que la danza es una apariencia, ya que rebasa todos los objetos que son usados para crearla -la gravedad, los cuerpos de los bailarines, el vestuario, etc. - y, si bien surge del movimiento del cuerpo, es algo distinto de ese mero movimiento. ${ }^{11}$ Eso distinto que es creado por el movimiento del cuerpo es creado para nuestra percepción, son fuerzas virtuales que se desprenden de la fuerza física, fuerzas que crean una imagen dinámica sui generis respecto de la ejecución de los pasos de baile.

La imagen dinámica creada por la danza se ofrece a través de la percepción a nuestra sensibilidad. No nos muestra un sentimiento particular, ni del coreógrafo ni del bailarín, nos muestra la idea del sentimiento humano, del

\footnotetext{
${ }^{11}$ Vemos cómo se repite lógicamente el tratamiento que hace del gesto y cómo coincide con Válery y Badiou en que, si vemos la gimnasia corporal, no vemos el arte de la danza.
} 
modo que sentimos. La imagen dinámica es una forma artística que vuelve visible la vida interior, la estructura de la existencia subjetiva, que carece de nombre y de palabras que la signifiquen. En el texto leemos:

[l]a existencia subjetiva tiene una estructura, no sólo se da con ella de un momento a otro sino que puede ser conocida conceptualmente, puede reflexionarse sobre ella, imaginarla y expresarla simbólicamente en detalle y hasta una gran profundidad. Sólo que no es nuestro medio usual, el discurso -la comunicación mediante el lenguaje- lo que sirve para expresar lo que sabemos de la vida del sentimiento. Existen motivos lógicos por los cuales el lenguaje no puede cumplir esa tarea, motivos que no trataré de explicar ahora. El hecho importante es que lo que el lenguaje no hace directamente -presentar la naturaleza y las pautas de la vida sensible y emocional- es llevado a cabo por obras de arte. Dichas obras son formas expresivas y lo que expresan es la naturaleza del sentimiento humano" (Langer 1966: 17).

Llegados a este punto en el que la danza es una apariencia de fuerzas virtuales que crean una imagen dinámica orientada a expresar la naturaleza del sentimiento humano, la autora se pregunta qué quiere decir expresar en una forma un sentimiento, y responde que "significa hacer una imagen externa de este proceso interno, para verla uno y que la vean los demás, es decir, darles a los acontecimientos subjetivos un símbolo objetivo" (18). Todo arte es una imagen creada en este sentido, una forma expresiva virtual; y tanto la particularidad de cada una de las artes como la diferencia de las artes entre sí residen en la sustancia con la que está hecha la imagen. La sustancia de la danza son esas fuerzas no físicas y sui generis respecto de la mecánica específica de las fuerzas físicas. El texto concluye insinuando el vínculo estrecho entre danza y gesto al modo en que lo trabaja en Sentimiento y Forma, afirmando en este sentido que "la danza crea un mundo de poderes que hace visible la estructura intacta del gesto" (20).

\subsection{LA PREOCUPACIÓN POR EL CUERPO}

En este apartado me interesa presentar algunos textos que abordan de manera específica la cuestión del cuerpo en la danza; algo que, como vimos anteriormente, no se hace de manera recurrente en la bibliografía específica. Vamos a trabajar con un texto corto de Susan Leigh Foster que se llama "Cuerpos de danza" y que se encuentra en Incorporaciones, un libro de 1992 editado por Cray y Kwiter, y con un libro compilado por ella en el año 1996, que 
se llama Corporealities. Dancing Knowledge, culture and power (2005). También vamos a incluir una referencia a la conferencia "Programa para una sociología del deporte", de Bourdieu, pronunciada en 1980 y editada como parte de Cosas Dichas (1997) y, por último, trabajaremos con un libro de Chantal Jaquet, Le corps (2001), específicamente con el apartado dedicado a la potencia (puissance) del cuerpo en el arte, dentro del cual dedica unas páginas a la danza.

"Cuerpos de danza" resulta un texto por demás interesante, ya que plantea que los trabajos y críticas que toman la cuestión del cuerpo, lo toman en consideración sólo parcialmente, al considerarlo como símbolo del deseo o de la utopía, lo termina por construir un cuerpo de de naturaleza esquiva para el análisis. Falta en estos enfoques para Foster "una perspectiva más sustanciosa del cuerpo basada en un análisis de los discursos o prácticas que lo instruyen" (en Cray y Kwiter 1992: 410). En este sentido, la autora sostiene que todos los métodos orientados a cultivar el cuerpo: las diversas disciplinas deportivas, atléticas, de interpretación, e incluso todos los procederes cotidianos del cuerpo que Mauss trabaja en "las técnicas del cuerpo", forman parte de la estructura de nuestra cultura, y la participación práctica y diaria del cuerpo en alguno de esos métodos de cultivo o de esas disciplinas lo convierte en un cuerpo de ideas. Del cuerpo así concebido, piensa que

[c]ada disciplina hace referencia a él con metáforas selectas y otros tropos que lo adornan. Estos tropos pueden proceder del discurso anatómico o de la ciencia de la cinesiología o pueden compararlo a una máquina, un animal o cualquier otro objeto o suceso del mundo. Pueden estar articulados como descripciones verbales del cuerpo y de sus actos o como actos físicos que le muestran cómo comportarse. Ya sean palabras o actos, estos tropos cambian el significado del cuerpo re-presentándolo (410).

En esta perspectiva la autora sostiene que, para la construcción de un cuerpo de danza, en el entrenamiento de un bailarín -al que le calcula entre 4 y 6 horas diarias, de 6 a 7 días por semana, durante 8 o 10 años- entran en relación al menos tres cuerpos diferentes que conforman el cuerpo de ideas: el cuerpo percibido, el cuerpo ideal y el cuerpo demostrativo. El cuerpo percibido remite al registro que el bailarín tiene de su cuerpo, y la mayoría de las veces alimenta la discrepancia entre lo que se quiere hacer y lo que se puede hacer. La percepción se sostiene en base a información visual, articular, táctil y kinestésica: "oyen los sonidos producidos por el movimiento, por una parte del 
cuerpo que toca a la otra, por la respiración y por las articulaciones y los músculos que crujen, restallan y chirrían al flexionarse, extenderse y girar" (411).

El cuerpo ideal al que tiene que llegar el cuerpo percibido no es uno sólo, sino que se compone de una diversidad de otros cuerpos e incluye diversas imágenes, visuales o cinestésicas de otros bailarines. El cuerpo ideal especifica una morfología corporal y también la pericia en la ejecución de movimientos. Sobre el cuerpo ideal y el percibido, Foster sostiene que se construyen y se transforman a la par durante el proceso de formación del bailarín -es decir, que no son estáticos en el transcurso de los 8 o 10 años de entrenamiento. En la representación del cuerpo ideal y del cuerpo percibido hay imágenes del aparato óseo, muscular, nervioso y de tejidos grasos, mientras que los pulmones, el estómago y el aparato circulatorio existen en grado mínimo y el sistema endócrino no existe en absoluto.

El cuerpo demostrativo interviene en el proceso de formación para la adquisición de las habilidades técnicas de la danza, a veces coincide con la figura del docente pero muchas veces emerge en el cuerpo de los compañeros de clase o en la figura que devuelve el espejo. Cada programa de enseñanza, cada técnica de danza, construye una topología del cuerpo y un conjunto de metáforas que se aplican sobre cada uno de estos tres cuerpos con el objetivo de formarlo, cultivarlo y transformarlo; algunas técnicas incluso constituyen una "personalidad expresiva".

Esta idea de personalidad expresiva resulta interesante ya que implica un planteo sobre el vínculo entre cuerpo y subjetividad ${ }^{12}$ y nos muestra que la parte no física de la danza, en cierto sentido, también se entrena en cierto sentido, y se construye con el objetivo de trasmitir una idea estética.

[c]ada técnica crea un cuerpo cuyo aspecto y forma de actuar son únicos. En general, el estilo y las habilidades que imparte solo se pueden trasladar parcialmente a otra técnica; los bailarines de ballet, por ejemplo, no pueden asumir el porte ni ejecutar el vocabulario de movimientos de la improvisación por contacto, y viceversa. El entrenamiento no sólo construye un cuerpo, sino que contribuye también a formar una personalidad expresiva que, en su relación con el cuerpo, ejecuta la danza. Puede surgir expresión estética cuando una personalidad utiliza el cuerpo como vehículo para comunicar sus pensamientos y sentimientos o cuando se fusiona con

\footnotetext{
${ }^{12}$ La autora no trabaja con la idea de subjetividad, sino con la de personalidad.
} 
él y articula su propia situación física. El cuerpo y la personalidad pueden también coexistir (en Cray y Kwiter 1992: 416).

Y, más adelante, habla de "(las) características claves de cada técnica a fin de proponer relaciones entre el cuerpo y la personalidad que podrían derivarse del hecho de instruir el cuerpo conforme una técnica determinada" (416).

En base a estos dos grandes ejes, referidos a los tres tipos de cuerpo y a la idea de personalidad expresiva, el texto de Foster recorre diversas técnicas de danza reconocidas y ejecutadas en occidente en el siglo XX -la técnica del ballet, la técnica Duncan, la técnica Graham, la técnica Cunningham y la técnica de improvisación por contacto-, explicitando en cada caso el tropos que construyen para significar el cuerpo y el conjunto de metáforas que lo acompaña, junto con la caracterización de la personalidad expresiva necesaria en cada caso.

Cierra el texto con una reflexión sobre la situación de la danza en los últimos 20 años del siglo $X X$, respecto de lo cual sostiene que la experimentación coreográfica, el eclecticismo y los nuevos géneros promovieron el entrenamiento del cuerpo de alquiler, el cual "no despliega sus habilidades como un mosaico de estilos separados, sino que aúna todos los estilos y vocabularios en una superficie uniforme e impenetrable. Al ser independiente de todo enfoque estético concreto, es un cuerpo que se alquila: se forma con el fin de vivir de la danza" (425). Este cuerpo se mide y califica con criterios biológicos y físicos, más que estéticos: se lo puede estirar más por aquí, darle más fuerza allá, etc. Finalmente, la autora asume una postura ética y crítica respecto de lo que esto implica en términos de la relación entre cuerpo y personalidad expresiva: "El cuerpo de alquiler, construido sin tener apenas en cuenta la personalidad, convierte a ésta en un interesado comerciante de movimiento que ofrece lo más atractivo en cada momento. Niega no sólo la existencia de una personalidad profunda y verdadera, sino también la de una personalidad capaz de relacionarse" (427). Subyace aquí un supuesto según el cual tanto el entrenamiento del ballet como el de la danza moderna y modernista (aunque en las fuentes exista la confusión indicada por Langer, en el punto en el que la danza moderna supone un cuerpo natural que, siguiendo la tesis de Foster, no existiría) implican el reconocimiento de una personalidad 
y de una relación irrevocable entre el cuerpo y ella, posibles a su vez por la presencia de una idea estética que articula la relación.

De Corporealities (1996) nos interesa la perspectiva con la que Foster presenta el libro y en la cual apunta a incluir los diversos trabajos que lo componen. Allí propone entender el cuerpo como una categoría de la experiencia cultural, y para ello considera necesario hacer un abordaje del cuerpo como cosa tangible en su realidad corporal, pero no a partir de un acercamiento naturalista o esencialista sino a partir de su reconocimiento como cosa construida, como materia e instrumento y como medio de expresión que reenvía siempre a un orden de sentido y de significados que no están inscritos en él. En este sentido sostiene: "bodies always gesture towards other fields of meaning, but at the same time instantiate both physical mobility and articulability. Bodies do not only pass meaning along or pass it along in their uniquely responsive way" ${ }^{13}$ (Foster 1996: 10). La idea fuerte aquí es que la realidad física del cuerpo es construida en relación a un campo de significaciones y al mismo tiempo es capaz de construir un nuevo mundo de significados (meaning-making).

La idea de que el cuerpo es una categoría de la experiencia de nuestra cultura se complementa con la forma en que propone entender la coreografía, no como forma estética de la danza sino como un elemento que nos muestra el trabajo de la técnica sobre el cuerpo. En este sentido leemos:

[c]horeography is psychic. It is critical. Historicizing. It is deployed here as a thinking tool, a mental physic. Not just to think through dance, which many of the essays do, but to rethink how disciplines do their work. Ethnography, historiography, dialectical materialism, psychoanalysis, hermeneutics. Each of these critical procedures is subjected to choreographic revision. As writings on how bodies get inscribed though cultural practices, and where they don't, this choreographic operations can perform for that broader interest in the body that still awaits development in language $(10)^{14}$.

\footnotetext{
13 Los cuerpos siempre significan a través y hacia, un campo de sentidos, pero al mismo tiempo, remiten a las instancias de movilidad física y articular. Pero el significado del cuerpo significa unciamente su forma de estar, no tienen una única respuesta como manera de ser (traducción propia).

${ }^{14}$ La coreografía es psíquica. Es crítica. Historiza. Se despliega como una herramienta de pensamiento, que es a la vez física y mental. No sólo como una manera de pensar a través de la danza, algo que muchos de los ensayos hacen, sino para repensar la forma en que las disciplinas hacen su trabajo. La etnografía, la historiografía, el materialismo dialéctico, el psicoanálisis, la hermenéutica. Cada uno de estos procedimientos críticos se somete a revisión coreográfica. Como escritos que son prácticas culturales y en los cuáles los cuerpos se inscriben, y cuando no lo hacen, estas operaciones coreográficas pueden generar un interés en el cuerpo que todavía espera su desarrollo en lenguaje (traducción propia).
} 
La idea entonces es entender la danza como una práctica corporal que es posible en el registro de una experiencia cultural, y la idea de producir una reflexión sobre la danza desde el cuerpo se orienta a evitar un tratamiento de la coreografía como clave de sentido (código cifrado) de la danza misma, y entenderla en cambio como un campo o una superficie desde la cual acceder al cuerpo como realidad significada y de significado. En este sentido, la danza como práctica cultiva cuerpos que, si bien son efecto de una disciplina y de una regularidad, son también cuerpos potencialmente creadores/creativos. La danza y la coreografía pueden entenderse como una estrategia orientada a desarrollar significados desde el recurso a la técnica corporal. La autora propone en este sentido una relación estrecha entre cuerpo y lenguaje o, más precisamente, entre cuerpo y discurso (entendido como lenguaje -sintaxisorganizado en estructuras simbólicas complejas -gramática-). La tarea de traducción del movimiento del cuerpo al significado y del significado al cuerpo es, según Foster, permanente.

Estas ideas son sumamente innovadoras en el contexto del pensamiento sobre la danza y sobre todo en relación a la problematización del cuerpo como objeto de la danza. Acordamos con ellas en varios puntos pero consideramos que el esfuerzo de la autora por separarse de los esencialismos no llega a tocar lo referente al significado, lo que vemos por ejemplo en la carga valorativa con la que define su categoría de "cuerpos de alquiler" y en el hecho de no poner en cuestión que el cuerpo de la danza se entrena para construir significados. Si bien se puede estar parcialmente de acuerdo con esto, no podemos dejar de decir que entender la danza como arte esencializa la función de la danza y más aún del cuerpo en la danza. Por un lado, porque para que haya significado tiene que haber intérprete; por otro, porque el significado surge en relación a un significante que nos hace hacer, y no en relación al hacer mismo.

El libro Le corps, de Chantal Jaquet (2001), es un texto de referencia obligado para quienes se interesan por la cuestión del cuerpo desde el ámbito de las ciencias humanas. El texto propone un amplio recorrido sobre el tema, partiendo de la especificidad del cuerpo humano y llegando hasta la sexualidad del mismo. En ese recorrido, que abarca diversos elementos -cuerpo político, cuerpo viviente, cuerpo-espíritu, cuerpo del trabajo-, dedica una sección al cuerpo en el arte y desarrolla unas páginas dedicadas específicamente a la 
danza. Aborda la cuestión en términos de la potencia del cuerpo (lo que puede un cuerpo) y sugiere que la danza le confiere al cuerpo el poder de la ligereza y la gracia. Incluso, sostiene que ninguna de las bellas artes muestra mejor que la danza la simbiosis perfecta que puede producirse entre espíritu y cuerpo: "la danse est le moment oú la chair devient espirit, oú le corps se transforme en son autre et fait éclater sa puissanse prodigieuse" (Jaquet 2001: 241). ${ }^{15}$ En esta perspectiva introduce su lectura del uso de la zapatilla de punta en el ballet como medio que utiliza el cuerpo para expresar el movimiento de las criaturas etéreas y la idealidad de su cuerpo, como algo que se adosa al cuerpo pero para pasar a formar parte de él, para transformarlo en su capacidad metafórica. En este sentido insiste en que no hay, en el cuerpo de la danza, un interés por representar el alma o el espíritu, sino que por medio de la danza el cuerpo mismo se vuelve traslúcido y liviano: "L'art choréographique implique une modification des rapports ordinaires entre l'espirit et le corps. Dans un ballet, en effet, c'est le corps qui mène la danse et qui soumet l'esprit à ses propres lois" $(242) .{ }^{16}$

Jaquet reconoce la necesidad de ejercicio, de entrenamiento, de descomposición y análisis del movimiento para el aprendizaje de los pasos e incluso para el armado y ordenamiento coreográfico; sin embargo, una vez que eso subyace, se olvida. La ejecución de una danza exige al cuerpo una inteligencia más intuitiva que reflexiva, en el momento de la danza el cuerpo gobierna. Agrega que la danza es negación y afirmación de la materialidad carnal del cuerpo. Afirmación por el lado del trabajo técnico y por el lado de la mostración "en otro contexto" de la simpleza y a la vez complejidad de los gestos cotidianos del cuerpo como, por ejemplo, caminar. Pero también negación de esa misma materialidad a partir del trabajo de revelación de las potencias surreales y divinas presentes en él. Así, leemos

[l]e réel s'efface et fait place au pur movement. La danse possède le pouvoir de modifier les choses; elle est l'art de mettre le rèel en mouvement, de le libèrer de sa fixité factice. C'est en ce sens que la puissanse du corps l'emporte sur celle de l'esprit, car elle ne se borne pas

\footnotetext{
${ }^{15}$ La danza es el momento en que la carne deviene espíritu, cuando el cuerpo se trasforma en su otro y explota su potencia prodigiosa (traducción propia).

${ }^{16} \mathrm{El}$ arte coreográfico implica una modificación de las relaciones ordinarias entre el espíritu y el cuerpo. En un ballet, en efecto, es el cuerpo el que conduce la danza y que somente al espíritu a sus propias leyes (traducción propia).
} 
à interpréter les choses, mais s'emploie a les transformer. Elle est l'expression d'une liberté en acte (247). ${ }^{7}$

La cuestión del cuerpo de la danza remite, entonces, no a la particularidad de este o aquel cuerpo danzante, sino a la potencia que tiene para volverse su otro, mostrando lo invisible y haciéndolo perceptible a los sentidos. A Jaquet le interesa mostrar cómo esta potencia del cuerpo puede o no articularse con un significado, ya que lo otro del cuerpo no se liga con valores morales, éticos o estéticos de manera necesaria. En el caso del ballet, puede haber un nexo de sentido entre movimiento -un movimiento específico- y la búsqueda de significado, pero el caso de la post-modern dance americana nos muestra que el otro del cuerpo no necesariamente está determinado por su relación con el espíritu. Para desarrollar esta idea, Jaquet toma la danza de Merce Cunningham y recuerda que para él el movimiento no es trascripción de una emoción, sino que posee un poder y una belleza propios e independientes de toda significación preestablecida. El movimiento es expresivo en sí mismo y más allá de toda intención, el cuerpo es signo de la potencia kinética. La danza surge en relación al azar y como respuesta a un desafío puesto al cuerpo por la composición de la danza misma, y la técnica no es un recurso preestablecido que pueda aplicarse mecánicamente a una situación problemática, sino el resultado del trabajo del cuerpo con la danza. En este sentido sostiene: "On ne commande au corps qu'en lui obèissant. La danse par ailleurs est tributaire de la morphologie initiale du danseur. Certes, le corps de danseur est formé par sa façon de se mouvoir et se métamorphose sous l'effet du mouvement, mais dans certaines limites seulement" (255). ${ }^{18}$ La potencia del cuerpo de la danza moderna es, tal como la del ballet, su condición de metamorfosis permanente: la danza actualiza aptitudes insospechadas del cuerpo, modificando así su modo de existencia, volviéndolo una forma de su otro.

\footnotetext{
${ }^{17}$ Lo real se desvance y deja lugar al puro movimiento. La danza posee el poder de modificar las cosas: ella es el arte de poner en movimiento lo real de liberar su fijeza ficticia. Es en este sentido que la potencia del cuerpo supera al del espíritu, ya que la danza no se limita a interpretar las cosas, se ocupa de transformarlas. Ella es la expresión de la libertad en acto (traducción propia).

${ }_{18}$ Al obedecer a la danza, nosotros controlamos al cuerpo. De otro modo, la danza sería tributaria de la morfología inicial de la bailarina. Mientras el cuerpo de la bailarina es formado por la manera de moverse, y su metamorfosis es efecto del movimiento, aunque solamente dentro de ciertos límites (traducción propia).
} 
El cuerpo de la danza es para Jaquet entonces cuerpo en movimiento, y ese cuerpo en movimiento es interpretado como potencia de metamorfosis, de transformación de su espacialidad en una forma de tiempo, poder de significar sin recurrir a una referencia de sentido explícita. El cuerpo no representa una otra cosa, es su potencia misma -el movimiento del cuerpo- la que se vuelve significativa.

Vemos aquí varios de los elementos trabajados más arriba, en relación a la propuesta de Valéry (1936). Recurre el tema de la danza como una forma de tiempo y como metamorfosis, y aparece de manera bastante clara el hecho de que el cuerpo de la danza es un cuerpo que se construye para no mostrarse, se construye para olvidarse. Ese olvido o eclipse del cuerpo de la danza responde, a nuestro entender, a la condición de medio a la que se lo reduce, en la medida en que la construcción del cuerpo para la danza tiene por objeto la puesta en obra de una pieza de arte. Hay si se quiere una negación del cuerpo de la danza.

Susana Tambutti, coreógrafa y teórica argentina de la danza, tiene un texto corto publicado en Teatro al Sur (2004, número 26) que se llama "El cuerpo, medida de todas las cosas". Allí hace un recorrido sintético pero completo de las formas en que el par cuerpo/representación se relacionó en la historia de la danza occidental. A lo largo del texto, la autora toca diversos niveles analíticos: trabaja a la vez con la idea del cuerpo construido técnicamente y visible a los ojos del espectador o del maestro -la morfología- refiriendo en este sentido al cuerpo-instrumento, con la idea del cuerpo como tema de trabajo, como cosa que tiene que ser enunciada por la danza, como tema poético, y por último refiere al cuerpo como sustancia de construcción de metáforas, como poder virtual. La hipótesis con la que trabaja Tambutti es que a lo largo de la historia de la danza el cuerpo ocupó alternativamente esos diferentes lugares; el análisis atento del problema nos muestra que, más que la aparición secuencial de esos diversos lugares, lo que hubo fue cierto predominio parcial de uno sobre otro según el género, pero siempre en el marco de una convivencia de niveles. En este sentido debería ser revisitada la referencia según la cual

[e]stas nuevas propuestas que, de alguna manera, continúan la tradición clásico racionalista, conviven con el despliegue de otras propuestas que restituyen lo psíquico y lo fisiológico dentro de la estructura total del sujeto y, más aún, la de dicho sujeto y su mundo. El cuerpo cobra así una nueva 
dimensión en la que tener un cuerpo es incluirse en un medio determinado y estar comprometido con él; son cuerpos vivientes y reales (Tambutti 2004: 9).

Por último, en este apartado querríamos presentar algunas ideas de Pierre Bourdieu sobre el cuerpo y la danza. Pero antes convendría hacer quizás dos aclaraciones: por un lado, si bien encontramos en la obra de Bourdieu varias menciones en relación al cuerpo, ${ }^{19}$ no ocurre lo mismo respecto de la danza; por otro, aunque también es cierto que es uno de los sociólogos que más sistemáticamente ha pensado el arte, el campo del arte y sus prácticas, ${ }^{20}$ Bourdieu no inscribe la mención a la danza en el contexto de sus reflexiones sobre el arte, sino que la ubica cerca del deporte, y lo hace justamente por la presencia del cuerpo. De hecho, el texto se llama "Programa para una sociología del deporte", es de 1980 y es el resultado de una intervención en un grupo de estudios sobre "Vida física y juegos".

Aquí, si bien Bourdieu propone una metodología para el estudio de las prácticas deportivas, hacia el final se arriesga a afirmar que lo dicho en relación al deporte también es posible de afirmarse respecto de la danza. Introduce varios elementos a considerar antes de problematizar la cuestión del cuerpo, el espacio de las prácticas y a la necesidad de un análisis estructural del campo, con el objetivo de ponerlo en relación con otros espacios de prácticas y de poner en relación los diferentes deportes entre sí, de reconocer la transformación histórica de un espacio de prácticas y fundamentalmente para ver, detrás de la unidad nominal de las prácticas, la dispersión en las maneras de practicarlas y la dispersión en relación a las categorías sociales de practicantes (Bourdieu 1980: 175). Otro elemento que introduce es el del sentido social de una práctica, que diferencia del sentido interno o del sentido técnico de la misma; esto es sumamente interesante porque el sentido interno y el sentido social, sin ser equivalentes, remiten los dos a cierta regla de organización de la práctica y difieren en relación a la interpretación que se hace de esa regla, y si bien Bourdieu aclara que la elasticidad semántica nunca es infinita, no siempre hay una correspondencia mecánica entre sentido interno y sentido social. Respecto de esto afirma que

\footnotetext{
${ }^{19}$ En La dominación masculina, El sentido Práctico, Meditaciones Pascalianas y El baile de los solteros, entre otros.

${ }^{20}$ Por ejemplo, en La distinción.
} 
[e]l sentido dominante, es decir el sentido social que le es atribuido por sus usuarios sociales dominantes (numérica o socialmente) puede cambiar: en efecto, es frecuente que en el mismo momento [...] reciba dos sentidos diferentes, y que el programa objetivado de práctica deportiva que designa un término como carrera a pie o natación [...] sea una apuesta de luchas [...] entre personas que se oponen a propósito del uso verdadero, del buen uso, de la buena manera de practicar la práctica propuesta (179).

La danza, en tanto campo de prácticas relativamente autónomo, se presenta como un espacio donde las relaciones entre teoría y práctica, que son también aquellas entre lenguaje y cuerpo, resaltan de manera específica determinando muchas veces su estructura, la lógica de su práctica -y el modo de practicarlay sus sentidos socialmente dominantes y aceptados. La importancia de esto reside para Bourdieu en el lugar que ocupa el cuerpo en la enseñanza, entendido si se quiere como el locus no reflexivo o no consciente del aprendizaje:

[h]ay una manera de comprender completamente particular, a menudo olvidada en las teorías de la inteligencia, la que consiste en comprender con el cuerpo. Existen cantidades de cosas que comprendemos solamente con nuestro cuerpo, más acá de la conciencia, sin tener las palabras para decirlo.

[...] una de las cuestiones planteadas es saber si es necesario pasar por las palabras para hacer comprender ciertas cosas al cuerpo, si cuando se habla al cuerpo con palabras, con las palabras justas teóricamente, científicamente, que hacen comprender mejor al cuerpo, o si, a veces, palabras que no tienen nada que ver con la descripción adecuada de lo que se quiere trasmitir no son mejor comprendidas por el cuerpo (182-183).

En las prácticas corporales -y en su enseñanza- se plantea más la lógica y la cuestión de la creencia que la de la comprensión; Bourdieu plantea que esto es así justamente por el lugar del cuerpo en la formación de la creencia, porque es a través suyo que la obediencia desaparece como tal y surge como creencia, término que Bourdieu define no casualmente como "lo que el cuerpo acuerda en el momento en que la mente dice no" (183). El autor cierra el texto poniendo en relación las disciplinas corporales con las instituciones totalitarias y con los regímenes totalitarios y llamando la atención sobre la importancia pedagógica que adquieren las disciplinas corporales en ese contexto y sobre el efecto de domesticación y de refuerzo simbólico, de construcción y mantenimiento de un cuerpo de ideas o de un espíritu de cuerpo.

Si bien es cierto que el cuerpo se organiza en relación a una creencia que borra el elemento obediente, la creencia surge en un sistema de ideas que es 
incorporado no sólo por la sumisión corporal, sino también por la reflexión que acompaña a esa creencia. De hecho, en danza, son muchas más las veces en que se cree más de lo que se obedece, porque el cuerpo resiste y se equivoca de manera regular. En palabras de Mary Wigman:

[p]ara señalar el valor dinámico de estos movimientos él les ponía nombres tales como orgullo, alegría, cólera, etc. Yo no necesitaba mucho más para lanzarme inmediatamente en un estado de rabia colosal, con sólo escuchar la palabra "cólera", entonces, el balanceo virtualmente estallaba en el espacio. Los movimientos al ser repetidos infinitamente se volvieron más 0 menos mecánicos. Pero yo me sentía feliz por el solo hecho de hacerlos, al menos una vez, de manera diferente, más personal. Entonces, la cólera de Laban se manifestaba aún más vehemente que la mía. Saltaba como picado por una tarántula, golpeaba con sus puños sobre la mesa de tal manera, que los papeles volaban por la habitación. Gritaba: ¡Tú, payaso, tú monstruo grotesco, con tu terrorífica intensidad has arruinado toda mi teoría de la armonía!

[s]e ponía furioso ante lo que él llamaba mi expresión super-yo, gritando que el movimiento mismo era la cólera y no necesitaba la interpretación individual (en Copeland y Cohen 1983: 71).

La preocupación por el cuerpo aparece en relación a la danza de manera más o menos similar; se reconoce su necesidad y se reconoce el trabajo que es necesario hacer sobre él, pero se niega su aparición como cuerpo al reducirlo a medio expresivo y condición necesaria para la ejecución y construcción de una obra de arte, obturando la posibilidad de que él mismo surja. De hecho se sostiene que, si se ve el cuerpo entrenado, si se ve la construcción que la danza hace del cuerpo, no puede verse la danza. Creemos que hay otros modos de problematizar el cuerpo de la danza, que sin abandonar y sin dejar de ver a la danza como forma coreográfica, sí nos permiten acceder al cuerpo como objeto construido (no metafórica sino prácticamente).

\subsection{EL CONOCIMIENTO DE LA DANZA COMO ARTE COREOGRÁFICO}

Aquí nos interesa mostrar algunos textos de referencia en el área de la danza que, con el fin de armar un área de pensamiento específico, tienen por objeto la reflexión sobre la disciplina. Son textos que en general buscan construir una perspectiva y un cuerpo de categorías, y si bien recurren a otras formas de pensamiento -en términos de modelos o en términos conceptuales-, todos comparten el interés por construir un conocimiento específico del arte coreográfico. Se orientan a ver la especificidad de la danza como objeto de 
conocimiento y comparten, al menos algunos de los textos a presentar aquí, la preocupación por la formación de formadores. Hay un supuesto según el cual debe haber un cuerpo de teoría propio de la danza para poder formar docentes e investigadores en danza ya que, se supone, no alcanza con los saberes técnicos de la disciplina.

En primer lugar vamos a presentar los aportes del libro publicado en 1988 de manera conjunta por Adshead, Briginshaw, Hodgens y Huxley, que lleva por título Teoría y práctica del análisis coreográfico. En línea con lo expuesto en el parágrafo anterior, una de las principales preocupaciones del texto es la de generar un conjunto de conceptos propios de una teoría de la danza que tenga por objeto a la coreografía como práctica artística. El interés por precisar un cuerpo de conceptos orientados al análisis y a la producción de conocimiento se explica en relación a la necesidad de separarse de la crítica de arte, forma de teoría o de producción de saber anclada la mayoría de las veces en una obra, en un autor o en un género. La crítica es una forma de saber sobre lo particular, específico o característico de un caso, en tanto la teoría y el análisis -tal como lo presentan en este texto- se orientan a construir y ofrecer un conjunto de conceptos y maneras de relacionarlos que sirvan al análisis de cualquier danza que presente una forma coreográfica. Los autores buscan también tomar distancia de los sistemas de notación de la danza, que no hacen más que registrar movimientos, dejando de lado la interpretación que de ellos hace el bailarín en cada ejecución (lo que deja de lado el significado y por tanto la posibilidad de análisis). El libro es el resultado de un conjunto de investigaciones radicadas en la Universidad de Leeds, en la carrera de Danza: esto explica en parte la preocupación por generar una teoría de la danza que sirva como herramienta tanto al docente como al bailarín, al investigador, al coreógrafo y también al crítico.

El libro tiene dos partes, una de presentación de problemas teóricos y explicitación de conceptos y la otra de aplicación del esquema teórico al análisis de obras específicas. A nivel de la justificación, la necesidad de autonomía para los estudios de la danza se sostiene al menos en tres elementos: por un lado por la difusión de la danza en las instituciones educativas en todos los niveles, cuestión que generaliza su práctica; por otro lado, y en relación con esta generalización, por la necesidad de preservar el 
aspecto de razonamiento artístico que la danza tiene (por necesidad de diferenciarla de la educación física); por último, para circunscribir el lugar que la danza ocupa en las prácticas culturales de la sociedad.

El supuesto de que la danza es una forma artística se coloca en primer lugar, ya que eso condiciona algunos elementos a considerar: el hecho de que una pieza de danza es resultado de un proceso creativo y deliberado, la necesidad de desarrollar aptitudes perceptivas para el acceso a la obra de arte, ya que consideran que a mayor conocimiento analítico mayor comprensión del objeto por analizar -en el caso del arte, la primera forma de acceso, y por tanto la primera forma de conocimiento, es perceptiva-, y el hecho de que sea un objeto creado para ser visto por otros, lo que implica que una misma danza puede tener múltiples contenidos (el asignado por el coreógrafo, el adoptado y expuesto por el intérprete y el percibido por el público). Teniendo esto en consideración presentan la pregunta ¿qué significa análisis coreográfico? A lo que responden que el análisis es un proceso que sirve a la comprensión de un fenómeno, y en general sirve para aportar razones respecto de la asignación de un significado: por lo tanto, el hecho de referirse a una actividad como "danza" ya implica iniciar un análisis.

En este sentido introducen la importancia del contexto, ya que muchas veces los significados que aparecen en los procesos interpretativos exceden lo que nos informa el movimiento del cuerpo. Sin embargo, el contexto no se entiende en términos de historia general o de contexto socio-histórico, sino como espacio-tiempo en el que la obra tiene lugar, cobrando relevancia elementos como el programa de mano, el espacio escénico en que se ejecuta, etc. Así, el libro va desplegando una serie de pasos a seguir y presentando niveles de acceso posibles para lograr el análisis de una coreografía. Sostienen que una primer operación es la observación, que en sí misma supone la capacidad de percepción, de nominación y de descripción de los componentes de una obra de danza, a los que clasifican en dos grandes grupos: a) los elementos mismos de la obra: el movimiento, los bailarines, el entorno visual, el sonido; y b) la percepción que se tenga de ellos.

Respecto del movimiento en tanto elemento central, hacen algunas observaciones que operan como niveles posibles de descripción, principalmente el hecho de considerarlo una acción humana -lo que remite a la 
posibilidad de asignarle significado-, que generalmente supone desplazamientos del centro de gravedad y por tanto asume dimensiones espaciales, y, por último, que tiene una cierta dinámica. Reconocen la utilidad parcial de los análisis fisiológicos del movimiento, ya que revelan solamente dimensiones vinculadas a las exigencias que cada tipo de movimiento necesita del cuerpo, pero descartan esa perspectiva en lo que refiere a posibles análisis del significado de una obra de danza. En relación a esto, los autores rescatan perspectivas antropológicas de análisis del movimiento ya que reconocen la funcionalidad del mismo en el contexto social; por más que eso pueda parecer alejado de una escena artística, los autores suponen que los movimientos que son significativos en una cultura son retomados, re-ubicados y re-significados en el arte. Sin embargo, insisten en la necesidad de un análisis autónomo de la danza (ni fisiológico ni antropológico).

Una vez reconocidos los componentes, es preciso identificar la forma coreográfica, cuestión que remite a la estructura coreográfica y a la relación de los componentes entre sí, en un momento determinado o a lo largo de toda la obra (estas diferentes dimensiones de análisis responden a intereses de investigación). También es posible distinguir entre forma visual y forma performática, la primera ligada al espacio y al segunda al tiempo. En este sentido leemos:

[u]na vez que ha sido aclarado el carácter de las relaciones [entre los elementos] puede valorarse la importancia relativa de las diferentes partes de la coreografía. Esto es fundamental para la interpretación de los bailarines y la comprensión de los espectadores, ya que las distintas secciones de la pieza pueden contribuir de forma diferente al significado o significados inherentes a la coreografía. La percepción de la estructura de la obra es obviamente fundamental para su apreciación [...] la capacidad de distinguir las secciones de una coreografía y retenerlas en la memoria mientras la actuación transcurre en el tiempo es una habilidad que puede desarrollarse a través de la práctica y para ello es de utilidad saber en qué aspectos hay que fijarse (Adshead en Adshead y Briginshaw, 1988: 73).

La idea aquí es que el reconocimiento de las partes relativas cobra sentido en el contexto de la forma total y de las relaciones que esas partes tienen en la totalidad de la coreografía.

Una vez que se reconocen los componentes y la estructura coreográfica viene el proceso de interpretación y comprensión del significado de la obra, momento en el cual se incorpora claramente la dimensión del significado a partir del 
reconocimiento del elemento perceptivo puesto en juego. En este punto reintroducen la idea de que una obra tiene múltiples contenidos, ya que la interpretación es un proceso que llevan a cabo el coreógrafo, el bailarín y el público. La interpretación como proceso de asignación de significado remite a su vez a la experiencia que tiene quien interpreta y a la comprensión del significado construido y asignado que esa experiencia potencia; en este sentido hay una vuelta a la idea de contexto escénico (genero, estilo, técnica) y al vínculo que la práctica artística tiene con el trasfondo social y cultural, en función del cual la coreografía puede entenderse en términos de una reelaboración, organizada en clave artística, de pautas de movimiento cotidiano (ya que si bien reconocen en el gesto el elemento universal de la danza, también reconocen que el mismo es significativo en la medida en que tiene una orientación cultural precisa). Suman otros elementos a considerar: género, estilo, tema, carácter y cualidad, y sostienen que estos tienen un vínculo estrecho con las normas o criterios estéticos que orientan la práctica artística y que señalan una serie de sentidos y significados que informan al proceso de interpretación de una obra específica, en la medida en que aportan criterios a tener en cuenta respecto del desarrollo del contenido, de la verosimilitud, lo razonable o pertinente de la presencia de tales elementos según el contexto.

Por último, cierran la primer parte del libro explicitando las diferencias entre evaluación, comprensión e interpretación. Definen la interpretación como un proceso de identificación de sentidos y de producción de significados que es necesario tanto para la evaluación como para la comprensión de una obra. En la comprensión, sin embargo, se ponen en juego sólo los criterios vinculados a principios estéticos en los que se inscribe una danza y se tienen en cuenta conceptos específicos del análisis artístico. En la evaluación se ponderan también valores compartidos: hay aquí un componente ético que no está presente en la comprensión. Los valores puestos en juego en la evaluación son de dos niveles: internos a la obra y a la comunidad de género a la que la obra pertenece, y externos a la obra, inscriptos en el sistema de valores existente a nivel social y cultural. La evaluación pone en juego algunos procedimientos que son la asunción y explicitación de valores, la emisión de juicios y la fundamentación de los mismos en relación a los componentes de la coreografía. 
Si bien sostienen que, en general, los análisis que se hacen sobre danza articulan o superponen ambas formas de interpretación, marcan la diferencia justamente con el interés de introducir precisiones y líneas claras de demarcación en lo que refiere a la producción de un cuerpo de teorías y un conjunto de conceptos destinados a la danza coreográfica. En una disciplina que nace, es sugestivo indicar la diversidad de niveles y perspectivas de abordaje y acceso.

A continuación sintetizaré los aportes que arroja el texto de Graham McFee, publicado en 1992 y que tiene por objeto el "entendimiento" de la danza. El autor sostiene que, lejos de querer aumentar meramente el conocimiento (aportando un cúmulo de datos específicos), busca generar nuevas formas de entender la danza, incrementar la comprensión de la danza en general, aportando criterios y conceptos para su abordaje. McFee se maneja con dos supuestos: que la danza es una forma artística y que, a mayor comprensión del fenómeno, mayor capacidad de apreciación y percepción del arte de la danza. Nos propone en ese sentido indagar sobre la naturaleza de la comprensión en danza a partir de ubicarla en el registro de las categorías artísticas y de la estética filosófica. Luego articula esta cuestión del conocimiento en danza con la dimensión educativa, aportando elementos que sirvan a los formadores para la transmisión de la danza como área de prácticas y de conocimientos humanos. En medio de este recorrido trabaja cuestiones vinculadas con la perspectiva institucionalista del arte, en cuyo marco se inscribe su perspectiva sobre la danza.

El núcleo a destacar es que la comprensión y el entendimiento de la danza como forma artística se desarrolla en el marco de la construcción de juicios artísticos, ${ }^{21}$ lógicamente racionales, que implican un componente subjetivo en la medida en que está en juego la dimensión personal de la percepción (McFee 1992), y un componente objetivo, ya que la respuesta dada como apropiada a un tipo de pregunta sobre el objeto artístico debe ser común a un conjunto de personas, debe ser compartida.

Uno podría decir que McFee ordena sus argumentos en torno a una pregunta central: ¿qué es la danza, en tanto conjunto de movimientos distinto a la

${ }^{21}$ Orientados por una obra de arte, y no simplemente por la belleza, gracia o elegancia de cualquier objeto, ya que esto sería un juicio estético. 
gimnasia o a la marcha? Instala en este punto una pregunta sobre la naturaleza del objeto y sobre las formas de descripción del mismo, ya que varias de las consideraciones que hace al dar respuesta a esta pregunta se orientan a pensar la "traducción" de una experiencia al lenguaje. En este sentido sostiene que no hay experiencia que sea preconceptual y que toda experiencia, y las formas de lenguaje que la comunican o explican, se entienden y dependen del contexto. Incluso, una misma situación y contexto pueden dar lugar a experiencias diversas. Esto le ayuda a sostener que, antes que las definiciones, para la comprensión de un fenómeno son útiles los ejemplos, ya que ellos nos vinculan de manera más inmediata con el contexto de significados en el que se inscribe, mientras que la definición supone la comprensión de todos los términos involucrados en ella para acceder al sentido.

Además del conjunto de conceptos con los que contamos para transitar/vivir una situación, McFee reconoce también la presencia de intereses a partir de los cuales nos acercamos a un objeto, intereses que construyen diferentes modos de ver, diferentes percepciones de la experiencia. En este sentido, y teniendo en cuenta que considera la danza como una forma artística, sostiene que el interés que predomina en la situación de percepción de una obra de danza es un interés artístico, orientado por la gracia y la belleza del objeto, pero también y fundamentalmente por la incorporación de los significados formales y de estilo construidos en la obra misma. Esto se explica considerando que el arte es una actividad intencional y deliberada, por lo que hay en los objetos artísticos elementos puestos en juego con un sentido; no es igual establecer juicios acerca de un cuadro -que tiene una composición, una técnica, un contexto socio-histórico de surgimiento y mostración- que juicios acerca de un paisaje natural, por ejemplo.

Una vez hechas estas consideraciones en relación a cómo se da la experiencia artísitica y a cómo apreciamos una obra de arte, detalla algunos elementos a considerar para la descripción de la naturaleza de la danza y el reconocimiento reconocer cuándo una secuencia de movimientos es danza y no otra cosa. En este punto reordena los elementos mencionados y sintetiza que aquello que experimentamos depende de los conceptos con que abordamos la experiencia y que por lo tanto las obras artísticas requieren de conceptos destinados a 
pensar el arte (como los de forma, estilo, significado). Cuando hacemos un movimiento con un interés artístico -no meramente estético- hacemos danza. Los movimientos de danza son acciones humanas y las acciones humanas tienen un significado. El significado de las acciones depende del contexto en el que las mismas se ejecutan, por lo que el conocimiento de este contexto, y de las reglas que lo organizan, es fundamental para la comprensión del significado de las acciones. Para entender el movimiento del cuerpo como una acción cuyo significado es la construcción de una obra de danza, debemos haber aprendido las reglas que gobiernan el contexto en el cual la danza se inscribe. La comprensión de las reglas que definen una situación permite que el objeto de la experiencia sea inteligible, nos brindan una clave de percepción y entendimiento. Entender la danza en términos de acción humana, de acción deliberada de un sujeto, nos corre de la perspectiva fisiologista de abordaje y nos sitúa, en términos del conocimiento de la cosa, más cerca de la búsqueda de comprensión de significado que de la explicación causal-mecánica. Introducir la danza en esta perspectiva le permite a McFee incorporar dos elementos importantes: por un lado, la dimensión intencional y de propósitos con la que se hacen las obras de arte, junto con los motivos y razones con la que se llevan a cabo las acciones humanas, lo que supone incorporar el elemento creativo de responsabilidad en el análisis de una obra; por otro lado, la cuestión de la precisión conceptual, ya que, si lo que nos permite entender una secuencia de movimientos como danza es el contexto en el que se inscribe, y si el contexto se interpreta por el conocimiento de las reglas que lo organizan, sólo será posible explicar el sentido de una secuencia de movimientos como danza si circunscribimos las categorías con las que se darán las explicaciones y reconstruimos los significados de las percepciones que la interpretación de los movimientos, en términos de acción humana, pone en escena.

La perspectiva de Mc Fee se sitúa, en cierto sentido, en el mismo plano que esta tesis: propone presentar una manera de pensar, una lógica de construcción de saber y de comprensión de un fenómeno. Sin embargo, nos parece limitada especialmente en relación a la importancia relativa que adquiere el contexto en relación al significado. La pregunta por el significado, más que recurriendo al contexto -que sí existe, no es nuestra intención 
negarlo- debería resolverse, desde nuestro punto de vista, en términos lógicos: la relación debería establecerse, más que entre significado y contexto, entre pares significantes. Esto supone algunas diferencias sustantivas respecto de la comprensión del fenómeno del lenguaje que desarrollaré más adelante.

André Lepecki, un antropólogo brasileño que se dedica a pensar los vínculos entre la danza, el performance art y las teorías filosóficas postestructuralistas, publicó en 2006 Exhausting dance. Performance and the politics of movement. El libro se volvió rápidamente un texto de referencia, al menos en Argentina. La tesis del libro se aplica a las producciones de danza de los últimos 25 años, ${ }^{22}$ y propone una desidentificación de la danza respecto del movimiento. La intensión de la nueva danza es "agotar, terminar", y la quietud en el contexto de una obra de danza pone en cuestión el sentido mismo de la danza, es decir, su ontología, en la medida en que la danza ha sido definida como movimiento del cuerpo. Teniendo esto en mente propone algunas articulaciones conceptuales. En primer lugar sostiene la tesis según la cual la ontología de la danza occidental desde el renacimiento supone como eje el movimiento contínuo del cuerpo, cuestión que con el advenimiento de la modernidad se radicalizó en el siguiente sentido: la modernidad es movimiento progresivo de la humanidad y de los sujetos que la constituyen. Así, la subjetividad moderna privilegia un tipo de experiencia de carácter solipsista en la cual el ego es constitutivo del sujeto de la representación, dejando al cuerpo por fuera de la experiencia subjetiva. Lepecki (2006) afirma que el crítico de danza John Martin sentenció, en la década del '30, la identificación entre danza y movimiento del cuerpo. En este sentido retoma a Martin y a continuación afirma:

[t]his beginning was the discovery of the actual substance of the dance, which it found to be movement" (Martin 1972: 6) For Martin, the choreographic explorations of Romantic and Classic ballet and even the antiballetic freeing of the body's expressivity spearheaded by Isadora Duncan, had all missed dance's true being. None had understood that dance was to be founded on movement alone (Lepecki 2006: 4). ${ }^{23}$

\footnotetext{
22 Teniendo en cuenta la fecha de publicación del libro.

23 "este comienzo fue el descubrimiento de la sustancia real de la danza, que resultó ser el movimiento." Según Martin, las exploraciones coreográficas del ballet romántico y clásico, e incluso la liberación antiballet de la expresividad del cuerpo encabezada por Isadora Duncan, habían todas ellas pasado por alto el verdadero ser de la danza. Ninguna de ellas había comprendido que la danza debía basarse expclusivamente en el movimiento. Lepecki, A (2009) Agotar la danza. Performance y política del movimiento. Universidad de Alcalá, España. P. 18.
} 
Esta identificación, además de ofrecer una identidad, construye al movimiento como fundamento de la danza. Por lo que hemos visto hasta aquí, esta idea no se cuestiona: desde Badiou hasta Foster, y más allá de los diferentes niveles de análisis y perspectivas para el enfoque, todos comparten el supuesto según el cual la danza es movimiento del cuerpo. Luego, habrá quien sostenga que el movimiento debe entenderse en términos de fuerzas imaginarias, o como creación de una ilusión, o incluso como movimiento mecánico del cuerpo físico que hay que esconder. Sin embargo el supuesto de que la danza es movimiento, no se cuestiona. En relación a esto, Lepecki (2006) sostiene que los diversos bailarines y art performers que introducen la quietud o el movimiento agotado en el marco de un espectáculo de danza ponen en cuestión la ontología misma de la danza, la certeza de su identidad, y abren nuevos horizontes para ciertas discusiones respecto de qué es la danza. Ya que no importa si se recurre al movimiento entrenado, encontrado 0 improvisado, lo que importa es que de hecho se recurre al movimiento para hacer danza.

Para Lepecki la identidad de la danza se clausura con la sentencia de Martin, pero puede rastrearse su constitución al menos hacia el siglo XVI, cuando aparecen los primeros manuales de danza encargados de escribir y describir las danzas de corte. Esto implicó la creación y adaptación de un concepto -el de coreografía, escritura de la danza- a las necesidades de precisión, y también reforzó cierta función de saber que quien escribe la danza, ya sea el maestro o el coreógrafo, tiene por sobre quien la ejecuta. En este sentido leemos: "Much of my arguments in this book turns around the formation of choreography as a peculiar invention of early modernity, as a technology that creates a body disciplined to move according to the commands of writing" (Lepecki 2006: 6). ${ }^{24}$

Luego retoma algunas tesis de Sloterdijk, de Ferguson y de Brennan, quienes estarían de acuerdo en interpretar la modernidad en términos kinéticos, instalando al movimiento como un modo de ser en el mundo, y vincula esta

\footnotetext{
${ }^{24}$ Buena parte de mi argumentación en este libro gira en torno a la formación de la coreografía cómo una invención peculiar de la primera modernidad, como una tecnología que crea un cuerpo disciplinado para que se mueva a las órdenes de la escritura (Lepecki 2009: 22)
} 
cuestión con la producción de subjetividad típica de la modernidad entendida a partir del disciplinamiento del cuerpo. En este sentido,

[i]f choreography emerges in early modernity to remachine the body so it can "represent itself" as a total "being-toward-movement", perhaps the recent exhaustion of the notion of dance as a pure display of interrupted movements participates of a general critique of this mode of disciplining subjectivity, of constitute being.

[...] some recent dance may be actually proposing political and theoretical challenges to the old alliance between the simultaneous invention of choreography and modernity as a "being-toward-movement" and the political ontology of movement in modernity $(7-8) .{ }^{25}$

Una vez que esclarece la articulación entre danza-modernidad-movimiento y subjetividad, dedica unas líneas a explicitar que retoma la categoría de subjetividad para oponerse a la idea de sujeto idéntico, interior y soberano de sí mismo. Retoma algunos elementos de Foucault y Deleuze para pensar la subjetividad en términos de agenciamiento, intensidad, tecnología y operaciones de subjetivación. Repensar la ontología de la danza desde esta perspectiva y en base al análisis empírico de obras de danza actuales implica para Lepecki una tarea política en un doble sentido, por un lado desarticular la unión entre danza y movimiento, lo que reenvía a la tarea de construir de nuevo un sentido para esta práctica, y por otro poner en el centro del análisis la relación entre movimiento y modernidad, lo que permite hacer una crítica política a las formas de experiencia hegemónicas de las sociedades modernas. Del mismo modo podemos pensar la dimensión política constitutiva de la producción de subjetividad y de las formas de representación (política o artística), para lo cual Lepecki (2006) propone la categoría de movilización.

Si bien el libro de Lepecki es novedoso en la totalidad de su propuesta, hay dos límites que nos gustaría marcar y que serán retomados en los capítulos siguientes. Por un lado, el análisis que propone a partir de pensar una nueva ontología, articula la danza al cuerpo y al sujeto en lugar de relacionarla con el movimiento; pero lo que ocurre entonces es una identificación entre cuerpo y

\footnotetext{
${ }^{25}$ Si la coreografía emerge en la modernidad temprana para remecanizar el cuerpo de manera que pueda "representarse a sí mismo" como un total "ser que genera movimiento", tal vez el reciente agotamiento del concepto de la danza como una pura exhibición de movimiento ininterrumpido forma parte de una crítica general de esta forma de disciplinamiento de la subjetividad, de constitución del ser (Lepecki 2009: 24) Alguna danza reciente puede de hecho estar proponiendo desafíos políticos y teóricos a la antigua alianza entre la invención simultánea dela coreografía y modernidad como un "ser hacia el movimiento" (Lepecki 2009: 24)
} 
sujeto que nos parece inconveniente, porque deja rastros de animalidad en el hombre y porque unificar el cuerpo al sujeto implica dotar al primero de un poder de actividad que no tiene en sí mismo y que tampoco tiene el segundo siquiera por sí mismo, sino en la medida en que "hay Otro"; esto divide al sujeto entre un saber y una verdad implicando la falta que lo hace actuar. Por otro lado, la apuesta del autor que, al proponer una nueva ontología de la danza, parece abandonar la preocupación por la forma coreográfica en tanto escritura y palabra que organiza el movimiento para pensar el movimiento en términos de movilización. Nos parece inconveniente ya que creemos que el hacer humano, en tanto poiesis, es necesariamente una cuestión de forma. La movilización como apuesta refuerza, desde nuestra perspectiva, algo de lo efímero de lo cual el mismo autor quiere escapar.

\subsection{CONCLUSIÓN}

De este capítulo nos interesa rescatar los elementos que hacen al diagnóstico a partir del cual propondremos una nueva forma de entender la danza. Principalmente, el hecho de que el cuerpo no ocupa un lugar preponderante en la reflexiones que se orientan a producir conocimiento sobre danza; incluso, cuando aparece se destacan sólo dos cuestiones: por un lado, su condición de medio específico y, vinculado con esto, la necesidad de entrenamiento del mismo; por el otro, la necesidad de eclipsar el trabajo que la producción del medio expresivo requiere. Es como si al verse la gimnasia del cuerpo entrenado para bailar no pudiera verse el baile, como si la expresión como característica de la danza quedara tachada por el virtuosismo que requiere el bailarín para ejecutar el movimiento. Vemos aquí una manera en que se retoma la tensión entre técnica y expresión que signa a la danza desde que se institucionaliza como arte. Creemos, entonces, y trataremos de evidenciarlo lógicamente en los capítulos siguientes, que la comprensión de la danza como arte y la reducción del cuerpo a medio y condición impiden la problematización y conceptualización del cuerpo de la danza. Incluso los esfuerzos más acabados, como el de Foster (1992) y el de Lepecki (2006) fallan en el punto en el que esencializan el poder de significación del cuerpo (lo que lejos de problematizarlo lo sacraliza), o cuando se ven obligados a deshacerse de la 
danza como forma coreográfica. Apuntamos que si queremos construir un pensamiento sobre el cuerpo de la danza es necesario abandonar la perspectiva que inscribe a esta en el registro del arte para pensarla como práctica corporal. 


\section{LA PREGUNTA POR EL CUERPO EN LA DANZA.}

\subsection{PRESENTACIÓN}

En este capítulo realizaremos una revisión crítica de lo expuesto con el interés de mostrar por qué no ha sido problematizado el cuerpo en tanto objeto de la danza. Ya dijimos que éste representa un punto ausente en la bibliografía específica sobre el tema. Nos interesa poner en evidencia cómo los ejes sobresalientes para el tratamiento de la danza dejan sistemáticamente de lado la pregunta por el cuerpo. Desde nuestra óptica, esto significa que no lo problematizan y, como consecuencia, no lo constituyen en objeto de investigación. En este contexto, entendemos la problematización como un trabajo que produce pensamiento, en la medida en que

[e]labora al respecto las condiciones en las que se pueden dar respuestas posibles [...] esta elaboración de un tema en cuestión, esta transformación de un conjunto de obstáculos y de dificultades en problemas a los que las diversas soluciones buscarán aportar una respuesta, es lo que constituye el punto de problematización (Foucault 1999: 360).

Es por esto que el cuerpo no aparece como un tema sobre el cual haya que hablar o construir saber.

La reducción del cuerpo a supuesto o instrumento nos muestra un tipo de relación entre él y la danza que, podríamos arriesgar, se vincula más con la lógica del consumo que con la del uso del cuerpo. Siguiendo a Giorgio Agamben (2005) entendemos el consumo en términos de "consumo utilitario", articulado a la sacralización de los objetos -en este caso el cuerpo- y a la imposibilidad de uso; de hecho, si

[1]lamamos espectáculo a la fase extrema del capitalismo que estamos viviendo, en la cual cada cosa es exhibida en su separación de sí misma, entonces espectáculo y consumo son las dos caras de una única imposibilidad de usar. Lo que no puede ser usado es, como tal, consignado al consumo o a la exhibición espectacular (Agamben 2005: 107).

Hemos visto, a lo largo de los capítulos anteriores, el esfuerzo coreográfico y teórico por separar al cuerpo de sí mismo, por velar el cuerpo que construye la danza sólo por el hecho de ver la danza como un espectáculo. Por el contrario, el registro del uso remite a la imposibilidad de hacer de algo una propiedad del sujeto, y por lo tanto instrumentalizarlo en relación a fines: el uso es siempre 
común y reenvía a la profanación como práctica destinada a desacralizar aquello que, vuelto objeto espectacular, se instrumentaliza en la lógica del consumo privado. En este sentido leemos:

[e]l uso es, así, siempre relación con un inapropiable; él se refiere a las cosas en cuanto no pueden convertirse en objeto de posesión. Pero, de este modo, el uso también desnuda la verdadera naturaleza de la propiedad, que no es otra que el dispositivo que desplaza el libre uso de los hombres a una esfera separada, en la cual se convierte en derecho (Agamben 2005: 109).

El método de trabajo propuesto en este capítulo es hermenéutico e interpretativo: iremos mostrando la ausencia, en la bibliografía específica, del cuerpo como problema de la danza, como recurso metodológico orientado a proponer una interpretación que nos permita hacerlo aparecer y, a partir de la problematización, construir un pensamiento sobre el cuerpo. Nos interesa abrir la posibilidad de construir una teoría para el análisis del cuerpo de la danza o simplemente proponer una categoría de análisis novedosa a partir de la resignificación de conceptos existentes y su rearticulación en relación a nuevos y diversos elementos significantes. Con esto queremos decir que la palabra cuerpo ya ha aparecido en las teorías y escritos sobre danza, pero lo que esa palabra significa en esos contextos no supone su tratamiento como objeto de las prácticas corporales ni, por tanto, su problematización como objeto de un saber específico. Ahora se apuesta no sólo a que aparezca la palabra, sino a que la palabra "cuerpo" signifique un modo de pensar la danza y su práctica. Para esto es necesario hacer algunos desplazamientos o corrimientos respecto de las formas en las que, convencionalmente, fue pensada y estudiada. En primer lugar, hay que dejar de pensar la danza como un fenómeno exclusivo del campo del arte, sacándola de la órbita de las prácticas artísticas; por otro lado, hay que dejar de pensarla sólo en términos de movimiento. Esto tiene como consecuencia entender a la danza en términos de una práctica corporal, lo que implica al menos dos supuestos: no podemos entender el cuerpo como un medio de comunicación, y tampoco como medio expresivo. Toda práctica corporal supone una preparación orientada a un rendimiento y a la ejecución de una performance, por lo que en este punto el cuerpo de la danza no perdería su estatuto de "instrumento". Sin embargo, la danza como práctica implica también un conjunto de acciones que construyen un cuerpo en el orden 
simbólico: aquí el cuerpo ya no es más un instrumento para fines heterotélicos ni un medio para fines autotélicos, ${ }^{1}$ sino que es un efecto, es resultado y no condición necesaria. Vemos, en este sentido, que el lugar lógico que ocupa el cuerpo si se entiende la danza como práctica es completamente otro que si se la entiende como arte.

No es posible la emergencia del cuerpo como tema y problema de la danza sin realizar aquellos corrimientos y apuestas metodológicas. Esto es así, en la medida en que la danza como arte reduce el cuerpo a un medio de expresión y, por tanto, a una condición de supuesto o instrumento, pero no de objeto construido en la práctica misma. Por otro lado, la danza como movimiento tampoco trabaja con el cuerpo como objeto de su acción, sino que concibe la espacialización de un organismo y lo interpreta en términos de medio de comunicación. Ahora bien, la realización de estos desplazamientos implica entender que el cuerpo no es algo que está dado a la naturaleza del hombre y no es algo que se desprenda de nuestra voluntad, sino que supone esa construcción como el resultado de un conjunto de prácticas en las cuales y por las cuales el cuerpo es hecho.

\subsection{LA CONCEPCIÓN ARTÍSTICA DE LA DANZA. EL CUERPO INSTRUMENTO Y EL MOVIMIENTO}

Una primera apuesta es pensar la danza escénica separada del arte. Esto tiene ciertas implicancias que nos obligan a presentar algunas consideraciones. En primer lugar, esto no quiere decir que la danza no sea arte sino que es posible, en la medida en que además de arte es una práctica corporal, pensarla desde otro ángulo. No desconocemos el trabajo del artista orientado a la producción de una obra de arte, pero nos interesa observar el conjunto de acciones que la danza supone como "modo de vida", como forma. Esto nos obliga a enfocar no

\footnotetext{
${ }^{1}$ Susana Tambutti, quien en el ámbito de la danza argentina es la primera que se pregunta por el cuerpo, instala esta discusión. Lo heterotélico remitiría a las formas de danza en que la lógica mimética y representacional obliga al cuerpo a ejecutar movimientos que tienen por finalidad mostrar un significado que está más allá del movimiento mismo, en tanto lo autotélico remite al reconocimiento del movimiento como elemento significativo en sí mismo, por lo que el cuerpo sería un instrumento puesto al servicio del movimiento puro. Agamben complejiza esta posición introduciendo la categoría de medio sin fin o medialidad pura, categoría que se vincula de manera estrecha con la categoría de uso. No introducimos esta discusión porque decidimos hacer énfasis en la categoría de práctica; sin embargo, reconocemos la pertinencia de la misma e incluso la necesidad de buscar articulaciones entre el concepto de práctica y el de medialidad pura, sobre todo en el registro de la ética.
} 
tanto la escena y la obra construida, cuanto el "trabajo" por el cual tiene que pasar el pensamiento y el cuerpo para llegar a bailar, es decir, a moverse de acuerdo a una forma.

Para entender esta apuesta creemos necesario introducir algunos elementos que nos permitan entender qué se entiende por "arte", de manera general y en la bibliografía específica en particular. También vamos a hacer una mención a la relación entre arte y estética y delinearemos algunos de los tópicos por los cuales pasó la discusión sobre el arte en el siglo XX, para ubicar allí la posición de la danza y la teoría de la danza.

El concepto de arte proviene de ars, que es la traducción latina del término griego techné, y se interpreta habitualmente como una "capacidad humana creadora respecto del mundo" (Henckmann y Lotter 1998: 22); sin embargo, tanto en la antigüedad como en el período clásico no se estaba de acuerdo en qué significaba la práctica del arte. Si para Homero, por ejemplo, el arte era de los dioses, que lo trasmitían a los hombres, para Platón el arte es una capacidad manual y de copia, lo que significa que tiene una relación de exterioridad con la verdad de la ideas, y nunca puede llegar a ella; en esta concepción no tiene sentido su promoción entre la vida de los hombres de la polis (la poesía solo tiene sentido si toma su materia de lo humano). Para Aristóteles, en cambio, aunque el arte tenga una condición mimética, logra su efecto con sólo idealizar rasgos generales del hombre y presentar la forma en un material determinado; esta idealización, realista o satírica, no debe sin embargo ser absurda ni contradecir la naturaleza de la idea.

En esta sintética presentación vemos una primera relación del arte, como techné, con la verdad, en tanto exigencia de verdad en el arte. Sin embargo, las reflexiones sobre el arte estaban en relación con su utilidad para la vida política y para la educación del ciudadano, no había en la antigüedad autonomía del arte como campo de acción con sentido propio. Durante la Edad Media, vinculado con una idea metafísica de la belleza, el arte comenzó a tener una función religiosa, si bien su producción seguía la idealización de aspectos generales de la vida humana y divina. Pero al cambiar el principio de producción de la idea, cambia su forma de manifestación. Recordemos que ni en la antigüedad ni en la Edad Media existían "espacios para el arte" como los museos; si bien en la antigüedad había teatros, el sentido de la escena era 
diferente del que tiene actualmente. La escena no sólo era pública, sino que estaba orientada a producir efectos, de catarsis por ejemplo, lo que nos permite arriesgar que tenía una función más cercana al rito que a la ilusión, el consumo o el espectáculo.

Con la modernidad temprana comienza una transformación en el arte a partir de la cual cambia su función, su sentido, sus formas de producción y circulación, y cambian también las formas de saber articuladas al arte. La estética filosófica, como disciplina específica orientada al conocimiento de lo bello, encuentra en el arte un punto de anclaje. Los elementos a considerar para este período son básicamente la idea de arte como producción desinteresada, la articulación de arte y belleza junto a la emergencia de lugares especiales para el arte y la constitución de un público. Hacia el siglo XX se constituye además un "mercado del arte".

La producción de arte asume una autonomía relativa del estado y de la religión pero también de la filosofía y de la estética. Si bien la estética como disciplina sigue analizando el arte, este último ya no se produce en referencia a la estética como lugar de la verdad. En el marco de lo que se denomina teoría del arte hay un conjunto importante y diverso de orientaciones: algunas que enfatizan la función social del arte, otras que remiten más al desarrollo interno del arte y se centran en discusiones de medios, estilos y escuelas, y otras sistémicas o institucionalistas que se centran en pensar las relaciones entre los agentes, recursos y lugares en relación a los que el objeto de arte se construye. Esto implica un análisis, ya no del objeto estético, de la obra de arte en sí misma, sino de los mecanismos, dinámicas y relaciones en el marco de los cuales la obra de arte circula. No hay una preocupación epistemológica, como aquella que ligaba la estética con la verdad, sino una preocupación comunicacional, de producción y recepción de mensajes en determinado contexto recursivo y en base a determinada legitimidad.

Entre los conceptos centrales sobre los que se articuló el desarrollo del arte moderno encontramos los de representación y mímesis, expresión y verosimilitud, y forma, contenido y técnica. Cada uno de estos conceptos entraña en sí mismo una serie de discusiones y posiciones cuya presentación detallada excede los límites de esta tesis; y, sin embargo, se introdujeron en capítulos precedentes con el interés de entender qué papel jugaron en relación 
a la danza. En las teorías de la historia del arte, algunos autores, por ejemplo Arthur Danto (2003), sostienen que el arte contemporáneo se ubica en un lugar especial, ya que representa el fin del arte, el fin de la institución arte tal como surge en la modernidad. Al respecto, el autor sostiene que este arte se define, entre otras cosas, por establecer un tipo de pregunta si se quiere existencial ¿qué es lo que hace que una obra de arte sea una obra de arte?, o bien ¿qué es arte?, o bien ¿qué diferencia el arte de la realidad? Las respuestas a estas preguntas comprometen las formas establecidas de producción y recepción de la obra de arte, lo cual pone en cuestión al medio mismo del que se sirve el arte y cada género. ${ }^{2}$ Se trata también de la puesta en cuestión de los límites y de la relación entre arte y vida, algo que, si bien se encuentra en las vanguardias históricas del siglo XX, se refuerza de manera intensiva en los años '60 de ese siglo. Este cuestionamiento busca mostrar, entre otras cosas, que no hay ningún ámbito "sagrado" que haga que un determinado conjunto de actos sea en sí mismo arte y refuerza en un sentido la lógica institucionalista de comprensión del fenómeno artístico: lo que hace que un conjunto de actos sea considerado arte es el marco institucional en el que circula.

En cuanto al material específico sobre danza, abundan los textos referidos a la historia y a la crítica. Aunque los escritos sobre teoría del arte de la danza aparecen en menor medida, podemos sostener que, casi sin excepción, todos se alejan de la perspectiva de la estética para pensar el arte y asumen de manera significativa la perspectiva institucionalista; a su vez, algunos orientan sus desarrollos a pensar la función social del arte. Cuando en este trabajo proponemos alejarnos de la mirada de la danza como arte apuntamos a alejarnos de estas miradas institucionalistas, artísticas y sociales sobre la práctica. Vimos, en el capítulo dos que los autores que trabajan sobre una teoría del arte de la danza aclaran que la diferencia de perspectiva que introduce una teoría del arte en relación a una estética es justamente lo que les permite separar la danza de la gimnasia (Mc Fee 1992; Adshead y otros 1999).

\footnotetext{
${ }^{2}$ El cuestionamiento a la especificidad de cada medio para cada una de las artes entró en escena con el modernismo, es decir a principios del siglo XX. Sin embargo, se suponía que tal medio era el indicado para tal arte sin cuestionar el uso del medio en sí. Creemos que en la danza contemporánea se está cuestionando esto en el intento de dar respuesta a la pregunta que se instala hacia los 1960: ¿qué es la danza? ¿qué diferencia a la danza del sólo movimiento. Cuestionarse el cuerpo en tanto medio de la danza es una forma de empezar a buscar respuesta a esa pregunta. La danza puede ser sólo cuerpo quieto.
} 
Nosotros no suponemos que la danza no es un objeto de arte que circula en un mercado y una institución arte, pero pensamos que mirarla sólo desde esa perspectiva obtura el análisis del cuerpo en términos de un cuerpo de la acción producido en y por la práctica simbólica en la que se inscribe. De hecho, veremos más adelante que el análisis de la danza en una perspectiva estética y no artística contribuye de manera fructífera a pensar el cuerpo y los usos del cuerpo en relación a la constitución de la subjetividad. Veremos también cómo la articulación de una perspectiva situada en las prácticas corporales, articulada a una perspectiva estética, en lugar de alejarnos de la gimnasia, el deporte o el juego, nos acerca a ellos. De manera preliminar adelantamos que los conceptos que se articulan en este sentido son los de práctica, técnica, forma y forma de vida.

Cuando Susana Tambutti (2008,) nos propone una historia de la danza entendida en términos de su creciente autonomía, lo hace teniendo en cuenta su estatuto artístico: de hecho, para pensar el arte remite a la tesis que desarrolla Arthur Danto en Después del fin del arte (2003) y la aplicación que él hace al fenoméno artístico del modelo del Bildugsroman. Cuando delimita el conjunto de acciones y significados de la danza sobre los cuales presenta su hipótesis de trabajo, lo hace siguiendo la definición que da Mc Fee (1992), quien inscribe a la danza y, aún más, a la enseñanza de la danza, dentro de lo que se denomina "institución arte", y busca diferenciarla incluso de los objetos que pueden caer en un registro estético, ya que el arte presenta un conjunto de determinaciones mayor que lo meramente estético.

Como vimos en el capítulo anterior, esto supone, en primer lugar, comprender la danza en vistas a la construcción de una obra de arte, lo que deja de lado toda una serie de acciones -entre ellas, el aspecto de gimnasia que su práctica implica. Por otro lado, y en la perspectiva institucionalista en que Mc Fee desarrolla su trabajo, los objetos de arte son interpretables en contexto (lo que supone a la vez registrar y conocer modos de producción, circulación y recepción). Esto significa que, en la forma de obra de arte, la danza tiene la función de significar algo. Esa significación es entendida en términos de comunicación, y el cuerpo de la danza es el instrumento -junto con otros que forman parte de la institución arte- por medio del cual esa comunicación se realiza. McFee (1992) no se preocupa por el contenido a comunicar, pero sí 
destaca que el encuentro entre diversas posiciones dentro de la institución coreógrafo, intérprete, público- es lo que termina por construir el significado de la obra; en este sentido, no cree que haya una intención que de manera unidireccional pase de un lado hacia otro, sino que el significado es construido intersubjetivamente, como resultado de una polisemia original.

Por último, cuando Pérez Soto (2008) propone sus lecturas sobre la historia de la danza lo hace con el interés de pensar el lugar del arte en la política actual; de hecho, su reconstrucción se orienta a pensar la relación arte/política a partir del caso específico de la danza. Su análisis puede entenderse en los términos de una sociología de la danza como práctica artística, y si bien en su libro aparece la pregunta por el cuerpo, lo hace de una manera muy radical, como espacio significante. Para Pérez Soto, el material o asunto específico de la danza es el movimiento, y es éste, más que la lengua, el significante más abstracto para poner en relación a otros significantes. Esto le permite sostener que la danza es lenguaje ${ }^{3}$ y que el cuerpo es el soporte material de ese lenguaje. En base a esta consideración, Pérez Soto sitúa a la danza en el campo de consideraciones artísticas, como espacio para la producción de sentidos y significados en el contexto de prácticas sociales más amplias. Por último, también aparece en este autor la idea de que la danza es una obra de arte construida relacionalmente, por coreógrafos, intérpretes y bailarines. Lo interesante, pero limitado, es que propone una concepción "no naturalista del movimiento" que, si bien tiene por efecto una interpretación no biologista del cuerpo, implica un radicalismo tal que, al interpretar la danza como un leguaje y al cuerpo como el soporte material del movimiento significante, asigna a la constitución del cuerpo y del movimiento una independencia y una autorreferencia que creemos no es viable ni deseable suponer, ya que eso tiene dos consecuencias de las cuales nosotros nos distanciamos. La primera es que vuelve a colocar al cuerpo en un lugar de condición necesaria para la danza (en vez de pensarlo como su producto), y la segunda es que confiere al

\footnotetext{
${ }^{3}$ Pensar la danza como lenguaje, y no el lenguaje de la danza, implica entender al movimiento como significante y a la danza como cadena significante; por eso el cuerpo es el espacio del significante, porque es el locus del movimiento. Sin embargo, creemos que esto representa una posición extrema, ya que sin una referencia al Otro simbólico no es posible el significante. Creemos que el movimiento no puede ser significante en-sí-mismo.
} 
movimiento un poder de significación casi mágico, ya que no se puede explicar cómo el movimiento asume la función significante. ${ }^{4}$

En esta tesis sostenemos que, si el movimiento puede ser significante, lo es porque traba una relación no sólo con el lenguaje, sino más específicamente con el discurso como forma organizada de lenguaje, ya que eso nos permite entender cómo una misma configuración de movimiento es en determinada situación un saludo al sol y en otra una entrada en calor. Además de esto, consideramos que la perspectiva puesta en la práctica nos permite comprender otros elementos de la danza que no la reducen sólo a su identidad con el movimiento (Lepecki 2006), lo que amplifica, al menos potencialmente, los elementos significantes que pueden aparecer en relación a un discurso determinado. Sostenemos que podemos pensar la danza como construida y codificada por el lenguaje, pero nunca como significante en sí misma, ni simbólica en sí misma. La danza adquiere significado por su articulación con el orden significante y no por ser representación simbólica de un significado socialmente construido. ${ }^{5}$

Estas son las principales diferencias que queremos marcar respecto de Pérez Soto (2008), ya que son también las que nos hacen tomar distancia del concepto de cuerpo con el cual trabaja. Si bien el autor se aleja de miradas románticas y biologistas del cuerpo, no deja de entender la construcción del cuerpo en la danza como soporte y condición necesaria del movimiento significante.

Aquí podemos recapitular algunos de los elementos puestos en juego al entender a la danza como parte de la institución arte. Ello supone hacer eje en que: a) el objeto de la danza es la realización de una obra de arte, entendida como la creación de un producto -terminado o no- y su puesta en circulación ante un público; b) la materia de la danza es el movimiento o sus opuestos, la quietud y/o las poses; $c$ ) identificar cuál es la función social del arte y de la danza como rama del arte. Vemos que ninguno de estos tres elementos toma al cuerpo como objeto de la danza, y si lo hacen, es sólo tangencialmente. Como vimos en el capítulo anterior, ni las precursoras ni la primera generación

\footnotetext{
${ }^{4}$ Sobre todo si tenemos en cuenta que en su argumentación deja de lado completamente la relación movimiento/lenguaje.

${ }^{5}$ Esto nos diferencia de los institucionalistas e incluso de la visión de Langer (1957).
} 
de bailarinas y coreógrafas de la modern dance buscaron liberar al cuerpo del entrenamiento, sino que buscaron liberar a la danza de un código particular de entrenamiento técnico y de forma compositiva.

Isadora Duncan (1902), por ejemplo, se refiere al ballet en los siguientes términos:

[l]a escuela del ballet de hoy, forcejeando vanamente con las leyes naturales de gravedad o con la voluntad natural del individuo, y trabajando en discordia por medio de su forma y movimiento con la forma y el movimiento de la naturaleza, produce un movimiento estéril que no da lugar al nacimiento de futuros movimientos, sino que muere mientras se realiza. La expresión de la escuela moderna de ballet, en tanto que cada acción es un fin, y ningún movimiento, pose o ritmo es sucesivo o puede realizarse como una acción en sucesión, es una expresión de degeneración, de muerte en vida. Todos los movimientos de nuestra escuela moderna de ballet son movimientos estériles porque son no naturales: su propósito es crear la ilusión de que la ley de gravedad no existe para ellos. Los movimientos principales y fundamentales de la nueva escuela de danza deben tener en su seno las semillas a partir de las cuales puedan evolucionar todos los demás movimientos y, a su vez, cada uno, por separado, dar a luz a otros en una secuencia sin fin hacia una expresión, pensamientos e ideas aún más grandes y magníficos (en Copeland y Cohen 1983: 68).

En esta referencia a "la danza del futuro" vemos claramente que la preocupación de Isadora es el movimiento y la expresión por medio del movimiento, y si bien en el texto citado ella llega al cuerpo, lo hace en tanto supuesto, en tanto medio del que se sirve el movimiento expresivo, pero no como su preocupación central. Al respecto leemos sobre el cuerpo que "(e)sta deformación a través del vestido incorrecto y el movimiento incorrecto es el resultado del entrenamiento para el ballet" (en Copeland y Cohen 1983: 68); esto lo sostiene para dejar en claro, páginas adelante, que el cuerpo de la danza es un supuesto que tiene que conservar su estado natural para poder ser expresivo, por lo que vuelve en ese punto a su preocupación central, la expresión artística por medio del movimiento: "(e)n esta escuela no enseñaré a las niñas a imitar mis movimientos, sino a realizar los suyos propios. No las forzaré a estudiar ciertos movimientos definidos, las ayudaré a desarrollar aquellos movimientos que les son naturales" (en Copeland y Cohen 1983: 69).

En el mismo registro podemos citar a Mary Wigman:

¿[n]o hemos hablado ya de la era técnica de la máquina? Y aunque pueda sonar paradójico, hay una correlación que no es fortuita entre lo que podemos designar como "técnica", y aquello que llamamos "danza 
moderna". No debe ser materia de asombro o confusión decir que nuestra era técnica engendró nuestra danza-motivada. Cuando ahora consideramos que la fuerza primitiva o el ritmo están detrás del motor; que toda máquina respira y simboliza fuerza rítmica, y al mismo tiempo, cuando recordamos que el ímpetu de la danza es también ritmo, tenemos entonces un fundamento definitivo, un nexo común entre, aparentemente, expresiones opuestas de la vida y las formas del arte. Es la expresión rítmica en y hacia la vida lo que inculca dentro de los jóvenes de hoy una consciencia positiva sobre la danza. El uso de movimiento rítmico corporal como medio para la expresión artística se ha vuelto natural, y es tomado como que así debe ser, por la consciencia de la danza de la gente de hoy... (en Copeland y Cohen 1983: 73).

Aquí vemos claramente los elementos expuestos arriba respecto de las implicancias que tiene entender la danza como arte y los límites que eso supone en relación al cuerpo como objeto.

Nos gustaría aún hacer una referencia a Doris Humphrey (1958) para mostrar el peso que adquiere el componente expresivo y la consideración del cuerpo como medio de expresión, situando al movimiento como materia de la danza: "me aventuro a decir que la danza no puede ser completamente intelectualizada sin perder el derecho a su público y comprometer su verdadera existencia [...] la comunicación en términos de movimiento no intelectual me parece la meta deseable" (Humphrey 1958: 178). Vemos además que la reducción del cuerpo a una condición se hace sobre el supuesto de cierta "naturalidad" del mismo, de cosa que nos viene dada como esencia. Más adelante leemos que "la danza en sí debe ser largamente soñada, provocando el movimiento instintivo y aprovechando destellos y visiones para seducir la imaginación. Es de esperar que las consideraciones estrictamente técnicas operen en el subconsciente ahorrándole al coreógrafo los peores errores" (180). Finalmente, queremos destacar una referencia de Humphrey a la cuestión del arte en la composición y definición de la danza moderna "pertenecemos al siglo XX, tenemos algo que revelar acerca de esto a la luz de la experiencia contemporánea; la danza es un arte de tanto alcance como la literatura y puede hablar sobre el hombre moderno como los autores y poetas" (189).

Sin embargo encontramos, en autores como Rudolf von Laban y Merce Cunningham, una tensión interesante de trabajar, ya que es ella la que nos habilita a pensar el cuerpo como práctica y a operar el cambio de perspectiva que proponemos. Pensando la danza el primero, y la educación el segundo, se 
quedaron en el análisis del arte; pero cuando el primero pensó la educación, y cuando el segundo pensó la danza, lograron llegar al cuerpo. Con esto queremos decir que el fenómeno en sí mismo va a depender de la perspectiva de análisis que uno adopte para su comprensión. El objeto que aparece depende de la mirada. Esta complejidad respecto del saber en danza aparece en Laban (1975) y en Cunningham (2008) como en ninguno de los otros autores citados, aparece esta complejidad respecto del saber en danza o el anterior o éste está de más. Nos gustaría hacer una referencia corta al primer polo de la tensión y trabajar en el próximo capítulo con referencias al segundo.

En Laban (1975) encontramos una definición de danza en términos de esfuerzo de movimiento a partir del cual es posible no solo conocer el movimiento desde la observación, sino dejar testimonio del mismo. Esto, que parece en cierto sentido secundario respecto de la preocupación en torno al cuerpo o la expresión resulta, en cambio, bastante importante, ya que nos deja ver el grado de codificación al que apuntaba la danza libre europea. Para el autor,

[p]arece, por consiguiente, que el hombre moderno debe crear su propio arte de movimiento, y puede verse un comienzo de ello en aquéllas formas de danza contemporánea que los norteamericanos, y con ellos los demás países de habla inglesa, llaman "danza moderna". Comparada con las reliquias de los bailes folklóricos medievales y con las formas de movimiento de la época de las monarquías absolutistas, la "danza moderna" es más rica y más libre en sus gestos y en sus pasos. Una segunda característica notable del arte contemporáneo del movimiento es la relación entre las nuevas formas de expresión de la danza y los hábitos de movimiento del hombre moderno (Laban 1975: 15).

En esta referencia vemos una idea evolutiva de la danza, que sigue un poco los pasos de la "civilización": la danza contemporánea a Rudolf von Laban es más libre en algunos aspectos, pero está condenada a la expresión del movimiento del hombre contemporáneo. De hecho, esa expresión debe responder a una forma técnica que haga hincapié en el flujo, porque la modernidad es fluida, pero debe hacerlo a partir de una nueva técnica (101 y ss.). Para Laban, el movimiento de la danza libre es expresivo en la medida en que crea estados mentales y compensa positivamente, liberadoramente, los estados mentales opresivos del movimiento del trabajo (y también, por qué no, del movimiento del ballet). Vemos que aquí la referencia al cuerpo no aparece. Sin embargo sí lo hace cuando problematiza la educación de los principios de esta danza y su utilidad más allá del arte (volveremos sobre ello en el siguiente capítulo). 
Por último, nos gustaría hacer una referencia a Cunningham, ya que, de los representantes de la danza norteamericana de 1960, fue quien más innovaciones aportó a la disciplina y sin embargo nos ofrece una descripción del trabajo cotidiano del bailarín con la danza que en nada se diferencia de la representación que se tiene de las clases de ballet, en contra de las cuales reaccionaron los primeros bailarines y coreógrafos de la danza moderna. Sostiene:

[q]uiero decir que la clase es muy rígida, los bailarines se limitan a realizar los ejercicios de determinada manera... Creo que éste es un problema al que se enfrentan muchos bailarines y seguramente algunos dejan la danza cuando se dan cuenta que van a tener que hacer esos ejercicios todos los días porque son una parte fundamental -el pilar, de hecho- de la vida de un bailarín (Lesschaeve y Cunningham 2009: 77).

Incluso, cuando menciona el proceso por el que tuvo que pasar un trabajo de danza para volverse una pieza de video, comenta que la manera fue "volver a la clase de técnica" (Lesschaeve y Cunningham 2009: 184), ya que allí advertía qué movimiento debía transformarse y en qué sentido debería hacerlo -pasar de una segunda posición a una cuarta posición en la forma coreográfica, por ejemplo- para que parezca grande ante la cámara. Aquí vemos la rigidez del trabajo del bailarín y la importancia que tiene, en danza moderna, el entrenamiento técnico, y vemos también que la idea de libertad que se utiliza habitualmente para oponer la danza moderna al ballet opera en términos imaginarios y de representación. El análisis de la práctica y la práctica misma ponen en duda que la libertad sea un objeto, un problema o incluso una categoría de la danza.

\section{La danza como movimiento y el cuerpo como medio durante los siglos XVII a XX}

La danza como arte es la manera de comprensión de la danza escénica occidental, lo hemos visto en los registros históricos y teóricos que presentamos en esta tesis. Esa comprensión implica entender el movimiento y su opuesto, la quietud, como el material específico de la danza, y supone además pensar en la articulación rítmica, formal y expresiva de este material en un todo coreográfico. La danza, como elemento del discurso del arte que emerge en el siglo XVII, atravesó diversas etapas que se corresponden en 
mayor o menor medida con discusiones de estilo. Veremos en este parágrafo que, por más diversos que sean los puntos de vista respecto de la articulación entre ritmo, forma y expresión, el lugar de "medio" del cuerpo no se abandona ni en el clasicismo, ni en el romanticismo, ni en el naturalismo, ni en el expresionismo, ni en el modernismo, ni en las vanguardias. El cuerpo "sirve" a la representación, la expresión, la evocación, la transmisión o la comunicación. De manera general, para la danza el movimiento es el pasaje de peso entre un lado y otro del cuerpo y puede implicar el desplazamiento o no. El pasaje de peso puede darse, además, entre distintas partes del cuerpo. También, el movimiento de la danza implica el gesto de la parte superior del cuerpo y el decoro de los brazos según los géneros. Existen conceptualizaciones del movimiento que lo clasifican de mayor a menor complejidad o amplitud.

De lo expuesto, nos parece necesario explicitar algunos elementos y pensar en las consecuencias que tiene la identificación de danza y movimiento. La tarea será desarticular este par significante, porque creemos que a partir de allí puede emerger el cuerpo como problema de la danza; de hecho, la principal consecuencia de articular danza y movimiento es obturar la pregunta por el cuerpo.

En este punto, el libro Agotar la danza (2006) de André Lepecki es una punta de lanza respecto al cuestionamiento de la naturalización de la relación entre danza y movimiento. ${ }^{6}$ Expusimos en el capítulo anterior los elementos que los estudios más específicos e internos a la disciplina, tanto como aquellas reflexiones de orden más filosófico, identifican como constitutivos y necesarios a la danza. Vimos allí que todos hacen mención al estatuto artístico de la danza y al movimiento como su material específico, y también registramos las formas o maneras en que ese movimiento se hace significativo para los diversos autores trabajados: como conjunto de elementos a desagregar con el objetivo de proponer un "análisis coreográfico", como conjunto de "poderes virtuales" destinados a construir una metáfora, como medio de comunicación orientado a trasmitir un mensaje, como alma de aquel impulso humano hacia el movimiento

\footnotetext{
${ }^{6}$ Lo siguiente que hay que poner en cuestión es la identificación entre danza y arte, algo que, si bien se esboza en esta tesis, excede sus límites en lo que remite a un tratamiento sistemático y exhaustivo.
} 
no destinado a la satisfacción de necesidades o como metáfora del pensamiento.

Ahora bien, a nosotros nos interesa decir que, además de movimiento del cuerpo, la danza es construcción de un cuerpo de acciones, donde el cuerpo se entiende en términos del resultado de su inclusión en el orden significante (Escudero 2012). El libro de André Lepecki (2006) sostiene que hay que agotar la relación entre danza y movimiento, y llega a decir que algunas manifestaciones contemporáneas de la danza europea y norteamericana muestran de hecho, a partir del recurso a la quietud, a la lentitud y a la construcción y mostración espasmódica del movimiento del cuerpo, el agotamiento y la crisis de aquella identidad. Entiende que el problema principal de esa identidad reside en haber querido someter el movimiento (que define como efímero y finito por naturaleza) a una lógica de la escritura. El interés por perpetuar o fijar aquello que necesariamente se escapa produce un efecto de melancolía que será característico de la ontología de la danza en occidente. Esta melancolía propone una relación con el objeto danza ubicada en una tensión descripta por Lepecki en términos de traer a la memoria aquello que siempre está ausente. Esto refuerza para el autor la identidad entre danza y movimiento, porque la danza se construye sobre una ontología cinética de la relación entre el creador de la danza, el público y el objeto danza en sí. La propuesta de Lepecki es borrar la escritura de la danza y así evitar la captura del movimiento en una forma estable: propone, si se quiere, pensar otra ontología de la danza a partir de otra política del movimiento en la que la quietud e incluso lo efímero se reconozcan como constitutivos. ${ }^{7}$

Creemos que este texto es acertado en el diagnóstico y en la pregunta que instala, sobre todo para la crítica y la teoría de la danza (ya que en la creación de danza la quietud como parte constitutiva de la misma ya había sido aceptada desde los años (60), pero no nos satisface la propuesta/respuesta que ofrece, por dos razones principales. Por un lado, porque su análisis se inscribe en una preocupación por la danza como obra de arte y su reflexión sobre la melancolía, si bien remite a una lógica de construcción de la

\footnotetext{
${ }^{7}$ Vimos que esto ya había sido experimentado por las vanguardias norteamericanas de los '60, respecto de las cuales Steve Reich decía que "por un tiempo largo, durante 1960, uno asistía a un concierto de danza donde nadie bailaba, seguido por una fiesta donde todos bailaban. No era ésta la mejor situación" (en Copeland y Cohen 1983: 91).
} 
subjetividad, se orienta a pensar de manera exclusiva una relación con el objeto artístico. Por otro lado, porque al proponer una nueva ontología de la danza a partir de reconocer otra lógica del movimiento, no atrapada en la escritura, limita el análisis del cuerpo de la danza a un cierto vitalismo, donde el cuerpo no pierde el estatuto de medio característico de la danza como arte, y donde se habilita a pensar el cuerpo en un cruce entre lo biológico y lo físico. Sobre este segundo punto, creemos que la apuesta de pensar la danza como práctica es superadora en tanto nos permite pensar un cuerpo del orden simbólico.

Pongamos en orden algunos elementos orientados a comprender las consecuencias de pensar la danza desde el movimiento en vez de pensarla en términos de práctica, especialmente en referencia al cuerpo. Entender la danza como movimiento reduce al cuerpo a una condición de medio, lo que implica esencializar una posición de instrumento y añorar (erradamente además) una naturaleza primera que su instrumentalización hace perder. Vemos aquí que estamos lejos de la discusión sobre si un código técnico es más o menos emancipador de la danza, y de hecho queda claro que ninguno emancipa a la danza. Sin embargo, lo que queda menos claro es por qué hay que pensar la emancipación y, si lo hacemos, por qué no pensar directamente sobre las formas de construcción y uso del cuerpo. Si ya no se pone en discusión el hecho de que una técnica sea mejor o peor que otra, no por eso se ha puesto en cuestión reducción de la técnica a instrumento y por tanto la reducción del cuerpo entrenado técnicamente a un instrumento de la danza. La apuesta de pensar la danza como práctica supone restituir al cuerpo un estatuto de objeto y reconocer a la técnica como constitutiva de ese cuerpo; para ello necesitamos dejar de identificar técnica e instrumento.

La reducción del cuerpo a medio o instrumento de la danza es una constante en los análisis de la danza como arte. Es necesario recordar aquí el acuerdo que existe en la bibliografía en reconocer como antecedente directo de la danza escénica occidental a los bailes de corte (en especial los franceses, pero también los italianos y los ingleses), que no tenían pretensiones artísticas, sino que en este contexto la danza era el medio que servía de utilidad a la educación del hombre y el cuerpo era el objeto de la práctica. La danza no tenía un fin en sí, no tenía autonomía respecto de la utilidad que brindaba para 
la formación de la nobleza en los buenos cuidados y en los buenos modales. El entrenamiento, el ejercicio y la educación del cuerpo servían a la construcción del imaginario social de un sector social determinado. Creemos que este origen ligado a la "educación de la persona" fue olvidado por la historia institucional y social de la danza como arte. Se reconoce, dentro de la historia oficial de la danza como arte, la emergencia de la forma coreográfica, de los tratados y los compendios que sirvieron a la codificación de los pasos que luego fueron estilizados en el ballet pero tiende a olvidarse la función de entrenamiento y de puro ejercicio educativo ${ }^{8}$ que tuvo; en el contexto de la corte, sin embargo, el cuerpo (y no la obra de arte, como se reclama desde los análisis artísticos de la danza) era una forma de construcción de subjetividad. Esto no quiere decir, claro está, que el arte no sea o no pueda ser una forma de construcción de subjetividad, sino que el cuerpo también lo es.

Si nos paramos sobre este elemento como antecedente de la historia de la danza, podremos pensar el conjunto de acciones y reacciones que desde allí se sucedieron en términos de una historia de la práctica de la danza, en la que, más allá de algunas diferencias aparentes, encontramos varios elementos de continuidad. Sobre estas continuidades es que proponemos una lectura alternativa de la danza, su historia y sus discusiones, ya que en esos puntos de ligazón entre los diversos géneros encontramos en común a la técnica. Esta es constitutiva de la relación del hombre con el mundo y es constitutiva de la práctica de la danza. El cuerpo en general y el de la danza en particular son construidos por la técnica, entonces, en un doble sentido. Aquí pensamos la técnica en términos de techné y no simplemente como instrumento (Agamben 2005; Esposito 2011).

La técnica es además un componente de la práctica, la cual entendemos según: a) su homogeneidad, en la medida en que funciona como regularidades y racionalidades que organizan la conducta (el ejemplo de la clase que nos daba Cunningham); b) su sistematicidad, en la medida en que el análisis de un dominio de prácticas supone poner atención en los ejes del saber, del poder y de la ética (sobre ellos hemos trabajado al analizar las teorías sobre danza, al identificar las relaciones históricas entre los géneros y al poner atención sobre

\footnotetext{
${ }^{8}$ A la manera de la danza en la antigüedad, al menos en algunos de los registros que trabaja Ricardo Crisorio en su tesis doctoral (2010).
} 
las concepciones que sobre la danza tenían los sujetos de la danza); c) su generalidad, entendida como recurrencia (la danza es recurrente en nuestra cultura, y la danza-arte es recurrente en la modernidad más allá de los diversos estilos asumidos, lo que permite investigarla en sus especificidades a la vez que plantea problemas generales que nos interesan, por ejemplo movimientopráctica cuerpo-danza danza-movimiento). A estas características se agrega el hecho de que un dominio de prácticas tiene un aspecto tecnológico y otro estratégico. La técnica articula estos dos aspectos, ya que una combinación determinada de técnicas, que organiza cierta tecnología "estructural y permanente", puede trastocarse estratégicamente para conservar el dominio de prácticas como tal, o para cambiarlo en función de una diversa relación de fuerzas y modificar estratégicamente la posición de la técnica en el conjunto de la tecnología. Lo más o menos opresivo de una técnica (discusión que, en nuestra perspectiva, no tiene sentido) no se vincula con el código de movimientos que la misma define, sino con la posición de la misma en el aspecto tecnológico de una práctica específica.

Ahora bien, antes de pensar explícitamente la continuidad entre las diversas formas de danza, que puede ser pensada a partir de la apuesta de entender el cuerpo como objeto de las prácticas, veamos aquello que sobre la continuidad emerge como "diferencias aparentes" y veamos cómo se constituyen a partir de la comprensión del estatuto de "medio" que tiene el cuerpo.

Pareciera quedar clara la condición de medio que toma el cuerpo en las formas de danza ballet, sea en su estilo clásico, romántico o moderno. Las discusiones que se dieron en el interior de la danse d'ecole (o danza académica), por ejemplo, no ponían en cuestión la necesidad de la técnica, del entrenamiento y de la codificación de los pasos para la danza. La estilización de los movimientos y el constante perfeccionamiento en la ejecución de los pasos, desde el siglo XVIII hasta la actualidad, evidencian que el trabajo del código técnico sobre el cuerpo es un supuesto sobre el cual el ballet no arroja ninguna pregunta. De hecho, si rastreamos en las Letres sur la danse de Noverre (1945), en la carta de Fokine al Times (en Copeland y Cohen 1983), en los escritos de Balanchine o Béjart (2005), vemos que la puesta en cuestión no es hacia el cuerpo y su lugar en la danza, sino hacia la "danza misma": "(I)a lección cotidiana de baile, de algún estilo, de alguna técnica, no debe tener 
como fin adquirir un nuevo virtuosismo ni agregar sobre el ya adquirido. No es una gimnasia, es una toma de conciencia" (Béjart 2005: 27). Las preguntas 0 los momentos críticos en los cuales hubo que "pensar" estuvieron orientados por problemas vinculados a consideraciones de orden artístico o estético. Básicamente, los ejes que cruzaron el desarrollo del ballet fueron la necesidad de representación de una narrativa, cómica o dramática, y la posibilidad de poner en movimiento, articulada al desarrollo temporal, una imagen poética. Ligado a ello, la adecuación del código técnico a esos fines artísticos y, consecuentemente, la ampliación y perfeccionamiento del código o su articulación con elementos y recursos provenientes de fuera del código.

La función básica de la danse d'ecole se orienta en torno a la representación y a la expresión, y en ninguna de sus variantes de estilo (clásica, romántica o moderna) se puso en duda que la danza tiene que representar una historia, el carácter de un pueblo, la belleza, o incluso la verdad, de una idea. Aún si consideramos en la figura de Michel Fokine un elemento de discontinuidad o de disrupción, podemos sostener que el sentido de la puntuación que él introduce se orienta a perfeccionar el código y a introducir la expresión como asunto del ballet. ${ }^{9}$ El estatuto del cuerpo en tanto instrumento de la danza no cambia radicalmente, sino que, incluso, se alinea aún con más detalle en relación al movimiento. El cuerpo es una función del código en el que se entrena, y el código es el medio de la creación artística. Dentro del ballet, si bien Balanchine introdujo una ruptura importante en relación a la representación a partir de su idea de ballet abstracto y su vinculación estética entre danza y plástica, no abandona la preocupación por la cuestión del significado y por la construcción de una pieza artística. El significado, en este caso, ya no se construye representacionalmente; Balanchine sostiene que el movimiento mismo evoca sentimientos y estados, y construye "sensaciones visuales". Una buena y formal combinación de movimientos abstractos genera en sí misma un significado inteligible para el público, sobre todo si se considera la importancia que tiene la música en sus trabajos. No abandona, en ese sentido, la preocupación por el mensaje ni por dejar claro que la danza es en cierto sentido visualización de la música (Bentivoglio 1985; Copeland y Cohen 1983).

\footnotetext{
${ }^{9}$ Noverre ya había comenzado a plantear esto, pero el punto cúlmine de la formulación llegó con Fokine
} 
Por otro lado, quienes, con una dosis mayor de romanticismo o racionalismo, cuestionaron el código del ballet por someter a la danza a cánones muy cerrados de entrenamiento corporal y de composición artística, no superaron la mirada sobre el cuerpo en términos de una "función del código". De hecho, lo vimos más arriba, el problema que instalaron los precursores de la danza moderna en Estados Unidos y en Alemania no giraba en relación al cuerpo como objeto construido en y por la práctica de la danza. Por el contrario, buscaban liberar el movimiento danzado con el interés de proponer otras formas artísticas. La consecuencia y los efectos de esta liberación recaen obviamente sobre el cuerpo que se construye en las prácticas, pero, justamente, recaen, no hay una "política práctica" orientada al cuerpo, sino orientada a la danza como arte.

El norte, en la discusión que instala el movimiento moderno en danza, viene dado por la oposición con la representación y la necesidad de incluir el elemento emotivo y expresivo. Pero el cuerpo sigue siendo una función del código, sólo que ahora los códigos se construyen con otro objetivo: se busca la traducción a una forma artística de una emoción individual y/o subjetiva, de una idea psicológica o social. Sobre esto, la idea central, que con matices sostuvo el conjunto de los precursores y la primera generación de bailarines y coreógrafos de danza moderna, giró en torno a la necesidad de recuperar, para la codificación del movimiento, una "naturaleza" supuestamente perdida por la mecanización del cuerpo que operó el código clásico. La naturaleza que se reclama es una naturaleza del cuerpo en su relación perdida con el universo natural y social. El movimiento fluido, el rechazo de las poses estáticas, el reconocimiento de la fuerza de gravedad, son elementos de la danza y del código moderno que suponen un "reconocimiento" de la naturaleza de la especie humana -las metáforas del movimiento en relación a las olas y las montañas, por ejemplo, dan cuenta de ello. La idea fuerte que sostenían vinculaba la fluidez del movimiento con una organicidad expresiva que se volvía más genuina a los fines del arte. Como si la fluidez no fuera el resultado de un entrenamiento, sino una manera originaria del movimiento del cuerpo, obturada por la cultura del trabajo en general y por el código clásico en particular. 
Recordemos, por otra parte, que en las primeras décadas del siglo XX, los movimientos artísticos discutían sobre dos ejes principales: las posibilidades y límites de sus medios expresivos (el plano y el color, el sonido y los sistemas, etc.) y la función social del arte (el arte comprometido vs. el arte por el arte). En la danza, los supuestos sobre los que se sostuvo la creación de las formas modernas, operaban sobre la siguiente articulación significante: lo orgánico implica reconocer la identidad del hombre con el mundo; por lo tanto, a mayor organicidad y fluidez del movimiento -por creación de un código que reconozca, por ejemplo, la ley de gravedad, o la respiración como principio regulador del código- más genuina es la expresión del artista y más situados están el artista y su arte en el mundo histórico, de lo que se desprende que el sentido de su obra es más verdadero (por menos artificial). Vemos acá tres cosas importantes para retener: la idea de liberar a la danza del apresamiento del ballet fue equivalente a expandir las posibilidades del movimiento, tanto en relación al código de entrenamiento como en relación a las formas compositivas; la expansión de las posibilidades de movimiento no fue equivalente a liberar al cuerpo de todo código, sino que éste continuó siendo una función, continuó conservando su estatuto de medio y siguió siendo instrumentalizado a una finalidad artística; los códigos que se crearon, al suponer que lo orgánico ${ }^{10}$ expresa más genuinamente la naturaleza humana, operaron una biologización del cuerpo desde la fisiología, que no encontramos siquiera en el código del ballet.

No sólo el cuerpo no es tomado como objeto de la danza, sino que la consecuencia que la danza tiene sobre el cuerpo -en la medida en que, aunque no lo tome por objeto, igualmente lo construye- es la creación de un cuerpo de la función -funcionalista- y del consumo, de la espectacularización (Agamben 2005). Si junto a este elemento consideramos los desarrollos de Rudolf von Laban (1975), podemos agregar que la danza del siglo XX opera también sobre una fisicalización del cuerpo, lo que implica que a la organicidad del cuerpo biológico se le suma la naturalización del cuerpo físico de las tres dimensiones (Crisorio 2011 mimeo). Si bien Laban, al introducir la pregunta por la pedagogía y el lugar de la danza en los sistemas educativos, desvía el

\footnotetext{
${ }^{10}$ Interpretado en términos de fluidez, de una relación no esquiva con la gravedad y de la respiración como base de la técnica.
} 
estatuto del cuerpo como mero instrumento y le asigna un lugar articulado a la "experiencia" (veremos esto en el próximo capítulo), cuando desarrolla su teoría del icosaedro como elemento ligado a la notación del movimiento, muestra su esfuerzo racionalista por trabajar y dar un estatuto objetivo a la expresión y a la forma artística. Esto redunda en hablar del cuerpo humano con las categorías y propiedades del cuerpo de la física y de la geometría, trabajando, por ejemplo, a partir de planos, direcciones, energía, dimensiones, flujo, palanca, fuerzas, etc.

Por otro lado, durante el siglo XX también se dio el fenómeno de la comprensión de la danza en términos de comunicación. El mismo se desarrolla hacia mediados del siglo XX y se articula histórica y epistémicamente con las discusiones en filosofía del lenguaje y semiótica. La idea fuerte en este punto es la de rechazar el representacionismo y el expresionismo. Este rechazo se entiende, una vez más, en el contexto de las discusiones de la danza como práctica artística. Sobre todo si, siguiendo a Tambutti (2008), entendemos el desarrollo de la danza en términos de una creciente autonomía respecto de otras formas y manifestaciones del campo del arte, y si aceptamos que la relación entre significante y significado es arbitraria y no natural. Una consecuencia de esto fue acercar la danza a la plástica, ya que permitía alejarla del drama y la narrativa y de las formas sociológicas o psicológicas de compromiso socio-existencial que supuso el expresionismo. Lo cual se ve claramente en los trabajos de Balanchine y de Cunningham. ${ }^{11}$ La idea central que se pone en juego en la comprensión de la danza como comunicación es doble: por un lado habilita a pensar la danza como un lenguaje, articulada a la transmisión de un código descifrable, en términos de mensaje o de idea; por otro lado, en la medida en que se desarticulan de alguna manera las referencias externas al objeto artístico y se centra la mirada en el medio expresivo, el material y el resultado, se refuerza una autonomía del objeto artístico, algo que, siguiendo la argumentación de Tambutti (2008), es central para comprender el fenómeno de la danza en perspectiva histórica.

Esto supone que el objeto construido -en nuestro caso, una pieza de danzapuede comunicar un mensaje, la obra se convierte en un signo que remite a un

\footnotetext{
${ }^{11}$ De los trabajos de Cunningham se puede citar Rainforest (1968) o Walk around Time (1973) y de Balanchine se puede citar Kamermusik № 2 (1978).
} 
código descifrable, lo que supone una relación, si bien arbitraria, al menos estable entre signo y significado. Pérez Soto (2008) que es quien ha llegado más lejos en la crítica a esta perspectiva, argumenta que descifrar el mensaje es una actitud modernista, en tanto interpretar las relaciones metonímicas es una actitud abstracta y sobre esto hay que situarse para pensar las producciones de danza de la segunda mitad del siglo XX. La danza muestra que los significados residen completamente en las relaciones entre significantes, y Pérez Soto (2008) lo muestra en el punto en que el movimiento se concibe como significante primordial; de hecho, radicaliza esta tesis al sostener que el movimiento como significante primordial opera no sólo ni exclusivamente para la danza, sino para la vida del hombre en general. El movimiento como primer significante lógico es constitutivo del sujeto que interpreta, y el cuerpo es el soporte material del significante en la escena. En este sentido, el autor sostiene que

[e]l sujeto que produce los significados no lo hace desde una interioridad o proyección de imagen mental sino que el sujeto es sólo por la actividad práctica y puramente física de coordinar sensaciones. No sólo la danza es un lenguaje sino que, de manera mucho más profunda, el lenguaje no es sino danza: movimientos de cuerpos humanos en que es posible distinguir coreógrafos, intérpretes y públicos (Pérez Soto 2008: 149).

Unas líneas más arriba había propuesto que "tanto el ser de las cosas determinadas como el ser de los sujetos determinados no son sino conjunciones, lugares, funciones, en ese universo de movimientos corporales" (149). Creemos que hay aquí un radicalismo extremo, que no logra explicar cómo el movimiento funciona como significante sin el recurso a un orden simbólico o, de manera más específica, a un discurso, que lo articule a un sentido histórico interpretable. Como si el movimiento pudiera prescindir del orden del lenguaje para significar, como si el movimiento fuera la significancia misma.

A su vez, la ubicación del cuerpo como soporte material del movimiento lo ubica una vez más en el lugar lógico de supuesto. La comprensión de la danza como práctica supone en cambio un cuerpo que es resultado, es producto. No es un cuerpo practicante sino un cuerpo practicado, nunca puede ser un elemento dado, siempre tiene que ser interpelado a hacerse. 
Si bien las perspectivas que comprenden a la danza como comunicación son en varios puntos más fructíferas que las perspectivas centradas en la representación y en la expresión, ya que introducen en consideración el lenguaje, la primacía semiótica para la comprensión de la danza implica dos cuestiones que en la perspectiva de esta tesis no nos interesa desarrollar: por un lado centra el análisis en la obra de danza, en la pieza danzada, lo que -en consonancia con las versiones institucionalistas de la danza- tiene por consecuencia dejar de lado un conjunto de acciones necesarias para la danza y el cuerpo de la danza, como, por ejemplo, la gimnasia. Generalmente se interpreta la obra como signo o como conjunto de signos. Por otro lado, a excepción de Pérez Soto (2008), que radicaliza la perspectiva del significante de manera que nos parece poco conveniente -como vimos arriba-, la mayoría de los análisis se basan en una analogía entre lenguaje y movimiento que nos deja ver cómo el lenguaje o el movimiento se comprenden en términos de códigos descifrables o de signos interpretables. Si bien estas posiciones también tienen matices -ya que entender la obra como código supone la comprensión completa de un mensaje, lo que deja de lado el equívoco y la pluralidad de sentidos, mientras que comprender la obra como signo abre una pluralidad de sentidos por parte del interpretante, sin implicar una idea de desciframiento-, hay una idea de convención que sedimenta y se comparte, lo que reduce la actividad significante en la medida en que el signo encierra y articula los diversos elementos en un sistema cerrado, y los presenta como dados y no como resultado de una decisión o una relación de fuerzas (Foucault 1995). En esta tesis, el lenguaje se entiende como práctica, no como un sistema de representación ni como un medio de comunicación. En este sentido, el lenguaje es capaz de hacer cosas y producir efectos de verdad (Crisorio y Escudero 2012).

\subsection{CONCLUSIÓN. CONTINUIDADES CONCEPTUALES EN LA COMPRENSIÓN Y CONSTITUCIÓN DE LA DANZA COMO ARTE}

Vimos, en base a la recapitulación que, más allá de las discusiones internas a la disciplina, ligadas a elementos propiamente artísticos como la representación, la expresión o la comunicación, más allá de las diferencias de 
género entre el ballet, la danza moderna y la danza contemporánea, y más allá de las diferencias en los códigos técnicos entre la danse d'ecole, la técnica Graham, Laban, Jooss-Leeder, Humphrey, Cunningham o la danza postmodern, la preocupación central de coreógrafos, bailarines, historiadores, teóricos y críticos no es la construcción del cuerpo de la danza. La construcción funciona de hecho, está claro, pero no se la problematiza, lo que significa que el cuerpo se supone dado de manera más o menos natural, se lo considera más o menos un obstáculo a superar, pero de manera general se sostiene que está antes de la danza y está para la danza

Veremos a continuación las continuidades conceptuales, o mejor dicho, las consecuencias que tiene, respecto de la construcción del cuerpo como objeto, el hecho de que se sostenga una continuidad a nivel de los supuestos entre los diversos estilos.

No hay, en ningún caso, una idea según la cual el cuerpo sea el resultado de la danza, o esté después de la danza y por la danza; por el contrario, siempre está dado de antemano. Otro de los elementos compartidos es la perspectiva artística para el abordaje de la danza, según la cual lo importante para el análisis y lo distintivo de la danza es el hecho de que se constituye como un objeto de arte. Aquí el cuerpo aparece como condición, como algo necesario, como soporte material del movimiento, como materia maleable. Si bien se reconoce el entrenamiento como elemento constitutivo y subyacente en el objeto artístico, ese entrenamiento debe ser olvidado, y hay un registro del cuerpo en la performance que puede pensarse en términos de consumo (de hecho, la discusión sobre la necesidad o no de registro respecto de lo efímero del arte de la danza encierra esta cuestión), de cosa sacralizada imposible de ser usada y que es además privada, lo que implica pensar en un cuerpo uno y propio.

Por otro lado, todos los estilos identifican danza con movimiento, lo que, como vimos, reduce el cuerpo a una condición de medio; si bien en el ballet hay una primacía de las poses como punto cúlmine hacia el que se orienta y en el que cobra sentido el movimiento, sigue siendo el movimiento y su conclusión sobre lo que se presta atención. Otro punto en común es el recurso a la técnica y la tensión que este elemento introduce en la construcción e incluso en la concepción de la obra de arte y del significado del arte (sobre esto volveremos 
en el capítulo siguiente). A lo que se suma el hecho de que, de manera general, tanto en las discusiones históricas como teóricas el asunto de la gimnasia y el uso del cuerpo queda velado y no problematizado. Por último, todos los géneros y todas las perspectivas suponen un cuerpo-ahí, más o menos natural, más o menos mecanizado y matematizado, más o menos orgánico, más o menos físico, más cerca o más lejos del alma -en todo caso, para nuestra perspectiva, esas diferencias son significativas sólo relativamente. Lo significativo, en todo caso, es la operación por la cual suponer un cuerpo como materialidad dada o como condición necesaria tiene por efecto su exclusión como asunto de la danza. Creemos que esto pasa por la especial articulación entre danza-arte-movimiento, ante la cual nosotros propondremos una articulación de la danza con el cuerpo y con lo gímnico ${ }^{12}$. Si bien es posible -e incluso necesario y conveniente- reconocer las diferencias que se dan entre las diversas formas de danza, aún en los diferentes momentos de la historia de la disciplina, no por eso debemos dejar de señalar que, en varias dimensiones de la práctica, compartían y aún comparten un conjunto de supuestos que definen qué es la danza, cómo se construye y ejecuta, y por tanto suponen un mismo objeto. Nuestro interés no es liberar a la danza de formas organizadas, racionales y articuladas a un orden simbólico de construcción, ejecución, circulación y composición; por el contrario, sostenemos que es imposible, en un sentido fuerte, liberar a la danza de toda forma y más aún de toda técnica.

La concepción artística de la danza nos muestra que las discusiones en torno a la representación, la expresión o la comunicación son internas y lógicas a un conjunto de supuestos que tienen la función de identificar danza y movimiento, en una identificación que reduce el cuerpo a una simple condición de medio/instrumento. Aún más, siguiendo a Gigena (2004) podemos sostener también que hay una idea del movimiento humano como algo expresivo que se sostiene entre los diferentes géneros y estilos de danza. $Y$ sobre esa concepción -que es un supuesto compartido y, con la excepción de Lepecki (2006), no discutido- es que se comprende la reducción del cuerpo a medio. La

\footnotetext{
12 Articulación en la que gímnico refiere sencillamente al ejercicio y no a "sistemas" de ejercicios, como es el caso de lo "gimnástico", que de modo general subordinan el ejercicio y por ende el cuerpo al entrenamiento (antes de Platón) o a la salud (desde Platón). No intentamos subordinar el ejercicio y, por ende, el cuerpo, a la danza-arte, sino vincular el ejercicio con la esfera de la acción y, por ende, con el cuerpo.
} 
comprensión de la danza en términos de una práctica corporal hace emerger el cuerpo como objeto y efecto de la misma; ni supuesto ni condición: resultado. Esto ocurre específicamente porque nuestra perspectiva problematiza el cuerpo humano a partir de elevarlo a elemento significante del orden simbólico en que se construye. El cuerpo, entonces, es una construcción simbólica dada en el registro de las prácticas sociales y culturales. Pero no por esto carece de materialidad; al contrario, su constitución como objeto evidencia los efectos de verdad que los discursos y las prácticas tienen en el cuerpo y por tanto la efectividad con la que el mismo opera en la realidad social y en la realidad de la danza.

Para nosotros, el cuerpo es un vehículo de subjetivación y por tanto una forma que puede tomar subjetividad. En este sentido nuestro trabajo sostiene la idea de que no hay una identidad entre sujeto y cuerpo, y que es justamente al ser diversos e irreductibles el uno al otro que pueden entrar en relación. ${ }^{13}$ Introducimos esta idea de subjetividad, que no había aparecido a lo largo del trabajo, ya que las discusiones respecto de la libertad o no que ofrece una forma de danza se dan en relación a la idea de sujeto libre y soberano, y las perspectivas que se centran en la perspectiva artística y dejan al cuerpo en el lugar de medio, supuesto o condición, también están pensando en la soberanía del arte como sujeto de la danza. Incluso quienes introducen la pregunta por el cuerpo (que son pocos y lo hacen en el marco de la perspectiva artística, ya que lo piensan como construcción poética de una obra) asumen una identidad entre sujeto y cuerpo que nos reenvía a la relación de propiedad que promueve la lógica del consumo. La idea de trabajar con los usos del cuerpo y no simplemente con "el cuerpo" implica a su vez algunas consideraciones más. Por un lado, no hay una esencia del cuerpo que nos permita hablar de él como un universal; por otro, no hay una naturaleza del cuerpo que nos informe sobre el destino último de su desarrollo; finalmente, el cuerpo como resultado de un conjunto de prácticas nunca puede ser un cuerpo propio: será siempre en algún sentido cuerpo del Otro (Lacan 2006) y, en ese punto, de lo común. El cuerpo

\footnotetext{
${ }^{13}$ La identidad sujeto/cuerpo termina por reducir lo humano a lo animal, movimiento que tiene consecuencias políticas importantísimas -ver para esto la discusión actual sobre biopolítica.
} 
se construye y esa construcción remite a un uso que en el caso de la danza es a la vez performático y discursivo. ${ }^{14}$

En el próximo capítulo mostraremos que las rupturas respecto de formas alternativas de entender el cuerpo de la danza no se encuentran entre los diferentes géneros o técnicas sino en la constitución de la práctica misma, en relación con las posibilidades de uso del cuerpo que la práctica habilita y con cómo se efectúan.

\footnotetext{
${ }^{14}$ Quisiéramos sortear la discusión sobre el dualismo cartesiano, ya que establecer una distinción entre ser o tener un cuerpo no es significativa para la perspectiva de análisis que queremos presentar en este texto.
} 


\section{LA PROBLEMATIZACIÓN DEL CUERPO DE LA DANZA}

\subsection{PRESENTACIÓN}

En este capítulo nos gustaría explicitar hacia dónde nos dirigimos cuando nos proponemos estudiar el cuerpo de la danza, lo cual está íntimamente entrelazado con la comprensión de la danza como práctica. Debería quedar claro aquí que nuestra pregunta se orienta al cuerpo y su uso como efecto de una práctica, más que hacia la danza. Queremos presentar una lógica de construcción y comprensión de la danza, que nos muestra un objeto hasta ahora descuidado y olvidado en los análisis de la misma: el cuerpo de las prácticas. Mirar de otro modo implica conocer de otro modo, y allí radica la novedad de esta tesis: no nos proponemos incrementar el conocimiento existente, sino saber algo nuevo. Para ello explicitaremos algunas cuestiones de método y de recorrido analítico.

\section{Cuestiones de método}

En un principio sosteníamos el interés por encontrar una definición única de cuerpo que sea útil al pensamiento sobre la danza. Buscábamos construir un signo. Sin embargo, la lectura sistemática sobre textos de danza y la práctica misma de la danza nos mostraron una multiplicidad de cuerpos y, en ese sentido, nos obligaron a reconocer la imposibilidad lógica y metodológica de construir una definición (Foster 1996: 410). Definir y conceptualizar genera una marca, opera una relación de fuerza que tiende a clausurar el movimiento de aquello que se quiere conocer, estableciendo una identidad que se pretende inmutable. Nuestro interés, por lo tanto, dejó de ser la producción de una definición y pasó a ser la problematización de un sentido del cuerpo que se construye históricamente y que por eso mismo es efectivo, funciona y produce efectos concretos en la realidad de la danza como campo de prácticas y en el cuerpo como sujeto de la danza.

Un primer problema fue, así, cómo ser fiel al interés de la investigación, orientada a construir conocimiento objetivamente válido, si, como vimos en los capítulos anteriores, el cuerpo se resiste a ser nombrado, se resiste en cierto 
sentido a constituirse en objeto de estudio. Ligado a esto aparece lógicamente la pregunta por el sentido (Nancy 2003). Si el cuerpo no aparece, y cuando lo hace es de manera supuesta, no problematizado, si hay tantos cuerpos como sujetos danzantes y, más aún, si cada sujeto danzante se topa con una multiplicidad de cuerpos -ya que, como dijimos, existe el cuerpo como medio o instrumento, necesario para la ejecución de la danza, existe el cuerpo como tema o metáfora de la que se ocupa la danza, existe el cuerpo como naturaleza a ser dominada a partir del entrenamiento, existe el cuerpo como máquina construida, existe el cuerpo como naturaleza original y por tanto verosímil (Escudero 2008)-, ¿qué sentido y qué posibilidad efectiva hay de sistematizar una forma de saber sobre eso? ¿Es posible conocer eso múltiple sin hacer cada vez una investigación de grado cero, una nueva etnografía? Es decir, ¿puede el conocimiento servir a otros como recurso, como escalón desde el cual parase y asomarse a una nueva pregunta? Respondiendo afirmativamente esto, deviene el cómo.

Poner atención y confiar en la verdad de lo diverso y fragmentado del cuerpo fue el nuevo punto de partida, fue el lugar desde donde relanzar el proceso investigativo. ¿Qué cuerpo queremos y podemos conocer? ¿Cómo vemos esa fragmentación, cómo accedemos a ella? Por la forma, como instancia más obvia, evidente. Por la economía -en tanto organización- como instancia observable más allá del lenguaje. Por el discurso, como instancia de significado, de sentido. En términos epistemológicos, la solución a este problema viene de la mano de lo que propone Foucault en Nietzsche, Freud, Marx (1995) en la medida en que no sólo se reconoce allí la dimensión de poder que funciona en toda producción y circulación de un saber o de un sentido compartido (en tanto olvido del origen), sino que también pone en escena la dimensión política constitutiva de toda verdad, la instancia de decisión y de marcación que el acto interpretativo implica. El hecho de elevar a significante un conjunto de acontecimientos, de juegos de lenguaje o de saberes responde a una política de la verdad y a una política de la interpretación. Entonces, si ya no pensamos en construir una definición, en producir un signo que funcione como sentido completo y cerrado respecto de un referente significativo, no por eso queremos dejar de producir saber, no queremos dejar de interpretar, en los términos que propone Foucault en el 
siguiente texto: "si la interpretación no puede acabarse nunca es, simplemente, porque no hay nada que interpretar. No hay nada absolutamente primario que interpretar pues, en el fondo, todo es ya interpretación; cada signo es en sí mismo no la cosa que se ofrece a la interpretación, sino interpretación de otros signos" (1995:43).

\subsection{CUERPO Y LENGUAJE}

El conocimiento es entonces un conjunto de palabras que son significantes respecto de otras, inscriptas en la lógica de los juegos de verdad y mentira; el conocimiento es por lo tanto del orden del lenguaje $y$, en relación al conocimiento de la danza, la relación cuerpo/lenguaje asume una complejidad particular. Las investigaciones sobre prácticas corporales, y sobre prácticas corporales artísticas, ligadas mayormente a la expresión de una forma, de un sentimiento, de la realidad social, se enfrentan a esa complejidad en diversas dimensiones.

En primer lugar, y como elemento propiamente sociológico, quienes investigan danza bailan o han bailado, tal es el caso de Sally Banes, Susana Tambutti, Susan Foster, Rudolf von Laban o Doris Humphrey, por nombrar sólo algunos ejemplos. De manera general, aunque no absoluta ni exclusiva, quienes queremos conocer algo de la danza o del cuerpo que baila partimos de una primera intuición informada en la experiencia vivida, corporal y subjetiva. Esto redunda en suponer que nuestra experiencia personal, y muchas veces privada, no comunicada sino simplemente sentida, puede ser "caso testigo" de lo que pasa "de verdad" -o de lo que pasa en general-; así, pensamos que es posible construir un conocimiento objetivamente válido desde lo biográfico y particular y no desde lo común y lo histórico. De hecho, sobre esta experiencia se basaba la crítica que Mary Wigman le hiciera sistemáticamente a su maestro Laban: "siempre tuve un profundo sentido para el ritmo y la dinámica, y mi creencia en que había que vivir el movimiento, y no solo hacerlo, era fuerte. Además, mi manera individual de expresión y reacción debe haber sido torturante para Laban como era para mí su infatigable intento de alcanzar objetividad" (Wigman en Copeland y Cohen 1983: 64) 
Tomar distancia del propio cuerpo para poder hablarlo es la ruptura (Bourdieu 1999) más radical que se tiene que hacer en este campo de conocimiento para evitar caer en "una declaración de amor al objeto". Es una ruptura epistemológica, ligada a la objetividad del conocimiento que se pretende construir, y es una ruptura política, ligada a los efectos de verdad y de sentido que genera el conocimiento construido.

Esta dimensión es bastante importante porque dejarse informar por la experiencia vivida, por el sentimiento que se tiene del cuerpo al bailar, introduce un problema ligado a la posibilidad de pensar una producción de saber que no esté mediada por lo simbólico ni por el lenguaje, en lo que refiere a la instancia de construcción del objeto, sino que requeriría de estos sólo al momento de traducir eso que se sabe por experiencia.

De aquí, una segunda dimensión a considerar: la idea de lenguaje corporal, que supone entre otras cosas que el cuerpo con su movimiento habla de algo de lo que la palabra no puede hablar. Esto significa entregar un voto de confianza a un supuesto poder de verdad del cuerpo que redunda en asignarle una capacidad de significación casi mágica. Se eleva el cuerpo a un lugar sagrado, por fuera del hombre. Se confía también en que el discurso del cuerpo tiene un poder y una potencia tal que nos permite mostrar aquel elemento de la experiencia subjetiva que ninguna palabra puede nombrar. "Podría sentenciarse: el cuerpo expresa genuinamente la verdad de mi ser". El cuerpo, como supuesto de la danza, implica una identidad sujeto/cuerpo que creemos inconveniente. Si bien los análisis con los que trabajamos no se sitúan en esta problemática, las fuentes sí evidencian claramente esa identidad, expresada mayormente en la forma "el cuerpo piensa". Doris Humphrey lo expresa de la siguiente manera: "la naturaleza física del arte [de la danza]. El movimiento es su esencia, su principio primordial y su lenguaje. La persona que se siente atraída por la danza como profesión, es notoriamente no intelectual. Piensa con los músculos, goza al expresarse con el cuerpo y no con las palabras" (1958: 15). También Bejárt, hablando de su entrenamiento, nos dice que "la barra, para mí, dejó de estar ligada a una técnica, a un estilo, a una cierta forma de baile; es un yoga que construye mi cuerpo y mi mente y me abre la posibilidad de intentar comprender toda otra forma de danza, ya que la danza es uno" (Béjart 2005: 21 cursivas suyas). Incluso Laban, en su fundamentación de la 
importancia de introducir la enseñanza de la danza en el sistema escolar, algo que sin embargo permite interpretar la danza más allá del arte, sugiere que

[l]a formación de los futuros docentes debe asegurar que los estudiantes sean preparados para la vida de manera tal que no aspiren simplemente a descollar desde el punto de vista intelectual o desarrollar sus aptitudes físicas, sino que los distintos esfuerzos humanos (denominador común de la actividad física y mental) se aprecien de manera más cabal y se utilicen para desarrollar su personalidad en un todo integrado.

[...] [c]uando se desvía el énfasis, acentuándose ya sea la experiencia física o la experiencia mental del flujo de movimiento, se está aplicando un procedimiento artificial que podría ser útil con determinados fines educativos. La experiencia indivisa del flujo de movimiento en la danza responde a un impulso que todos los niños y adultos sienten (Laban 1975: 107-108, cursivas nuestras).

Ahora bien, si uno quiere hacer un trabajo de investigación que exceda lo etnográfico, deberá al menos poner atención en esto. Veamos varios elementos a considerar. Lo más obvio: el cuerpo no habla. Se mueve, se enferma y se cura, se entrena, se educa, se ensucia y se limpia. Hace, pero no habla. Hace lo que el habla dice. ¿El habla de quién? Del Otro, del lenguaje como principal dispositivo que captura al hombre en su constitución; también, más simplemente, de un otro, del maestro, del coreógrafo, como forma particular en la que el lenguaje se encarna (Stavrakakis 2009; Marchart 2009). Entonces, el cuerpo no expresa nada si no se lo pone en relación, si no se lo pone en medio de un sistema de interpretación específico, en un circuito de prácticas, si no se lo sumerge en un esquema de interpretación construido históricamente y sostenido en su función por un conjunto de cosas y personas (Foucault 1989; 2001). Alguien interpreta lo que el cuerpo expresa; si no, una vez más, el cuerpo se mueve, se viste, pero no más que eso. El caso de Laban puede resultar ejemplificador: para él la danza es movimiento y el movimiento es manifestación del esfuerzo, que a su vez está compuesto de diversos elementos.

[l]a idea básica en el aprendizaje de la nueva danza es que las acciones, en todo tipo de actividad humana, y por consiguiente también en la danza, consisten en sucesiones de movimientos en las que un esfuerzo definido del sujeto acentúa cada uno de ellos.

[...] [l]a diferenciación de un esfuerzo específico se hace posible porque cada acción consiste en una combinación de elementos de esfuerzo, que provienen de las actitudes de la persona que se mueve hacia los factores de movimiento Peso, Espacio, Tiempo y Flujo. El aprendizaje de la nueva danza alienta el desarrollo de una conciencia clara y precisa de los 
diferentes esfuerzos de movimiento [...] el conocimiento del esfuerzo humano, en especial de los realizados por el hombre industrial, es la base de la enseñanza de la danza (Laban 1975: 19).

Aquí tenemos sintetizado un esquema de interpretación, vemos claramente su historicidad -de hecho nos habla del hombre industrial- y vemos las coordenadas que nos ofrece para comprender la danza, el movimiento e incluso el cuerpo de la danza. Sin estas coordenadas, nunca entenderíamos por qué el racionalismo analítico de Laban se mezcla con un romanticismo de tipo naturalista, y tampoco comprenderíamos por qué clasifica sus movimientos no sólo en relación a los planos y direcciones de ejecución, sino con nombres tales como; deslizar, flotar, dar latigazos, dar toques, retorcer, arremeter, etc.

El cuerpo de la danza es efecto del discurso organizado de sus maestros, coreógrafos, críticos y analistas. El lenguaje y el discurso capturan al cuerpo, lo marcan y lo construyen; de hecho, no hay cuerpo por fuera del lenguaje, por lo menos en la comunidad de los seres vivos llamados hombres. Si algo (una persona, pero también una cultura o un dispositivo) no nombra a una secuencia rítmica de movimientos como danza, el cuerpo tampoco baila -simplemente se mueve. Si no se enuncia y, por tanto, si no se interpreta, no opera como práctica corporal.

Sostenemos entonces que el cuerpo no habla, está formado por la palabra, que no es lo mismo. Si bien es cierto que podemos interpretar al sujeto por el cuerpo, no menos cierto es que ese cuerpo es efecto del lenguaje, es una mediación si se quiere y, como tal, es simbólica. No interpretamos lo que nos dice el cuerpo, sino lo que nos ex-pone de otra relación, la del sujeto con el discurso, con el Otro histórico. Ésta es la idea fuerte encerrada en la frase "el cuerpo se construye": inter-viene. A esto deberíamos agregar que es una construcción subjetiva pero impersonal, no es volitiva sino in-tensiva. (Nancy 2008). Y tampoco el movimiento es, como expusimos en el capítulo anterior, el significante primordial de la danza.

Un tercer elemento a considerar es el hecho de que, en ciencias sociales, hay una primacía semiológica para analizar los discursos como metodología de investigación ligada al análisis de los sujetos sociales (Birman 2008). Esto supone que la palabra expresa o representa algo que "es", y que cuando hay alguna falla o falta de correspondencia entre la palabra y el signo, entre la 
palabra y la cosa, es una falta no estructural, sino que viene desde afuera de la relación, como contexto o factor interviniente. No se asume la falla como estructural a la relación entre lo que la palabra dice y aquello que se significa (Stavrakakis 2009). ¿Cómo hacemos para analizar un discurso partiendo del supuesto de que el enunciado no significa su verdad? (Foucault 1997). Un primer movimiento que se puede hacer es el de pensar el lenguaje como una práctica, lo que implica correrse del paradigma representacional y empezar a pensar en términos de los efectos de constitución que tiene, su positividad. Pensar el lenguaje como práctica implica aceptar su capacidad de hacer cosas. En el área de la danza, el hecho de asumir una posición epistemológica ligada a la semiótica, sumado a la consideración expuesta arriba de que quienes investigamos danza bailamos, produce por resultado una identificación entre el enunciado y la cosa, entre significado y significante. Aún se va un poco más allá: hay algo así como una correspondencia "connatural" o esencial entre significado y referente, lo que anula en cierto sentido la función significante del lenguaje y la tarea política de la construcción de conocimiento, que me interesa sostener a partir de las ideas expuestas arriba en referencia a Foucault (1995). Una vez más, la idea de Wigman (en Copeland y Cohen: 1983) respecto de la necesidad de vivir el movimiento es sumamente ilustrativa. Pero también podemos referir aquí la siguiente propuesta de Humphrey, según la cual, el bailarín

[a] fin de componer para sí mismo, tendrá que auscultar su corazón y escuchar las misteriosas voces interiores que son la guía de la originalidad. Si compone para otros deberá respetar su individualidad, recordando que no son como él y empeñando toda su inteligencia para llegar a comprenderlos física, emocional y psicológicamente (1958: 20).

También podemos mencionar algunas reflexiones de Cunningham, quien, siendo el que más reparos toma respecto de la intención y la posibilidad de trasmitir un significado por referencia a un movimiento, al reflexionar en uno de sus trabajos sobre al recurso lumínico expresa:

[t]odas esas alusiones a disturbios y bombas atómicas no se correspondían con mi experiencia y no estaba haciendo nada artificial, así que me pregunté de dónde venían esas luces en mi propia experiencia. Medité mucho al respecto y se me ocurrió que tal vez podía ser el hecho de viajar por la carretera a altas horas de la noche cuando estábamos de gira con la furgoneta (Lesschaeve y Cunningham 2008: 126). 
De esta compleja relación entre cuerpo y lenguaje es que a veces surgen los equívocos respecto del cuerpo de la danza. Un saber sobre danza no debería tratar sobre el cuerpo particular del bailarín ni sobre el cuerpo que la danza representa; eso debería quedar del lado de la crítica especializada y de la teoría estética o teoría del arte. Tampoco debería hablar de la experiencia corporal de tal o cual coreógrafo o bailarín. Un saber de la danza deberá indagar sobre el cuerpo que se constituye en objeto de las prácticas específicas que el dispositivo danza implica, desarrolla y despliega. De hecho, cuando Foucault desplaza el análisis de las epistemes hacia las prácticas, no hace más que reconocer al lenguaje como una forma de práctica, en la cual el discurso es una forma específica, la formación discursiva otra y el enunciado otra. El hecho de pensar el lenguaje como práctica nos posibilita pensar su uso $y$, en ese sentido, pensar la relación sujeto/cuerpo y cuerpo/lenguaje entre medio de los sistemas de interpretación históricos y de los esquemas de significación que organizan la experiencia. Esto nos permite trabajar con la idea de forma sujeto como construcción histórica y con la idea de que el cuerpo no habla, sino que es informado por el lenguaje en medio de un sistema de prácticas que habilitan modos de subjetivación. Es decir, que si el cuerpo expresa algo es porque antes fue hablado, fue objeto de discursos o fue elevado a significante.

\subsection{PROBLEMATIZACIÓN}

Quizás deberíamos marcar en primer lugar que el trabajo de investigación que proponemos reenvía a la lógica de la problematización tal como sostiene PotteBonneville (2007) respecto del trabajo de Foucault: "el término problematización adquiere un sentido reflexivo: viene a caracterizar la mirada de Foucault sobre la historia, mirada desde la cual la pregunta sobre la constitución de sí es susceptible de ser planteada de otra manera"; más adelante, cita directamente las palabras de Foucault: "creo que el trabajo que debe hacerse es de problematización y de perpetua re-problematización. Si el trabajo del pensamiento tiene algún sentido -diferente del que consiste en reformar las instituciones y los códigos, es el de retomar desde la raíz la 
manera en que los hombres problematizan su comportamiento" (PotteBoneville 2007: 225).

Quisiera resaltar que la lógica de la problematización se liga de manera directa con la cuestión de la forma sujeto y de la subjetividad. De hecho nos informa cómo trabajar este tema escapando al dualismo cartesiano y nos brinda la posibilidad de hacerlo sin proponer un monismo que no le escaparía al dualismo sino que simplemente lo discutiría. De hecho, en la referencia anterior vemos explícitamente que problematizar remite a la pregunta sobre la constitución de sí, ${ }^{1}$ y este es un elemento clave si se tiene en cuenta el tema de investigación de esta tesis, que es hacer aparece el cuerpo como objeto de la danza a partir de construir una lógica de pensamiento con asiento en la práctica. El cuerpo es un locus posible de subjetivación, es en potencia significante para la forma sujeto, para el Otro histórico. En el texto de PotteBoneville leemos que "el término problematización obedece (...) a describir el cuestionamiento del sujeto hacia sus propias prácticas, sin postular por ello una subjetividad fundadora y distanciada respecto del contexto de pertenencia que ella interroga" (2007: 274). Con la idea de problematización Foucault busca restituir el juego del pensamiento sobre el sujeto y no reproducir el poder del sujeto sobre el pensamiento (Foucault 1999).

Es este dominio complejo de la relación pensamiento, subjetivación y verdad el que se organiza con la categoría de problematización; citemos in extenso a Foucault (2002) para concluir con esta idea:

[l]o que distingue al pensamiento es que es algo completamente diferente del conjunto de las representaciones que sustentan un comportamiento; es otra cosa que el dominio de las actitudes que lo pueden determinar. El pensamiento no es lo que habita una conducta y le da un sentido; es, más bien, lo que permite tomar distancia con relación a esta manera de hacer o de reaccionar, dársela como objeto de pensamiento e interrogarla sobre su sentido, sus condiciones y sus fines

[...] De hecho, para que un dominio de acción, para que un comportamiento entre en el campo del pensamiento hace falta que cierto número de factores lo hayan vuelto incierto, le hayan hecho perder su familiaridad, o hayan suscitado en torno a él cierto número de dificultades. Estos elementos se desprenden de procesos sociales, económicos o políticos. Pero no juegan en ellos más que un papel de incitación. Pueden existir y

\footnotetext{
${ }^{1}$ En francés se diferencia el je del moi. El sí no es el yo, no remite a una interioridad: al menos así aparece la idea de sí en la obra de Foucault, siempre en el dominio de las prácticas. Ver, entre otros textos, Foucault (2000).
} 
ejercer una acción durante largo tiempo, antes de que haya problematización efectiva para el pensamiento (Foucault 1999 Vol.3: 359).

Pasamos de la problematización al pensamiento y vemos que el sentido o el objetivo del pensamiento no son las diversas respuestas informadas y más 0 menos completas que se den a una cuestión, sino la problematización misma que permite que haya una respuesta como forma.

Lo próximo en este texto es ver que la problematización se da en el orden de las prácticas, y remite de hecho a las transformaciones que, de las dificultades de una práctica, se presentan como un problema general. En este sentido el pensamiento no da respuestas ni traduce las dificultades de una práctica, sino que, al problematizar, elabora las condiciones en las que las diversas respuestas pueden ser dadas, define elementos que formarán distintas respuestas según se organicen de un modo u otro. Esto nos brinda una solución al problema de cuándo parar con la interpretación y de cómo construir una forma de saber que no se limite a ser una definición cerrada, a construir un signo. Esta idea de problematización como forma en que se mueve el pensamiento nos muestra que la manera de detener la interpretación -de alojar una marca- remite a un nivel operativo, a elaborar condiciones y definir elementos. Luego, qué sentido se construye sobre esa marca, qué operación significante se abre, tiene que ver con el modo, con la modulación de los elementos y con la elaboración de las condiciones.

Tenemos aquí un recurso metodológico que nos permite sostener que, si el cuerpo puede ser nombrado de tantas formas como he visto en mi trabajo de investigación, es porque hay en esa diversidad algún elemento que lo sostiene. Si puede ser dicho de tantas formas, arriesgo, es porque el lenguaje que lo dice es un modo de problematización del cuerpo.

Un ejemplo de problematización nos lo ofrece Merce Cunningham cuando sostiene que

[t]ampoco comprendía el ballet en realidad, había tantos detalles técnicos con los que no estaba familiarizado que simplemente tenía que aprender cómo se hacían [...] Aprendí, y la verdad es que todo me resultó bastante confuso, creo precisamente porque yo tenía cierta base técnica y no empecé como principiante, así que trataba de dominar todos aquellos pasos sin saber nunca realmente de qué iban, pero hice un gran esfuerzo y al final todo empezó a tener más sentido; practicaba solo tratando de identificar cuáles eran los principios básicos sobre los que se sustentaban aquellos pasos, o los de Graham. 
[...] Por aquél entonces me resultaba bastante complicado hablar con bailarines [...] era un poco como chismorrear, que es entretenido y a mí también me divierte, pero yo quería hablar de ideas [...] Lo que me proponía era descubrir cómo se mueve la gente en base a mi propia experiencia, que siempre estaba tratando de expandir. Si veía algo que no comprendía, lo probaba. Sigo haciéndolo. Hay muchas cosas que veo y no comprendo, cosas que se hacen con los pies muy rápido, saltos que nunca entendí a pesar de poder ejecutarlos [...] Lo que intento decir es que siempre resulta interesante mantenerse fuera de uno mismo, en cambio si no sales de lo tuyo, te quedas atascado en lo que sabes y nunca pruebas a hacer nada más (Lesscheave y Cunningham 2008: 48-49).

La problematización como recurso metodológico nos permite trabajar la cuestión del sujeto, tal como vimos arriba. También nos permite trabajar las prácticas y proponer la práctica como categoría metodológica. Para ver en qué sentido, citemos a Foucault cuando plantea "analizar, no los comportamientos ni las ideas, no las sociedades ni sus ideologías, sino las problematizaciones a cuyo través el ser se da como poderse y deberse ser pensado y las prácticas a partir de las cuales se forman aquéllas" (Foucault 2004b: 14).

Aquí habría que recordar que las prácticas se entienden en términos de

[l]a racionalidad o la regularidad que organiza lo que los hombres hacen (sistemas de acción en la medida en que están habitados por el pensamiento) que tiene un carácter sistemático (en los dominios del saber, poder y ético) y general (recurrente) y que por ello constituye una experiencia o un pensamiento (Castro 2004: 274).

Bien, las problematizaciones están en las prácticas entendidas como formas más o menos organizadas de la experiencia; de hecho, uno puede pensar las prácticas como aquellas respuestas a la problematización que funcionan detrás de ellas. Cuando hay dificultades en el domino de las prácticas opera el pensamiento resignificando elementos y coordenadas. El pensamiento como práctica no es ajeno a la racionalidad, regularidad y sistematicidad. Por eso, la idea no es la de un trabajo del sujeto sobre el pensamiento, sino del pensamiento sobre el sujeto. "Cuando empecé a estudiar ballet, muchos de esos bailarines modernos lo encontraron muy extraño, raro, hasta descabellado, pero a mí me daba igual, porque yo simplemente quería estudiar ballet" (Lesscheave y Cunningham 2008: 51); en esta referencia vemos cómo es la práctica la que nos constituye, y no nosotros quienes la practicamos. Fue la preocupación de Cunningham por saber y entender la que lo obligó a estudiar ballet, no su voluntad (aunque en la referencia pueda parecer eso). 
Por eso nuestra preocupación política-epistemológica por comunicar el pensamiento, por establecer un discurso que pueda usarse -pero usarse del modo que se propone en estas páginas- como una problematización, como un intento por formalizar elementos y coordenadas que posibiliten la respuesta como forma, que nos permita capturar lo fragmentado de la experiencia del cuerpo. Fundamentalmente, queremos proponer un pensamiento que opere sobre nosotros, que si echamos mano de él sea porque su uso trastocó en algún sentido la posición tenida antes de ponernos en contacto con él.

\subsection{LA DANZA COMO PRÁCTICA CORPORAL Y LA EMERGENCIA DEL CUERPO}

Antes que nada es necesario precisar qué entendemos por cuerpo y qué por prácticas corporales, ya que la palabra cuerpo y la palabra práctica denotan un conjunto variado de significados, comunes y especializados, de los cuales nos queremos diferenciar. Habrá quedado claro que no nos interesa la idea de cuerpo entendido en términos de un organismo biológico, y tampoco la idea de cuerpo físico como unidad de una masa o la idea de un cuerpo pre-objetivo abierto al mundo en una relación de inmediatez.

Respecto de la práctica, no nos interesa pensarla como aquello que los hombres hacen, sino como aquello por to cual los hombres son hechos. Nuestro interés general se orienta a indagar sobre la relación sujeto/cuerpo teniendo como eje la danza entendida como una práctica -lo que remite necesariamente a formas de subjetivación históricas y particulares-, y proponer a partir de allí una forma nueva de pensar el cuerpo de la danza. La categoría de práctica con la que trabajamos es la que propone Foucault, especialmente la que desarrolla en la versión de 1984 de la conferencia "Qué es la llustración", en la que introduce como consideraciones principales el carácter sistemático, homogéneo y regular de la misma -elementos que aparecen en otros trabajos del autor- y en la que suma lo que define en términos de aspectos tecnológicos y estratégicos. Para nosotros, entonces, la categoría de práctica remite a un conjunto de elementos que tienen ciertas características definidas en términos de una racionalidad o regularidad que organiza la conducta, que las reviste de homogeneidad y que les determina un aspecto 
tecnológico, de organización y conjugación particular de técnicas. A su vez, las prácticas son sistemáticas, ya que suponen los dominios del saber, del poder y de la ética -de la constitución de subjetividad- y generales, lo que supone su recurrencia en una configuración histórica determinada.

Entender la danza como una práctica corporal supone una comprensión del cuerpo de la danza en términos de su constitución como objeto de esas prácticas, a la vez que opera como una precisión (un nivel más de determinación, una mediación más) respecto de la categoría foucaultiana de práctica. Aquí, el significado que damos a las "prácticas corporales, por ejemplo, no es un equivalente de actividades físicas o de movimiento humano, sino que indica las prácticas históricas, por ende políticas, que toman por objeto al cuerpo" (Crisorio 2011:3, mimeo). Considerar las prácticas corporales y el cuerpo que ellas construyen como el objeto de investigación supone la adopción de una perspectiva o mirada epistemológica según la cual "el discurso funda el objeto del cual se va a hablar, si el objeto de estudio es producido por los enunciados, un discurso se funda en la separación que establece respecto de otro, al que obviamente excluye" (Crisorio 2011: 1, mimeo). En esta línea cabe destacar que la danza es considerada una práctica tanto en su aspecto performático -de ejecución de los pasos- como en su aspecto discursivo, en la medida en que su ejecución está orientada tanto por el conjunto de saberes técnicos sistematizados en manuales y libros de texto específicos, como por los discursos de la crítica especializada y de los análisis sobre estética de la danza y los estudios de arte. El lenguaje que sostiene y constituye a la danza es considerado también una práctica y no simplemente un sistema de representación o un medio de comunicación.

Es necesario reconocer que la danza como práctica corporal se configura por un conjunto de acciones y de discursos que, si bien reenvían a una lógica interna, son parte de una episteme, emergen como resultado de un conjunto de posibilidades históricas y políticas, y que en la bisagra entre lo histórico y lo disciplinar se constituyen campos de experiencia, formas de circulación de la palabra y de producción del cuerpo que son irreductibles, es decir, que al tiempo que conservan algo de lo social y de lo disciplinar específico se articulan de una manera particular, distintiva. Esto implica reconocer que la danza como práctica no es solamente una manifestación artística que expresa o critica lo 
que pasa en la historia y en la sociedad, ${ }^{2}$ sino que también es una configuración de la experiencia ${ }^{3}$ de un conjunto de sujetos, que funciona y circula en los bordes de lo que hegemónicamente constituye el campo. Es allí donde nos interesa alojar la pregunta, para acceder a un espacio de la práctica y del discurso que no ha sido explorado. Es justamente en relación a una consideración metodológica respecto de la genealogía que Foucault propone la idea de lo menor. Esta idea es planteada en términos de "saberes sujetos" y remite a aquel contenido histórico que no está elevado a la categoría de lo válido.

[e]n primer lugar quiero designar contenidos históricos que fueron sepultados $o$ enmascarados dentro de coherencias funcionales 0 sistematizaciones formales.

[...] eran estos bloques de saber históricos que estaban presentes y enmascarados dentro de conjuntos funcionales y sistemáticos, y que la crítica ha podido hacer reaparecer.

[...] en segundo lugar [...] entiendo toda una serie de saberes que habían sido descalificados como no competentes o insuficientemente elaborados (Foucault 2000:17-18).

Luego de estas referencias, se entiende en qué sentido lo menor remite necesariamente a una condición social, es decir histórica y, por ende, política, aunque no a la forma hegemónica, funcional o sistémica.

Del mismo modo en que más arriba precisamos el concepto de práctica, aquí precisaremos qué entendemos por cuerpo. Sostenemos que el cuerpo se construye en las prácticas simbólicas, a partir de su inclusión en el orden simbólico a través de la palabra. En nuestro concepto, el lenguaje no es un sistema de representación ni un medio de comunicación, sino una práctica. En

\footnotetext{
${ }^{2}$ No es que esta manifestación no exista, por supuesto: hay compañías, coreógrafos y bailarines que la representan. Pero no es el modo en que nos me interesa problematizar la danza.

${ }^{3}$ La idea de experiencia de Foucault remite en primer lugar a la diferencia entre ésta y la experiencia fenomenológica. Aquí, tanto Castro (2004) como Revel (2008) estarían de acuerdo en sostener que la experiencia fenomenológica "funda un lugar en el que descubrir significaciones originarias" (Castro 2004: 128), proponiendo la experiencia como una forma de "volver a captar la significación de la experiencia cotidiana para encontrar en qué el sujeto que soy es en verdad efectivamente fundador, en sus funciones trascendentales, de esa experiencia y de esas significaciones" (Revel 2008: 46). En cambio, Foucault trabaja con la idea de experiencia en un sentido diferente, como de-subjetivación y como instancia de transformación: ambos movimientos situados en la lógica de la práctica, ya que la experiencia empieza a concebirse como una forma histórica de subjetivación. Acá la idea de experiencia es casi equivalente a la de pensamiento (entendido en los términos planteados arriba), en la medida en que este último es el dominio en cuyo orden "la formación, el desarrollo y la transformación de las formas de experiencia puede tener lugar" (Castro 2004: 128).
} 
este sentido, el lenguaje es capaz de hacer cosas y producir efectos de verdad. El cuerpo que creemos propio es en verdad "un regalo del lenguaje" (Lacan 1977). No es, entonces, una representación (ficción, espejo o ideal de algo que no es, o que es distinto de sí), ya que esto supone algo que es natural o socialmente, ni un sustrato natural (biológico o físico) cargado de simbolismos por la cultura (a esto nos remite la categoría de corporeidad). El cuerpo es una construcción dada en el registro de las prácticas culturales.Pero no por esto carece de materialidad; al contrario, su constitución como objeto evidencia los efectos de verdad que los discursos y las prácticas tienen en el cuerpo y por tanto la efectividad con la que el mismo opera en la realidad social. En este sentido sostenemos que "(e)n tanto unidad real, sustancial y carente de alteridad, es el producto del discurso occidental respecto de él, igual que en cuanto superficie o volumen cerrados que definen un interior y un exterior" (Crisorio 2010). Por todo esto, en nuestra perspectiva, "lejos de pertenecer a la naturaleza, el cuerpo es de la cultura y tiene una historia en la que hay que indagar, no para saber qué o cómo ha sido sino para elaborar un concepto de cuerpo nuevo más que un nuevo concepto de cuerpo" (Crisorio 2011: 3, mimeo).

\subsection{ELEMENTOS PARA UN ANÁLSIS DEL CUERPO DE LA DANZA. LA CUESTIÓN DE LA TÉCNICA}

Como dijimos antes, nuestro interés no es liberar a la danza de formas organizadas, racionales y articuladas a un orden simbólico de construcción, ejecución, circulación y composición. Por el contrario, sostenemos que es imposible, en un sentido fuerte, liberar a la danza de toda forma y más aún de toda técnica. Por lo tanto, pretendemos mostrar que son esas formas organizadas, racionales y articuladas a lo simbólico las que posibilitan su existencia como práctica (aún si son también resultado de la práctica), y que según las combinaciones particulares que cada género y estilo proponga, se construirá una forma diversa.

Hemos venido revisando, en las teorías y en la historia de la danza, dos elementos centrales: a) la reducción y naturalización del estatuto artístico de la danza (algo que es histórico); y b) la suposición del cuerpo como medio, 
condición y material de la danza. En base a ello, hemos considerado que la comprensión de la danza en términos de práctica corporal ofrece una perspectiva de análisis que nos habilita a pensar nuevos problemas $y$, fundamentalmente, nos permite problematizar el cuerpo en tanto objeto construido por la práctica de la danza. Nosotros también suponemos un cuerpo de y para la danza, pero nuestra suposición es sensiblemente distinta de las anteriores en dos órdenes: a) lo suponemos en la medida en que lo interpelamos y b) lo suponemos resultado y efecto de la práctica de la danza. Dijimos más arriba que el lugar lógico del cuerpo es lo que cambia entre una perspectiva de análisis y la otra: al proponer otra forma de analizar la danza, construimos otro objeto (ya no el arte, sino el cuerpo).

Ahora bien ¿por qué nos interesa problematizar el cuerpo? Fundamentalmente, porque creemos que es una manera de pensar al sujeto y a las prácticas que, en el sentido en que nosotros las entendemos, remiten a formas de subjetivación. Las prácticas corporales son racionalidades que organizan las conductas, que toman por objeto al cuerpo y que en esa construcción constituyen también subjetividad.

Presentemos algunas consideraciones respecto de estos conceptos a partir de definir lo que el sujeto no es. El sujeto, igual que el cuerpo, no es una sustancia que se identifique con la mente o con el alma, no es soberano de sí ni idéntico a sí mismo (a su cuerpo, a su personalidad, a su nombre propio). No es una esencia que remita a una cualidad que lo signe a priori de su historicidad. Sin embargo, se forma o constituye en relación con las ideas de organismo, de cerebro, de mente, de alma, que asumen la función de unificarlo. Al marcar esta dualidad simplemente queremos indicar que no es éste el problema o asunto a desanudar. De hecho, el sujeto está dividido pero se unifica constantemente. Si hay algo que caracteriza al sujeto -como al cuerpo- es que se construye en medio de un sistema de relaciones de significación y de prácticas significantes. En tanto construcción, es histórico y asume una propiedad formal. Es por lo tanto una forma sujeto. La posibilidad de hacerse sujeto remite a las diversas prácticas de objetivación y de subjetivación, y cuando esas prácticas se sustancializan, o adquieren una forma sostenida en el tiempo y una cualidad más o menos estable tanto ética cómo política y económicamente (es decir, cuando sostienen un sentido del mundo y accionan 
prácticas ligadas al mantenimiento de ese sentido), podemos hablar de subjetividad (Foucault en Dreyfus y Rabinow: 2001).

Problematizamos el cuerpo porque eso nos permite pensar y acceder a una forma sujeto. Hemos visto cómo, de manera más o menos explícita, las transformaciones de la danza, que tuvieron el efecto de construcción de nuevos géneros (la danza moderna en relación a la clásica y la danza contemporánea en relación a las dos anteriores), tenían como elemento de la argumentación no sólo el eje artístico -articulado a liberar a la danza- sino un eje de sesgo humanista según el cual la liberación de la danza implicaba una liberación subjetiva:

[e]s sencillo observar que mucha gente tiende a exagerar la importancia de ciertas acciones, lo que afecta la naturalidad y destreza de sus movimientos; a su vez se descuidan otras acciones [...] Este equilibrio de esfuerzos alterado, que tiene un efecto perjudicial sobre la eficiencia y el bienestar individual y colectivo, está mucho más generalizado de lo que se cree. Sólo puede corregirlo una persona que haya experimentado la gama total de la cantidad de esfuerzo humano y que tenga un conocimiento suficiente de la coordinación natural de los diferentes esfuerzos entre sí (Laban 1975: 59).

Esto nos muestra, por un lado, cierta equivalencia entre subjetividad y personalidad; pero fundamentalmente nos permite ver que, en caso de que exista algo así como la libertad subjetiva, nunca es posible completamente. En todo caso, se da siempre parcialmente y en relación a un código, a un orden y a una forma, y sin embargo no está dada en la supuesta "naturaleza" de ese código o esa forma, sino en la relación histórica y particular que pueda darse hacia esa forma o ese código, relación particular que no está dada en la forma, no es exclusiva de un género. La particularidad está dada en la relación a esa forma, en el uso que habilita en términos de la constitución de una estética de la existencia. ${ }^{4}$

La categoría de estética de la existencia remite a la construcción de la vida subjetiva en términos de una obra de arte, entendiendo el arte en relación a la verdad y a la belleza; no hay, en la estética de la existencia, un contenido alienado en una forma, sino que la forma es la constitución del contenido. Es en este sentido que introducimos la categoría de estética de la existencia para pensar la construcción de subjetividad $-y$ no el arte-: es preciso haber sido

${ }^{4}$ Que es bien distinta de la idea moderna de arte y sobre todo de las concepciones institucionalistas. 
objeto de otro y también objeto de sí para poder volverse sujeto y, además, es preciso aprender a regular la propia estética en una ética para que esa objetividad se convierta en un principio de actividad. Para ello se necesita poner en juego un saber hacer (en nuestro caso, la danza como contenido) que implica un aprendizaje y un método. Esta concepción de estética como método de constitución de una vida subjetiva permite hacer énfasis en las acciones de la danza que no se ven en escena, que no aparecen en la pieza terminada y sin las cuales la danza no sería posible - de hecho, ni siquiera sería posible pensar al bailarín en términos de una función necesaria a la obra. Esta perspectiva nos pone de relieve aquello que la perspectiva artística borra, el trabajo cotidiano y metódico de la danza sobre el cuerpo. Aquí la dimensión del aprendizaje queda resaltada de una manera sensiblemente significativa: el saber puesto en orden en la práctica metódica se adquiere en una relación de aprendizaje que involucra al menos dos y esa relación no acaba nunca, al menos si se pone atención en las acciones que la práctica supone. No nos referimos estrictamente a la gimnasia corporal que la danza implica, sino también al conjunto de cosas que hay que labrar para realizar una forma coreográfica. Cada pieza supone un proceso de construcción y de aprendizaje. Nos acercamos aquí a la formulación de la danza como práctica y a circunscribir el problema de la relación sujeto/cuerpo en la danza. Al respecto podemos referir el siguiente texto:

[c]omencé a coreografiar con otros bailarines; hasta entonces todos los que habían trabajado conmigo tenían otro tipo de formación -o eran bailarines de clásico o habían estudiado el estilo Graham- y, pese a que algunos habían tomado clases conmigo también, su fuerte eran otras técnicas y al principio a mí eso no me iba bien. Yo no hacía más que pensar que no tenía el menor sentido andar quejándome, que si no estaba contento -con o sin razón-, tenía que hacer otra cosa, así que empecé a desarrollar una especie de técnica: eso era lo que había estado haciendo solo, pero no había encontrado la manera de trasmitirlo a otras personas. Poco a poco se fueron aclarando las ideas y simplemente cambié mi manera se enseñar (Lesscheave y Cunningham 2008: 62).

Esto nos remite a la pregunta por cómo el sujeto se gobierna a sí mismo, qué prácticas establece como modos de ser en la relación que entabla consigo mismo, qué pragmática de la vida -en el ejercicio positivo del poder hacerinstituyen ciertas prácticas de subjetivación que se acompañan de instancias de decisión y grados de libertad. El ejercicio positivo del poder, la constitución 
de sí como sujeto ético, implica una lógica del aprendizaje: uno tiene que cultivarse en modos de sujeción que son propios y alternativos a los modos de sujeción del poder del otro, y estas prácticas de sí, este buen gobierno de sí comienzan a materializarse en relación al cuerpo. El cuerpo aquí es entendido como el objeto a partir del cual es posible individualizarse, en relación a un conjunto de prácticas determinadas y particulares, donde el concepto de práctica implica una actitud y un modo de vida que se articula más con la lógica del resultado que con la de la intención.

El vínculo entre gobierno de sí, ética y estética, implica poder hacer de la propia vida una obra en constante creación, crearla no de una vez y para siempre sino permanentemente. Veamos qué dice Foucault:

[c]on el cristianismo se produjo un lento, gradual desplazamiento en relación a la moralidad de la antigüedad, que era esencialmente una práctica, un estilo de libertad. Por supuesto también ha habido ciertas normas de conducta, que gobernaban el comportamiento de cada individuo. Pero el deseo de ser un sujeto de moral, y la búsqueda de una ética de la existencia, eran en la antigüedad solamente un intento de afirmar la propia libertad y dar a la propia vida una cierta forma [...] Esta elaboración de la propia vida como una obra de arte personal, si bien obedecía a ciertos cánones colectivos, estaba en el centro, pienso, de la experiencia moral, la voluntad de moralidad en la antigüedad; mientras en el cristianismo, con el texto religioso, la idea de voluntad de dios, el principio de la obediencia, la moralidad tomó gradualmente la forma de un código de normas (en Kaminsky 2003: 134).

Más adelante leemos:

[e]n primer lugar, yo realmente creo que no existe un sujeto soberano, fundacional, una forma universal de sujeto que pueda hallarse en cualquier parte [...] Creo, por el contrario, que el sujeto es constituido a través de prácticas de sujeción, o de una manera más autónoma, a través de prácticas de liberación, de libertad, como en la antigüedad; sobre la base, por supuesto, de una cantidad de reglas, estilos, invenciones que se pueden encontrar en el entorno cultural (136).

Ahora bien, en la práctica de la danza, la manera que hay para crear cuerpos y formas subjetivas de relación al cuerpo es a través de la técnica, no sólo en términos de codificación de movimientos (la técnica clásica, por ejemplo) sino también en términos de técnicas de improvisación y composición de las formas coreográficas y de la escena. Creemos que la técnica es constitutiva del cuerpo de la danza; más aún, es constitutiva de toda forma sujeto. ${ }^{5}$ La estética de la

\footnotetext{
${ }^{5}$ No del sujeto como asunto, dónde describimos más arriba una relación al lenguaje -aunque el discurso puede también considerarse una técnica- sino de una forma sujeto.
} 
existencia se construye en la práctica de la danza en relación a un uso del cuerpo, y el cuerpo se usa, en la danza, técnicamente. Desde esta perspectiva, el cuerpo es un objeto de uso en todos los géneros, y ese uso es el que permite o sirve de acceso al vínculo entre cuerpo y subjetividad. En la danza, el uso es relativo, entre otras cosas, a la técnica. Pensar el cuerpo de la danza implica entonces pensar la técnica como elemento constitutivo y eje articulador de la relación sujeto/cuerpo.

\section{Cuerpo y técnica}

Comencemos viendo qué significa entonces la técnica y a qué refiere la cuestión de la técnica. Identifiquemos por qué la técnica nos habilita a pensar el cuerpo y una estética de la existencia y en qué medida nos aleja de las discusiones sobre las diferencias entre los géneros de danza. Para ello trabajaremos con dos referencias principales: Martín Heidegger y su texto de 1953 "La pregunta por la técnica", y algunos pasajes del libro El hombre sin contenido (2005), escrito por Giorgio Agamben y publicado por primera vez en 1970. Agregaremos a estas referencias principales algunas consideraciones a partir de textos de Umberto Galimberti, Roberto Esposito y Susana Tambutti.

En primer lugar tenemos que reconocer que la propuesta de esta tesis es pensar la técnica "a la manera griega", es decir, a partir de la palabra techné, lo que supone un trabajo reflexivo sobre ciertas formas de pensar instaladas en el inconsciente de la ciencia "moderna". Veremos incluso que la techné nos lleva de nuevo al arte, pero tal como lo concebían los griegos, lo que significa pensarlo en forma sustantivamente distinta a aquella en que la modernidad, la estética filosófica y las teorías sobre danza lo han conceptualizado, reduciendo el arte a lo artístico y a la institución arte -mercado del arte.

"La pregunta por la técnica" (1994) propone una reflexión sobre la técnica moderna; sin embargo, las primeras páginas son reveladoras respecto del significado de la techné. En primer lugar cabe destacar una lógica epistemológica a partir de la cual toda pregunta, en este caso por la técnica, nos instala en el registro del pensamiento, y todo pensamiento nos lleva a través de lenguaje; de aquí la necesidad de precisión en la conformación de una respuesta. En segundo lugar, tenemos que mencionar la diferencia 
sustantiva que hay entre la técnica y lo técnico, respecto de la cual el autor aclara que la pregunta por la técnica remite a la esencia de la técnica y a nada técnico concretamente. La pregunta por la esencia (que define en términos de lo que dura o perdura) es para Heidegger la pregunta por la verdad. Lo técnico en sí puede ser correcto, puede corresponder a la necesidad histórica del hombre, pero solo en la esencia se devela la verdad de la técnica. El autor asocia esta verdad de la técnica con la episteme y con un conjunto de palabras entre las que encontramos reflexionar, develar, traer-ahí, hacer-salir-de-lo oculto, traer-a-la presencia, producir y poiesis.

Para pensar esas relaciones el autor hace un primer corrimiento respecto de lo que denomina definición instrumental y antropológica de la técnica, ya que esta forma común de entenderla no nos ofrece una relación con su esencia, con su verdad, sino sólo con su adecuación a lo histórico, remitiendo a su condición de instrumento, de medio para un fin:

[e]l uno dice: la técnica es un medio para unos fines. El otro dice: la técnica es un hacer del hombre. Las dos definiciones de técnica se co-pertenecen. Porque poner fines, crear y usar medios para ellos es un hacer del hombre. A lo que es la técnica pertenece el fabricar y usar útiles, aparatos y máquinas; pertenece esto mismo que se ha elaborado y se ha usado, pertenecen las necesidades y los fines a los que sirven. El todo de estos dispositivos es la técnica, ella misma es una instalación, dicho en latín: un instrumentum. La representación corriente de la técnica, según la cual ella es un medio y un hacer del hombre, puede llamarse por lo tanto, la definición instrumental y antropológica de la técnica (Heidegger 1994: 1).

Lo correcto, en relación a la pregunta por la técnica, no es lo verdadero. La verdad es "develar en su esencia lo que está ahí adelante", y el uso y la representación instrumental de la técnica no nos ofrecen en ninguna medida ese develamiento.

Para poner en evidencia la relación que la techné tiene con la verdad, el autor remite, por un lado, a la explicitación de la teoría aristotélica de las cuatro causas, que lejos de interpretar en el paradigma experimental ligado a la lógica de la causa-efecto, reenvía al elemento de responsabilidad presente en la verdad develada por la techné. La causa material, la causa formal, la causa final y la causa eficiente se co-pertenecen en el hacer aparecer del hacer humano, pero sólo la causa eficiente implica la reflexión y en ese sentido la responsabilidad. Heidegger sintetiza esta idea en el ejemplo de la copa sacrificial que trabaja en el texto: “(e)I platero reflexiona sobre, y coliga, los tres 
modos mencionados del ser responsable (...) los tres modos mencionados anteriormente del ser responsable le deben a la reflexión del platero el aparecer" (Heidegger 1994:4). El interés del autor al introducir esta reflexión sobre la causa es arrojar una crítica a la representación ordinaria de la causa como mero efectuar, ya que es ese mecanismo el que permite sostener la idea de causa ligada a la lógica de la causa-efecto y genera la reducción de la techné a su dimensión puramente instrumental y de medio. En este sentido, define la causa como responsabilidad y la responsabilidad como dejar venir el advenimiento.

En este nudo entre techné y responsabilidad del hacer aparecer se define la relación de la techné con la verdad, que el autor define a partir de un criterio de igualdad: "¿qué tiene que ver la esencia de la técnica con el hacer salir de lo oculto? Contestación: es lo mismo" (5). Es preciso entonces cuestionar la representación de la técnica como medio, para llegar a su esencia entendida en términos de hacer salir de lo oculto; sólo allí "descansa la posibilidad de toda elaboración creadora." De hecho, el autor sostiene que "la técnica no es pues un mero medio, la técnica es un modo del salir de lo oculto. Si prestamos atención a esto se nos abrirá una región totalmente distinta para la esencia de la técnica. Es la región del desocultamiento, es decir, de la verdad" (6)

Luego, una vez que queda claro el vínculo entre techné y verdad, el autor introduce otras dos consideraciones importantes; una es la que menciona en términos de una relación de consuno entre techné y episteme, y la otra es la relación intrínseca que la techné tiene con lo poiético. Respecto de la relación con la episteme, sostiene que

[a]mbas palabras son nombres para el conocer en el sentido más amplio. Lo que ellas mientan es un entender en algo, ser entendido en algo. En el conocer se hace patente algo. En cuanto que hace patente, el conocer es un hacer salir de lo oculto. Aristóteles distingue con especial atención (Eth. Nic. VI, c. 3 y 4) la episteme de la techné, y lo hace desde el punto de vista de lo que en ellas sale de lo oculto y del modo como lo hacen salir de lo oculto. La techné es un modo del Žlhyeæein. Saca de lo oculto algo que no se produce a sí mismo y todavía no se halla ahí delante, y por ello puede aparecer y acaecer de este modo o de este otro (5-6).

El hacer salir de lo oculto que pone en juego la techné no debe entenderse como equivalente al obrar y al fabricar sino al producir, al hacer aparecer algo que no estaba; la techné implica entonces un pasaje del no ser al ser. 
En mayor o menor medida, el pensamiento de la filosofía contemporánea retoma esta idea de techné para pensar diversas dimensiones de la actualidad. Tomemos por ejemplo las referencias de Foucault (1990) a las "tecnologías", que nos remiten a modos producción que no pueden entenderse bajo ningún concepto en términos de su mera instrumentalidad. De hecho, no son medios que se puedan usar, sino las formas -y sus combinaciones- de producción, circulación y organización del poder, del saber y de la ética que nos constituyen, que nos producen, que nos hacen ser, al tiempo que nos indican los límites de lo que somos.

En esta tesis nos interesa presentar también el vínculo que la techné tiene con la forma, algo que con diversas consideraciones trabajan Galimberti (2001), Esposito (2011) y fundamentalmente Agamben (2005). El primero, por ejemplo, en la introducción a un libro titulado Psiché y Techné, orientado a trabajar la relación entre tecnología y psicología, sostiene que, por déficit biológico, es decir, por no estar estabilizado por sus instintos, el hombre construye por su acción procedimientos técnicos que recortan "en el enigma del mundo, un mundo para el hombre" (Galimberti 2001:3). ${ }^{6}$ Con esta idea el autor introduce dos elementos que atravesaron toda esta tesis. Por un lado, la imposibilidad de situar en lo biológico nada que defina al hombre; al contrario, lo biológico es deficitario, y por eso tampoco podemos entender al cuerpo del hombre desde esa biología. El otro elemento que nos muestra esta idea es que no hay naturaleza en el mundo sino por la acción del hombre, que produce un mundo para él. Sin la acción del hombre sólo hay enigma; por lo tanto, y en relación al cuerpo, podemos decir que no existe un cuerpo si no es a partir de su producción en la acción y de su introducción en el orden simbólico (mundo para el hombre). El autor es taxativo cuando sostiene que la "técnica es la esencia del hombre" (Galimberti 2001: 3).

En cierto sentido la reflexión, acotada pero precisa, que introduce Roberto Esposito en Bíos. Biopolítica y Filosofía (2011), trabaja de otro modo la idea según la cual la técnica es la esencia del hombre. En el contexto de la reflexión sobre el concepto de biopolítica y sobre la relación entre vida y política, el autor sostiene que, si la biopolítica es la acción política que toma por objeto la vida

\footnotetext{
${ }^{6} \mathrm{Si}$ bien Galimberti es en un sentido un funcionalista sistémico, no podemos negar que introduce de manera clara estos dos elementos.
} 
en su estatuto biológico, deberíamos preguntarnos, otra vez con los griegos, qué es la vida. Sabemos que existen en el vocabulario griego dos términos para referir a la vida: zoé, que la refiere al simple mantenimiento biológico, y bíos como vida calificada, forma de vida. La bíos, nos dice el autor, se asoma sobre la zoé situando a la biopolítica en una "zona de doble indiscernibilidad"; esto ocurre por diversas cuestiones, pero una de ellas es "porque refiere a un concepto -justamente el de zoé- de problemática definición él mismo: ¿qué es, si acaso es concebible, una vida absolutamente natural, o sea, despojada de todo rasgo formal?" (Esposito 2011:25). A continuación, desarrollando este problema, Esposito se pregunta "si no existe una vida natural que no sea, a la vez también técnica; si la relación de dos entre bíos y zoé debe, a esta altura, incluir a la techné como tercer término correlacionado, o tal vez debió incluirlo desde siempre" (25).

Vemos aquí que el autor introduce como idea fuerte no sólo aquélla según la cual no hay nada de natural en el hombre y en la vida del hombre, sino algo más importante a los fines de esta tesis, la idea según la cual no hay vida sin forma, que a su vez está dada por la techné. A partir de considerar estos elementos podemos sostener que el cuerpo del hombre no es nunca una naturaleza que se mantiene sólo en su pura vida biológica, el cuerpo es ya una forma de vida, es una construcción que tiene una forma. La techné hace aparecer el cuerpo en el mundo del hombre y lo hace aparecer con una forma inteligible. ${ }^{7}$

La categoría de techné es importante también para pensar el cuerpo de la danza. Por un lado, la crítica a la representación instrumental de la técnica nos llevó a mostrar la relación de cercanía entre techné y poiesis; por otro, la crítica a la concepción de la danza como arte (como lo artístico en sentido moderno) y su comprensión en términos de práctica nos permitió definirla a partir de pensar las acciones orientadas a la producción de una forma coreográfica. Si entendemos al cuerpo como producido en el orden simbólico por la techné, también podemos desembarazarnos de la concepción de cuerpo como medio, es decir, de la interpretación instrumental del cuerpo de la danza, y podemos

\footnotetext{
${ }^{7}$ No es nuestra intención identificar techné y orden simbólico. La techné es un concepto que nos permite pensar el cuerpo de la danza, mientras que el orden simbólico nos reenvía a una referencia epistemológica de más alcance.
} 
proponer su constitución como objeto de la práctica, su emergencia, su aparecer como objeto construido y no como cosa a ser dominada. Preferimos en esta tesis llamar código a aquello que de manera rápida y común se denomina técnica; llamar combinaciones y formas a aquello que, también de manera poco reflexiva, se llama comúnmente lenguaje corporal; y por último llamar a la gimnasia del cuerpo, a las formas de improvisación y generación de movimientos, a las formas de composición y producción y a las formas de enseñanza y transmisión de la danza, techné.

Completaremos esta apuesta con una referencia a Giorgio Agamben, quien articula poiesis con techné, con forma y con gnosis. El autor introduce en este sentido la dimensión del saber, que en el texto de Heidegger habíamos visto en relación a la responsabilidad como reflexión y a la cercanía entre techné y episteme, y nos deja claro en qué medida el arte como institución moderna desvirtúa el sentido del arte como poiesis y techné. Esto nos brinda herramientas conceptuales que contribuyen de manera sustantiva a sostener la tesis sobre la necesidad de pensar a la danza de otro modo, de introducir en la teoría de la danza otra perspectiva, otra epistemología y otra mirada, específicamente la que nos ofrece la perspectiva de la educación corporal a partir de la idea de práctica corporal (ver más arriba).

En un registro similar al de Heidegger, Agamben (2005) trabaja llevándonos hacia los griegos, y nos muestra cómo "el hacer del hombre" no se reducía a una única palabra, ni por lo tanto a una sola manera de comprender la acción del hombre. La antigüedad conocía las categorías de praxis y de poiesis, la primera relacionada a la producción destinada a satisfacer necesidades y la segunda articulada a la producción de un modo de verdad, a la construcción de un "espacio en el que el hombre encuentra su propia certeza" (Agamben 2005:113). Con la modernidad, argumenta el autor, esas diferencias se suturaron en favor de la categoría de praxis, entendida no sólo como un hacer orientado a la necesidad sino como una voluntad de hacer, a lo que agrega que hubo una convergencia e inversión en la significancia que ese par conceptual proponía. A partir de allí, la praxis extiende su campo de aplicación e incluso el arte (la institución arte S. XVII) comienza a pensarse con esa categoría, lo que lleva a la emergencia de una estética entendida como metafísica de la voluntad en virtud de la cual el arte aparece como resultado de una praxis, impulso 
creador, determinante en la comprensión de la acción; esto redunda en "el olvido del estatuto productivo original de la obra de arte como fundación de un espacio de la verdad" (Agamben 2005: 117). El objetivo del autor, en el libro, es realizar una crítica a la estética filosófica, al arte y a la teoría del arte, y fundamenta su empresa justamente en la reducción histórica de poiesis a praxis:

[l]o que los griegos querían significar con la distinción entre poiesis y praxis era precisamente que la esencia de la poiesis no tiene nada que ver con la expresión de una voluntad (respecto a la cual el arte no es de ningún modo necesario): ella reside en cambio en la producción de la verdad y en la apertura de un mundo para la existencia y actuar humanos (Agamben 2005: 117).

Es a partir de esta consideración que el autor sostiene que techné era la palabra que utilizaban los griegos para caracterizar y definir a la poiesis. Encontramos en la definición que utiliza Agamben el mismo registro que Heidegger: la techné no es un simple fabricar sino un modo de la verdad, de la a-leteia.

Esa producción es intensa, y es posible a partir de una gnosis, de un saber. Esto nos aleja, no sólo de la definición instrumental de técnica, sino de la idea de la técnica como algo operativo ligado a un hacer mecánico que deja de lado el pensamiento, la reflexión y el método. La techné abre un espacio de la verdad a partir de una relación al saber que posibilita dar origen a una obra, a una forma. La producción poiética no tiene como finalidad el objeto producido, sino el espacio de verdad que el objeto abre por su emergencia misma, la "poiesis no es un fin en sí, no tiene en sí misma su límite, porque la obra no se lleva a la presencia a sí misma" (Agamben 2005: 119). Uno bien podría articular esto con la idea foucaultiana de estética de la existencia.

De aquí se desprende que las discusiones en las teorías de la danza interpretadas en el paradigma del arte, y ligadas a pensar la autonomía de la danza respecto de otras formas de arte, carecen de sentido si las pensamos al modo griego. La autonomía en el registro de la poiesis y de la techné no es posible, porque siempre está en juego una relación al fundamento como algo diverso del espacio de verdad producido, y el espacio de verdad es a su vez abierto por una acción y un objeto que no tienen por resultado la verdad misma. 
La techné como ars poiética es principio -arché- de algo que es otro de sí mismo.

Ahora bien, la poiesis entendida como techné, como producción de un espacio de verdad, se comprende también en relación a la categoría de forma, que Agamben articula con la reflexión sobre el ritmo y la estructura. Algo es radicalmente otro que su principio y que la suma de sus partes porque tiene una forma y la forma es medida y logos. Accedemos a la techné como acción creadora a partir de la forma producida, del estar de la presencia como desocultamiento.

El cuerpo de la danza y la danza misma es una forma producto del hacer poiético en tanto techné, pero las teorías del arte como institución y la comprensión de la danza como fenómeno artístico y bien cultural que circula en el mercado del arte, dejan absolutamente de lado esta discusión. De hecho, la crítica del arte a la técnica se organiza no sólo en base a la comprensión instrumental de la técnica, sino en base a la conclusión, errada desde nuestro punto de vista, según la cual el aspecto técnico como recurso formal compositivo termina por alienar el contenido del objeto estético creado en una forma inerte. Según lo expuesto en estas líneas, vemos por el contrario que sólo a partir de una comprensión no instrumentalista de la técnica emerge la posibilidad de producción de un espacio de verdad -para nosotros, el cuerpo de la danza. Así, sólo a partir del recurso a la techné como acción poiética y a la forma como modo del estar en la presencia de la techné es posible acceder a ese espacio de verdad, el cuerpo de la danza.

Agreguemos en este apartado una reflexión proveniente del campo de la danza, con el objetivo de mostrar la pertinencia de recurrir a la techné como elemento para pensar el cuerpo de la danza. La reflexión que ofrece en esta dirección Susana Tambutti en su escrito "Una aproximación al problema de la técnica en la danza. Entre la tecnofilia y la tecnofobia" (2011) es un aporte importante para avanzar en algunas consideraciones que esta tesis plantea. Por un lado, en la identificación entre técnica entendida como techné y el lenguaje corporal, lo que pone en el eje de la cuestión la relación entre techné y forma. Antes de la instrumentalización del código técnico, el lenguaje de movimiento era en sí mismo un modo de desocultamiento de la belleza de los cuerpos. Por otro lado, al pensar la relación entre techné y cuerpo propone una 
pregunta en la cual el cuerpo mismo pasa a considerarse un asunto a tener en cuenta, sin embargo, inscribir su análisis en una preocupación artística, el cuerpo queda situado en el lugar de médium de la danza. Si en este punto retomamos la perspectiva agambeniana para trabajar el concepto de techné podemos cuestionar sensiblemente la idea de cuerpo medio de la danza, entendida ésta última como arte, para pensar el cuerpo como el resultado y por lo tanto, objeto mismo de la techné. En este sentido, Tambutti (2011: 4) se pregunta “¿por qué la técnica académica podría tener algún contacto con el concepto de techné en el sentido griego del término? ¿Qué era aquello que des-ocultaba utilizando el cuerpo como medio?" Vemos acá la identificación entre técnica y código de movimiento que mencionamos arriba, y vemos la reducción del cuerpo a medio: en lugar de ubicar el cuerpo como resultado mismo de la acción productiva de la techné.

En base a lo expuesto, podemos sostener que la techné es un modo de hacer aparecer una forma; para nosotros, el cuerpo de la danza y la danza misma son, en tanto productos de una techné, una forma que además es histórica. Creemos que no tiene sentido pensar las diferencias entre los géneros de danza como sustantivas, ya que todos comparten este elemento común, esta condición de ser resultado de una techné, en la medida en que esa es una forma constitutiva de la relación entre el hombre y el mundo. Vimos también que el recurso a la categoría de techné nos permite sortear la interpretación instrumentalista de la técnica y, fundamentalmente, esquivar la tensión, constitutiva de la danza desde su emergencia como arte, entre técnica y expresión, entre forma y contenido. También creemos que la referencia a la techné para pensar el cuerpo nos permite no sólo abordarlo como resultado de un hacer, sino ligarlo a la estética de la existencia, en la medida en que ese hacer propone ya un tipo de relación que, entre otras cosas, se articula a un saber y a un modo de obrar. En definitiva, podemos pensar la techné en relación a la práctica ya que ambas comparten una relación a los ejes del saber, del poder y de la ética. 


\subsection{CONCLUSIÓN}

En este capítulo resta mencionar que el cuerpo de las prácticas y de la acción no carece de materialidad; decir que se constituye a partir de su inclusión en el orden simbólico no equivale a decir que el cuerpo es una realidad simbólica. Las acciones de la danza, la práctica cotidiana, los ensayos, las formas de improvisación, generación y composición del movimiento y también la enseñanza -más o menos institucionalizada- son prácticas que se organizan en el eje del poder, del saber y de la ética, y si en algún aspecto son intangibles -en el sentido en que no se pueden tocar: por ejemplo, la palabra del docenteen otros aspectos son materiales. La ropa utilizada, las salas de ensayo, los espacios escénicos, los cuerpos puestos en juego. Las escuelas y sus saberes, los libros, las fotos, los vídeos, los elementos escénicos y la gimnasia, son todos elementos del orden simbólico que producen el cuerpo de la danza. Si bien cada persona que llega a aprender danza lo hace con un cuerpo, al mismo tiempo, su inclusión en el dispositivo danza, y más aún la práctica de la danza -cuando puede profanarse algún elemento del dispositivo en función del cual organizar activamente la conducta-, produce por efecto un cuerpo. Ese cuerpo, resultado de la práctica, no le pertenece al bailarín sino a la danza. El uso activo del cuerpo de la danza permitirá la emergencia de un sujeto en la medida en que organiza una relación a la práctica en términos de una estética de la existencia y reconoce en ese cuerpo de la danza un locus significante. Aquí estamos lejos del cuerpo propio y del cuerpo morfológico caracterizado por su simbolismo: estamos situados en un cuerpo que fue hecho, que en cierto sentido es del Otro, pero en y con el cual nos animamos a hacer, a producir. 


\section{CONCLUSIONES}

En estas páginas nos interesa presentar una reflexión en la cual se articulen de manera sintética las tesis principales que sostienen este trabajo. En primer lugar cabe recordar el carácter interpretativo y hermenéutico de esta tesis, en función del cual se definió una metodología de trabajo centrada en el análisis de textos que fueron tomados como documentos históricos, a los cuáles se sumó el análisis de trabajos científico-analíticos sobre la danza. Sobre la base de esta tarea se desarrolló en el texto un método de exposición muchas veces más descriptivo que sintético, lo que por momentos eclipsa la lógica analítica sobre la que se despliega el contenido. Subyace a esta perspectiva la idea de que teoría y práctica tienen una relación de relevo permanente, y fundamentalmente la concepción de que la teoría es de hecho una práctica. Recordemos que la práctica para nosotros es un conjunto de racionalidades que organizan la conducta, son formas de hacer históricas que tienen por efecto la producción de nuestras acciones.

Podemos pensar lo expuesto en estas líneas en la lógica del futuro anterior. Lo dicho aquí, en el final, es lo que ofrece el criterio de inteligibilidad de las páginas que anteceden. La idea expuesta en el primer capítulo, según la cual, a pesar de recurrir a la historia, nuestro propósito no es hacer historia, se comprende al ubicar el contenido histórico en la clave analítica que surge del análisis hermenéutico. En la medida en que la práctica danza se identifica con la institución arte, surgida en la modernidad, y se define al movimiento del cuerpo -e incluso a la quietud- como su material específico, las preocupaciones y temas que aparecen en la historia interna de la disciplina se sujetan a la racionalidad propia del arte, a la producción de obras, a los criterios de belleza o verosimilitud, a la autonomía de la danza respecto de otras disciplinas artísticas e incluso a la adecuación de tal o cual código de movimiento -o técnica de entrenamiento- para la expresión, representación y manifestación de ideas artísticas.

Del análisis y la descripción histórica expuestos en el capítulo 1, concluimos que la danza, el hacer de la danza un arte y el hacer arte con la danza no implican, en ningún sentido lógico ni óntico, una problematización del cuerpo. 
En la historia interna de la disciplina el cuerpo no fue un problema, ni un objeto que se conciba como tal en términos de su producción práctica.

Una conclusión similar extrajimos del capítulo 2, en el cual ya no estábamos situados en la historia de la disciplina sino en la producción de teoría sobre danza. Vimos que, en el abanico de materiales analizados, la pregunta por el cuerpo de la danza aparece muy tardíamente -hacia fines del siglo XX- y precisamos que esa preocupación se ubica más en relación a pensar los efectos que para el intérprete tiene el entrenamiento polivalente, que en pensar el cuerpo que en la práctica y en la acción se construye en la danza. En este sentido, la clave de interpretación de la danza sigue siendo artística. Del capítulo 2 también pudimos desprender que el hecho de ubicar al movimiento como materia específica de la danza impide el pasaje a la práctica, impide, por decirlo de alguna manera, construir una comprensión del cuerpo de la danza como acontecimiento del discurso.

Así, el hecho de que la danza no haya problematizado el cuerpo se vincula con dos elementos precisos: con la reducción de la danza al campo del arte, y por tanto con su definición en términos de movimiento, y con el hecho de que el cuerpo es asumido como una condición para la danza, como un instrumento. A su vez, esa asunción implica una concepción del cuerpo como algo que nos viene dado como natural y sobre el cual se puede operar sólo en función de necesidades plásticas/artísticas. Este supuesto explica la imposibilidad que tuvo la danza, así como la teoría de la danza, de problematizar el cuerpo: al asumirlo como natural se cierra la posibilidad de ver la constitución histórica del cuerpo, e incluso la reducción del cuerpo a instrumento de la danza. También explica por qué, cuando se instala el cuerpo como tema, sólo se hace inscribiéndolo en la dimensión imaginaria de producción de metáforas artísticas. El cuerpo es un tema del arte y no de la racionalidad práctica que supone su construcción como efecto de la práctica y del conjunto de acciones que la producción de una forma coreográfica requiere del cuerpo. El cuerpo objeto de las prácticas es, para la danza y la teoría de la danza, un cuerpo natural, más o menos entrenado, más o menos estilizado, pero natural. Los desarrollos técnicos del siglo XX son claros en esto: la puesta en juego de la respiración y la gravedad como supuestos de mayor expresividad para la danza lo demuestran al suponer un cuerpo biológico y la organicidad de esa biología. 
También lo hacen los desarrollos de Laban en relación a las formas de composición, ya que el cuerpo de Laban es un cuerpo físico-natural, una masa en movimiento. El espacio labaniano, a partir del cual puede leerse el movimiento del cuerpo de la danza, es un espacio de tres dimensiones que pretende escapar a su inclusión en el discurso, a su constitución en el orden simbólico. Incluso, las gráficas de notación buscan ofrecer las tres dimensiones en el plano único del papel.

¿Cómo hacemos para escapar a esta asunción del cuerpo como elemento natural, como resto de naturaleza en el artefacto de la danza? Si, como dijimos, la danza no problematiza el cuerpo por el hecho de pensarse en términos de arte y por lo tanto en términos de movimiento, el primer desplazamiento que tenemos que hacer es respecto de la concepción y de la comprensión artística de la danza. Ya no entender a la danza como arte sino como práctica. Esto nos lleva de inmediato a una segunda cuestión, que tiene que ver con la relación entre técnica e instrumento, términos que también se anudan en el cuerpo que se supone natural. Si operamos aquí un segundo desplazamiento, podemos empezar a pensar otro lugar lógico para el cuerpo, ahora como resultado y no como condición; y podemos pasar a otra relación con la técnica ya que nos movemos hacia una estética de la techné. A nivel de la danza en tanto forma coreográfica, el desplazamiento nos lleva del arte a la práctica y, por lo tanto, del movimiento del cuerpo a las racionalidades que organizan su hacer. A nivel del cuerpo, el corrimiento nos lleva del instrumento -e, incluso, de la concepción naturalista del cuerpo en tanto instrumento- al cuerpo objeto construido por la danza, lo que implica a su vez pensar que la danza no es simplemente un objeto construido por el movimiento del cuerpo y que el cuerpo no sólo es resultado del entrenamiento sujeto al código de movimiento.

El cuerpo se hace y la danza es un hacer. El hacer del hombre, cuando lo articulamos a la construcción de sentido (y no sólo a la reproducción y satisfacción de las necesidades) y a su inteligibilidad a partir de una forma, es resultado de una techné. El desplazamiento, a nivel del cuerpo, del instrumento al objeto nos aleja de la técnica en su sentido instrumental y antropológico, pero no nos aleja de la techné en el sentido griego, en tanto estatuto poético del hacer del hombre en la tierra. 
En los capítulos 3 y 4 de la tesis trabajamos con estos elementos de manera analítica, justificando y argumentando cómo y por qué el cuerpo emerge como problema en el registro de las prácticas a partir de su inclusión en el orden simbólico. Queda clara a partir de estos capítulos la posición epistemológica que tomamos en relación a la teoría del lenguaje y, a partir de allí, cómo concebimos la relación entre cuerpo, discurso y práctica. Se precisa también la idea de práctica corporal como aquel conjunto de acciones, regularidades y racionalidades que toman por objeto al cuerpo, lo cual nos sirve como argumento para sostener la afirmación según la cual para que aparezca el cuerpo como problema de la danza es preciso pensar a ésta como práctica y no como arte.

Circunscribir la mirada, precisar una pregunta y acotar la respuesta a las necesidades del análisis lógico nos llevó de manera clara a explicitar la relación y los términos de la última, tal como lo hicimos en esta tesis y sintetizamos en estas conclusiones; sin embargo, en los capítulos 3 y 4 hubo un elemento que no cesó de inscribirse. Si el problema de esta tesis es el cuerpo de la danza, nuestro análisis nos llevó a sostener que la danza no ha problematizado el cuerpo, no lo ha constituidocomo objeto de análisis ni de un obrar analítico. Este diagnóstico se vincula con la reducción de la danza a arte y con la asunción de la perspectiva artística abierta en la modernidad como criterio de producción y comprensión de la danza, lo que supone a la danza como movimiento del cuerpo y al cuerpo como instrumento de la danza. Ante esta situación proponemos y practicamos dos desplazamientos, del arte a la práctica y del instrumento al objeto, encontrando en la categoría de techné una clave para operar, en futuras investigaciones, tales corrimientos, en la medida en que allí se articula una relación entre el hacer y la forma que pone en juego la construcción de sentidos.

En este recorrido, el elemento que no cesó de inscribirse fue el sujeto. Ahora bien, es preciso reconocer que el sujeto no es el tema de esta tesis, y si bien en los momentos en que apareció tomamos nota del mismo y situamos lógicamente la relación que el par sujeto-cuerpo implica, no profundizamos en el asunto. Sin embargo, no profundizar en la cuestión del sujeto no significa ignorar su insistencia, y, si bien no podemos concluir nada de la relación danza-sujeto o cuerpo-danza-sujeto, sí es oportuno concluir que un análisis del 
cuerpo de la danza proyecta e implica, en potencia, la pregunta por el sujeto. Es parte del resultado de este trabajo dejar abierta la pregunta por la relación entre la práctica de la danza, la construcción del cuerpo y la emergencia del sujeto. El cuerpo supone un sujeto, la problematización como modo de relación al saber supone un sujeto: no podemos dejar de anotar estos elementos y puntuarlos como pistas para un futuro análisis. Podemos pensar en una estética de la danza, alejada de los criterios propios de la modernidad para pensar el arte, y asumir para ello la categoría de estética de la existencia que nos ofrece Michel Foucault (2002). A partir de allí podemos pensar, por ejemplo, el cuerpo de la danza como un locus para la subjetivación, situando incluso en la categoría de techné un vehículo para esta estética, lo que nos permite integrar, en una misma constelación conceptual, los elementos que trabajamos en esta tesis y la cuestión del sujeto.

Hay, por último, algo que también aparece en esta tesis, no como conclusión pero sí como elemento, y cuya relación con la comprensión de la danza como práctica creemos necesario pensar: la cuestión de la educación del cuerpo y más precisamente la cuestión de la Educación Corporal. Así como la estética de la existencia nos permite articular cuerpo, danza, sujeto y techné, la Educación Corporal nos permite articular la relación sujeto, cuerpo, danza y saber, y nos coloca frente al problema o al desafío de argumentar el sentido ético-político que tiene educar el cuerpo con la danza, a partir de incluirla como un contenido de la Educación Corporal. A partir de la inclusión de la educación como tema, la constelación conceptual, lejos de diferenciarse, se amplifica. La Educación Corporal se diferencia de la Educación Física en el objeto que construye, y ese objeto es justamente el cuerpo. No es casual que la naturalización del cuerpo (en términos biológicos o físicos) funcione en la danza como arte y en la educación física, y no es casual tampoco que se eclipse la problematización de las formas de construcción del cuerpo con las que indefectiblemente operan, aun sin reconocerlo o justamente por no reconocerlo.

La Educación Corporal nos habilita e incluso nos invita a pensar la danza como un contenido de su enseñanza, ya que hace eje en el cuerpo construido por las prácticas en el orden simbólico y pone en juego la relación que el cuerpo y la educación tienen con el sujeto; nos propone también una ética que, pensada 
en términos estéticos, nos brinda criterios y herramientas para una crítica al individualismo y al instrumentalismo con que se ha pensado el cuerpo de la danza, al menos hasta ahora. Esta tesis concluye ofreciendo criterios de análisis para pensar el cuerpo de la danza y hace suyo el convite de la Educación Corporal a pensar la danza como un contenido a ser enseñado. Sujeto y educación son asuntos que esta conclusión mantiene abiertos. 


\section{BIBLIOGRAFÍA}

- Adshead, J. y J. Briginshaw, V. (Comp.) (1999). Teoría y práctica del análisis coreográfico, España: Generalitat Valenciana.

- Agamben, G. (2005). El hombre sin Contenido, España: Áltera

- Agamben, G. (2000). Estancias. La palabra y el fantasma en la cultura occidental, Buenos Aires: Pre-textos.

- Agamben, G. (2004). Infancia e Historia, Buenos Aires: Adriana Hidalgo.

- Agambe, G. (2002). Lo abierto, Buenos Aires: Adriana Hidalgo.

- Agamben, G. (2005b). Profanaciones, Buenos Aires: Adriana Hidalgo.

- Agamben, G. (2011). "Qué es un dispositivo", en Revista Sociológica, año 26, ำ 73, pp. 249-264.

- Agamben, G. (2006) Medios sin fin, España: Pre-Textos.

- Aubert, J. y Milner, J-C. (Comps.) (2007). Lacan, el escrito, la imagen, Buenos Aires: Del Cifrado.

- Bajtin, M. (1987). La cultura popular en la Edad Media y en el Renacimiento. El contexto de Francoise Rabelais, Alianza Universidad: Madrid.

- Badiou, A. (2009). Pequeño manual de inestética, Buenos Aires: Prometeo.

- Banes, S. (1987). Terpsichore in sneakers. Post-Modern Dance, Connecticut: Wesleyan University Press. Traducción mecanografiada de Susana Tambutti.

- Bardet, M. (2012). Pensar con Mover. Un encuentro entre danza y filosofía, Buenos Aires: Cactus.

- Baril, J. (1987). La danza Moderna, Buenos Aires: Paidós.

- Benjamin, W. (1991). El Narrador, Madrid: Taurus.

- Bentivoglio, L. (1985). La danza contemporánea, Italia: Manual Longanesi \& Milano. Traducciòn mecanografiada de Susana Tambutti.

- Bernard, M. (1995). Le corps, Francia: Editions du Seuil.

- Birman, J. (2008). Foucault y el psicoanálisis, Buenos Aires: Nueva Visión.

- Bourdieu, P. (1980). "Programa para una sociología del deporte" en Cosas Dichas (1997). Madrid: Gedisa, pp. 173-184. 
- Bourdieu, P., Chamboredon, J.C. y Passeron, J.C (1999). El oficio de Sociólogo, España: Siglo XXI.

- Bourdieu, P. (2000). El Sentido práctico, España: Taurus.

- Castro, E. (2011). Diccionario Foucault, Buenos Aires: Siglo XXI.

- Chantel, J. (2001). Le corps, Paris: Presses Universitaires de France.

- Chauviré, Ch. y Fontainde, O. (2008). El vocabulario de Bourdieu, Buenos Aires: Atuel.

- Coppeland, R. y Cohen, M. (1983). What is Dance. Readings in Theory and Criticism, Londres: Oxford University Press. Traducción mecanografiada de Susana Tambutti.

- Cray, J. y Kwiter, S. (1992). Incorporaciones, España: Teorema.

- Crisorio, R. (2008) "De una semiótica a una hermenéutica en la investigación de las prácticas corporales" Ponencia presentada en el I Encuentro Latinoamericano de Metodología de las Ciencias Sociales, La Plata, 10 de Diciembre de 2009, Facultad de Humanidades y Ciencias de la Educación, La Plata: UNLP.

- Crisorio, R. (2011) "Educación corporal" texto inédito.

- Crisorio, R. (2010) Homero y Platón. Dos paradigmas de la Educación Corporal, Tesis de Doctorado en Ciencias de la Educación. Facultad de Humanidades y Ciencias de la Educación, La Plata: UNLP. Mecanografiada.

- Danto, A. (2003). Después del fin del arte, España: Paidós Ibérica.

- Deleuze, G. (2006). Foucault, Madrid: Paidós Estudios.

- Dreyfus, H. y Rabinow, P. (2001). Michel Foucault: más allá del estrutcturalismo y la hermenéutica, Buenos Aires: Nueva Visión.

- Escudero, C. (2008) "El cuerpo: un recorrido temático y conceptual" en revista Question Vol.1 ํo 19. La Plata: Facultad de Periodismo y Comunicación Social, UNLP.

- Escudero, C. (2012) "Consideraciones epistemológico-conceptuales para el estudio del cuerpo en la danza" en Revista Latinoamericana de Metodología de las Ciencias Sociales, Vol. 2. № 1. La Plata: UNLP

- Esposito, R. (2004). Bíos. Biopolítica y Filosofía, Buenos Aires: Amorrortu. 
- Foucault, M (2010 b). Gobierno de sí y de los otros, Buenos Aires: Fondo de Cultura Económica.

- Foucault, M. (1983). "Qué es la llustración". En Obras Esenciales. Volumen 3, (1999) Barcelona: Paidós, pp. 335-353.

- Foucault, M. (1989). Vigilar y Castigar, México: Siglo XXI.

- Foucault, M. (1991). Microfísica del poder, Madrid: La Piqueta.

- Foucault, M. (1995). Freud, Nietzsche, Marx, Buenos Aires: El cielo por asalto.

- Foucault, M. (1997). El orden del discurso, España: Tusquets.

- Foucault, M. (1984) "Polémica, política, problematización" en Estética, ética y hermenéutica Obras Esenciales. Volumen 3 (1999), Barcelona: Paidós, pp. 353-362.

- Foucault, M. (2000). Tecnologías del yo, España: Piados.

- Foucault, M. (2002). Hermenéutica del Sujeto, Buenos Aires: Fondo de Cultura Económica.

- Foucault, M. (2004a). Historia de la sexualidad. La voluntad de saber, Argentina: Siglo XXI.

- Foucault, M. (2004b). Historia de la sexualidad. El uso de los placeres, Argentina: Siglo XXI.

- Foucault, M. (2004c). Historia de la sexualidad. El cuidado de sí mismo, Argentina: Siglo XXI.

- Foucault, M. (2010a). El cuerpo utópico. Las heterotopías, Buenos Aires: Nueva Visión.

- Foucault, M. (2010c). El coraje de la verdad. Buenos Aires: Fondo de Cultura Económica.

- Foster, S. (1992). "Cuerpos de danza" en Cray, J. y Kwiter, S. (Comp.) Incorporaciones, España: Teorema, pp. 409-428.

- Foster, S. (1996). Corporealities. Dance, Power and Knowledge, Londres: Routledge.

- Galimberti, U. (1999) "Introducción" de Psiché e techné. L'uomo nel'etá della técnica, Milano Feltrinelli. Publicada en Revista Artefacto. Pensamientos sobre la técnica, № 4, año 2001, traducción de Flavia Costa, disponible en http://www.revista-artefacto.com.ar/pdf notas/93.pdf 
- Gigena, M. (2004). "Danza, lenguaje y texto. Algunas perspectivas" Material de cátedra Teoría General de la Danza. Buenos Aires: IUNA-UBA. Versión mecanografiada.

- Giles, M. (2007). "Educación física y educación corporal: matrices corporales" en I Encuentro de Cuerpo y Cultura de la UNLP. La Plata: UNLP, versión mecanografiada.

- Grüner, E. (1995) "Michel Foucault: una política de la interpretación" en Foucault (1995) Freud, Nietzsche y Marx, Buenos Aires: El cielo por asalto.

- Guillot, G. y Prudhommeau, G. (1974). La gramática de la danza clásica, Buenos Aires: Hachette.

- Heidegger, M. (1994). "La pregunta por la técnica" en Conferencias y artículos. Barcelona: del Serbal. También disponible en http://www.bolivare.unam.mx/cursos

- Henckmann, W y Lotter, C. (1998). Diccionario de estética, Barcelona: Crítica.

- Humphrey, D. (1962). El Arte de Crear Danzas, Buenos Aires: Eudeba.

- Kaminsky, G. (Ed.) (2003). El yo minimalista y otras conversaciones, Buenos Aires: Biblioteca de la mirada.

- Laban, R. (1970). Danza Educativa moderna, España: Paidós.

- Laban, R. (1992). Apuntes de Esfuerzo y forma, Traducción para uso de cátedra por Silvana Cardell.

- Lacan, J. (1993). Psicoanálisis, Radiofonía y Televisión, Anagrama: Barcelona.

- Lacan, J. (2007). Mi enseñanza, Paidós: Buenos Aires.

- Langer, S. (1966). Los problemas del arte. Diez conferencias filosóficas, Buenos Aires: Infinito.

- Le Breton, D. (2006). Antropología del cuerpo y modernidad, Buenos Aires: Nueva Visión.

- Leeschaeve, J. y Cunningham, M (2009). El bailarín y la danza, España: Global Rhythm.

- Lepecki, A. (2006). Exhausting dance. Performance and the politics of movement. Londres: Routledge. 
- Lepecki, A. (2009). Agotar la danza. Performance y política del movimiento, España: Universidad de Alcalá.

- Marchart, O. (2009). El pensamiento político posfundacional. La diferencia política en Nancy, Lefort, Badiou y Laclau, Fondo de Cultura Económica: Buenos Aires.

- Mc Fee, G. (1992). Understanding Dance, Londres: Routledge. Traducción mecanografiada de Susana Tambutti.

- Mora, A.S (2010). El cuerpo en la danza desde la antropología. Prácticas, Representaciones y Experiencias durante la formación en Danzas Clásicas, Danza Contemporánea y Expresión Corporal, Tesis de Doctorado en Ciencias Naturales (Orientación Antropología) de la Facultad de Ciencias Naturales y Museo, La Plata: UNLP.

- Nancy, J-L. (2008). Corpus, España: Arena.

- Nancy, J-L. (2003). El sentido del mundo, Buenos Aires. La Marca.

- Nietzsche, F. (2002). El origen de la tragedia, Buenos Aires: Ediciones del Libertador.

- Nietzsche, F. (2004). Así habló Zarathustra, La Plata: Editorial Creonte.

- Noverre, J. (1962). Cartas sobre la danza y los ballets, Buenos Aires: Editorial Eudeba.

- Pérez Soto, C. (2008). Proposiciones en torno a la historia de la danza, Santiago de Chile: LOM.

- Potte Bonneville, M. (2007). Michel Foucault, la inquietud de la Historia, Manantial: Buenos Aires.

- Ranciére, J. (2000). "Política, identificación, subjetivación" en Arditi (Ed.) El reverso de la diferencia. Identidad y política. Caracas: Nueva Sociedad, pp. 145.152.

- Regner, O. (1962). El Nuevo libro del ballet, Buenos Aires: Eudeba.

- Rocha Bidegain, A.L (2012). El aprendizaje motor: una investigación desde las prácticas, Tesis de Maestría en Educación Corporal, Facultad de Humanidades y Ciencieas de la Educación, La Plata: UNLP.

- Roger, P. (2006). Entrevistas con Michel Foucault, Buenos Aires: Paidós. 
- Schmidt, J., Servos, N. y Weigelt, G. (1984) Pina Bausch Wuppertal Dance Theatre Or the Art of Training a Goldfish. Excursions into Dance. Köln: Ballet-Bühnen-Verlag. Traducción mecanografiada de Susana Tambutti.

- Sorell, W. (1981). La Danza en su Tiempo. New York: Anchor Press/ Doubleday, Garden City.

- Stavrakakis, Y. (2008). Lacan y lo político. Prometeo Libros: Buenos Aires.

- Tambutti, S. (2009). "Itinerarios teóricos de la danza" versión mecanografiada de las clases de Teoría General de la Danza, Facultad de Filosofía y Letras, Buenos Aires: UBA.

- Tambutti, S. (2008). "Intinerarios teóricos de danza" en Revista Aisthesis, № 43, Santiago de Chile: Pontificia Universidad Católica de Chile, pp. 11-26.

- Tambutti, S. (2011). "Una aproximación al problema de la técnica en la danza. Entre la tecnofilia y la tecnofobia", ponencia presentada en el $9^{\circ}$ Congreso Argentino y 4ํㅡㄴ Latinoamericano de Educación Física y Ciencias de la Facultad de Humanidades y Ciencias de la Educación, La Plata: UNLP, versión mecanografiada.

- Tambutti, S (2004). "El cuerpo como medida de todas las cosas" en Revista Teatro al Sur, № 26, Buenos Aires: Artes del Sur, pp. 6-10.

- Tambutti, S. (2007). "La expresión como criterio de verdad" en Revista DCO. Danza, Cuerpo, Obsesión, Buenos Aires, Edición Independiente, pp. 10-12.

- Valéry, P. (1994). Teoría poética y estética, Madrid: Editorial Visor, colección La Balsa de Medusa.

- Wesemann, A. (2001). "La libertad de la danza consiste en liberarse del teatro. Apuntes sobre la danza alemana", versión mecanografiada. 